\title{
Welded and Hydrogen Charged Zircaloy- 4 and Welded Stainless Steel 347 Property Data and Microstructures for the Target Solution Vessel and Support Lines of SHINE
}

\section{Approved for public release.} Distribution is unlimited.
Lauren Garrison John Echols Nathan Reid Chris Bryan

February 2021 


\title{
DOCUMENT AVAILABILITY
}

Reports produced after January 1, 1996, are generally available free via US Department of Energy (DOE) SciTech Connect.

Website www.osti.gov

Reports produced before January 1, 1996, may be purchased by members of the public from the following source:

\author{
National Technical Information Service \\ 5285 Port Royal Road \\ Springfield, VA 22161 \\ Telephone 703-605-6000 (1-800-553-6847) \\ TDD 703-487-4639 \\ Fax 703-605-6900 \\ E-mail info@ntis.gov \\ Website http://classic.ntis.gov/
}

Reports are available to DOE employees, DOE contractors, Energy Technology Data Exchange representatives, and International Nuclear Information System representatives from the following source:

Office of Scientific and Technical Information

PO Box 62

Oak Ridge, TN 37831

Telephone 865-576-8401

Fax 865-576-5728

E-mail reports@osti.gov

Website http://www.osti.gov/contact.html

This report was prepared as an account of work sponsored by an agency of the United States Government. Neither the United States Government nor any agency thereof, nor any of their employees, makes any warranty, express or implied, or assumes any legal liability or responsibility for the accuracy, completeness, or usefulness of any information, apparatus, product, or process disclosed, or represents that its use would not infringe privately owned rights. Reference herein to any specific commercial product, process, or service by trade name, trademark, manufacturer, or otherwise, does not necessarily constitute or imply its endorsement, recommendation, or favoring by the United States Government or any agency thereof. The views and opinions of authors expressed herein do not necessarily state or reflect those of the United States Government or any agency thereof. 
ORNL/SPR-2020/1879

ORNL/SPR-2020/1879

Material Science and Technology Division

Welded and Hydrogen Charged Zircaloy-4 and Welded Stainless Steel 347 Property Data and Microstructures for the Target Solution Vessel and Support Lines of SHINE

\author{
Lauren Garrison \\ John Echols \\ Nathan Reid \\ Chris Bryan
}

Reporting period: FY20

Date Published: February 2021

Prepared by

OAK RIDGE NATIONAL LABORATORY

Oak Ridge, TN 37831-6283

managed by

UT-BATTELLE, LLC

for the

US DEPARTMENT OF ENERGY

under contract DE-AC05-00OR22725 
ORNL/SPR-2020/1879

\section{CONTENTS}

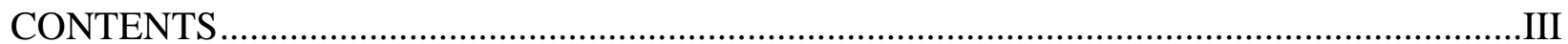

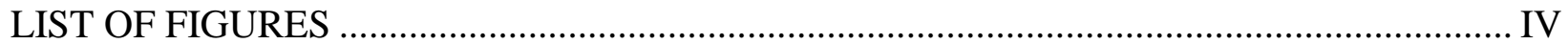

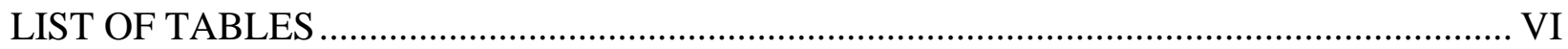

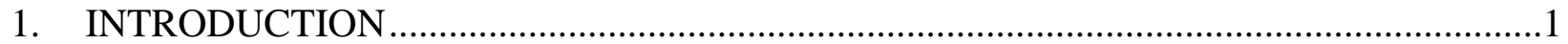

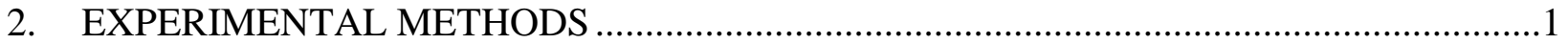

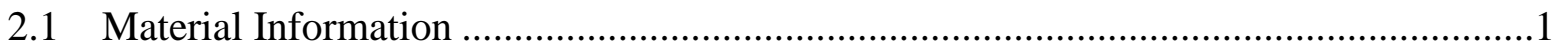

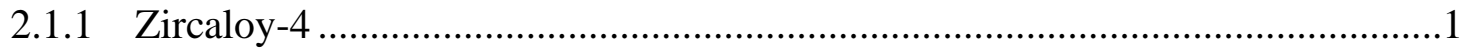

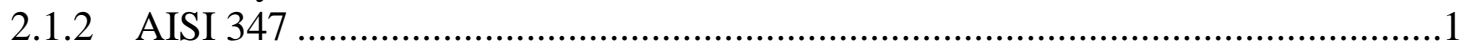

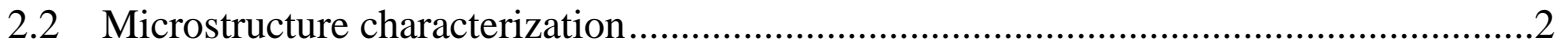

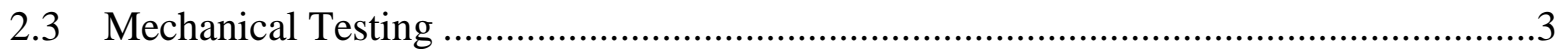

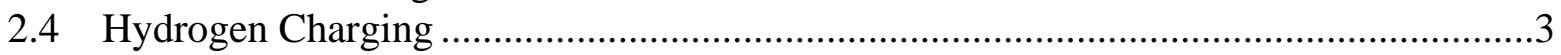

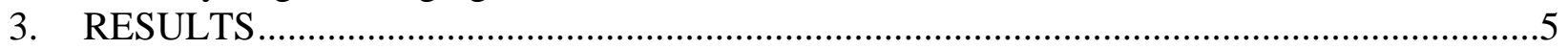

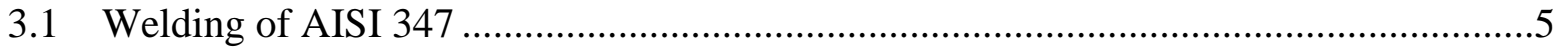

3.2 Explosive Welded Plate........................................................................................14

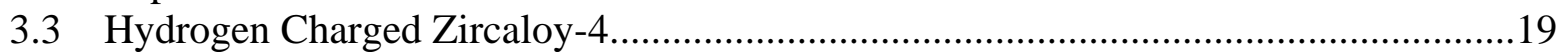

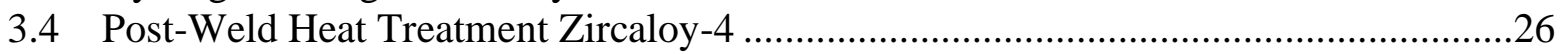

3.4.1 Optimizing Total Elongation with PWHT ……………………..................27

3.4.2 Microstructural Evolution of PWHT ..........................................................29

3.4.3 Second Phase Precipitates ……………......................................................

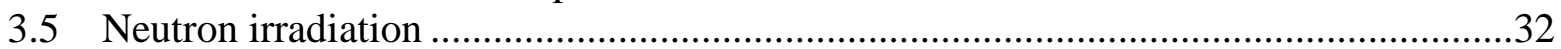

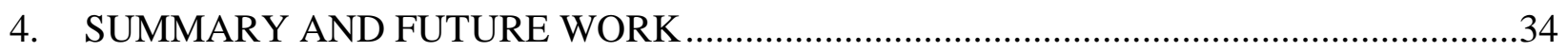

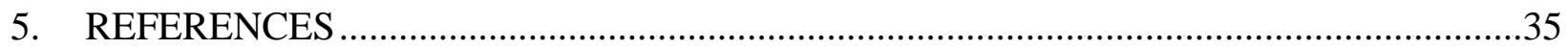

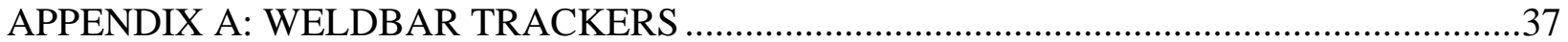




\section{LIST OF FIGURES}

Figure 1. EBSD was performed on the top surface of the alloy 347 materials, and tensile samples were cut in perpendicular directions A and B. Reproduced from [1]......

Figure 2. Schematic diagram of SS-3 tensile specimen geometry used for tensile testing .............3

Figure 3. Picture of a glass tube containing four tensile samples in the upper section and a $\mathrm{Ni}$ foil pouch with $\mathrm{TiH}_{2}$ powder in the lower left end.

Figure 4. Weld bar geometries. Two bars and filler material are necessary for complete welds.

Figure 5. (a) Welding workspace. (b) The GTAW bars had to be clamped with a metal sheet on top because they are narrow. (c) The FCAW bars were directly clamped to the table.

Figure 6. Penn Stainless GTAW bar number P2 is shown after or during each of the six weld passes, starting at (a) and ending with (f).

Figure 7. Photographs of welded 347 stainless bars used to manufacture tensile samples.

Grid shown is $1 \mathrm{~cm} \times 1 \mathrm{~cm}$.

Figure 8. Radiographs of welded 347 bars used to manufacture tensile samples. Annotations indicate weld defects to be avoided during machining or artefacts from imaging..

Figure 9.(Left) Example sample machining layout for a GTAW weldbar. (Right)

Schematic for machining/tracking samples by the depth from which the sample was taken.

Figure 10. (a) Tensile yield strength (YS) and ultimate strength (UTS) and (b) tensile uniform elongation (UE) and total elongation (TE) for symmetric Penn GTAW specimens from depth 1 (weld face) to depth 5 (weld root).

Figure 11. Tensile curves for symmetric Penn GTAW specimens from depth 1 (weld face) to depth 5 (weld root)....

Figure 12. Tensile yield strength (YS) and ultimate strength (UTS) and tensile uniform elongation (UE) and total elongation (TE) for 8 different material varieties of AISI 347 welds.

Figure 13. Tensile curves for symmetric Penn and Rolled GTAW and FCAW welds. .12

Figure 14. Tensile curves for asymmetric Penn and Rolled GTAW and FCAW welds. .12

Figure 15. Representative fracture surfaces from all weld/cut combinations.

Figure 16. Composite SEM images from coupon samples from two weldbars. Preliminary analysis on the width of the FZ and HAZ is shown with dotted lines.

Figure 17. Picture of the side of the explosion weld plate. The zoomed in feature shows an SEM micrograph of the weld interface. EDS mapping of the $\mathrm{Cr}$ signal gives a better contrast of the waveform at the interface.....

Figure 18. CAD model of the tensile specimens for tensile-shear testing. Each mode determines whether the break will occur in the base metal (light grey-colored), cladding metal (brass-colored), or directly at the interface by varying notch placement. Not pictured are SS-3 specimens for control tests of each metal.

Figure 19. Schematic diagram of shear strength test fixture and specimen (left) and shear specimen (right)[9] 
Figure 20. (a) CAD model of shear strength test fixture and specimen (a) orthographic view and (b) Side view showing small specimen lip (brass-colored) overhanging the front "shear block". (c) image of the completed fixture.

Figure 21. Tensile yield strength (YS) and ultimate strength (UTS) and tensile uniform elongation (UE) and total elongation (TE) for explosion weld materials.......................17

Figure 22. Tensile curves for explosion weld materials.

Figure 23. Fracture surfaces of the base metal (B4, B5), half cladding half base metal (FCFB9 and FCFB10), and the cladding 347 layer (GCGB2).

Figure 24. Tensile data for base metal (no weld) Zry-4 with varying amounts of hydrogen charging.

Figure 25. Fracture surfaces of Zircaloy- 4 base metal with increasing amounts of hydrogen charging, (a) 0 ppm H, (b) 200 ppm H, (c) 370 ppm H.

Figure 26. Tensile data from Zry-4 samples that were welded and had varying amounts of hydrogen charging.

Figure 27. Fracture surfaces of Zircaloy-4 welded without a PWHT and increasing amounts of hydrogen charging: (a) 0 ppm H, (b) 200 ppm H, (c) 380 ppm H, (d) $380 \mathrm{ppm} \mathrm{H}$.

Figure 28. Tensile data from Zry-4 samples that were welded, PWHT at $600^{\circ} \mathrm{C}$, and hydrogen charged to various levels.

Figure 29. Fracture surfaces of Zry-4 welded and PWHT with varying amounts of hydrogen charging: (a) 0 ppm H, (b) 200 ppm H, (c) 400 ppm H.

Figure 30. Total Elongation as a function of hold temperature or time. Average values are shown with large/dark icons and individual data points are shown with small/light icons. The black/grey markers at the left-hand side in each case represents the weld bar with no PWHT.

Figure 31. SEM micrographs of fracture surfaces Base metal, no PWH,T and 1-hour PWHT holds over a range of temperatures. Whole bar surfaces are shown above higher magnification images. Examples are pointed out for coalescent and intergranular failures.

Figure 32. Composite polarized light micrographs showing the same areas in a sample (ZO44) with no PWHT (top) and following an $800^{\circ} \mathrm{C}, 48$ hour PWHT (bottom). a) and b) show the fusion zone with the sample edge at the bottom of the images, c) and d) show the transition from the HAZ (right) to the fusion zone (left), and e) and f) show the transition from the base metal (right) to the HAZ (left).

Figure 33. (Left) Polarized light composite image of a weldbar (PWHT $48 \mathrm{hr}, 800^{\circ} \mathrm{C}$ ) cross-section showing large grains in the HAZ, which fit the criteria for blocky alpha. (Right) polarized light micrograph of a tested tensile sample (ZGB2, PWHT $24 \mathrm{hr}, 800^{\circ} \mathrm{C}$ ) showing a large single grain in the failure area............................31

Figure 34. SOCAP relationship with TE for this work

Figure 35. Perforated capsule design used in this work. Exploded view (top), from left to right, shows perforated housing, spacer, samples, and endcap. Cross-sectional view (bottom) shows the same as assembled with dimensions given in $\mathrm{mm}$.

Figure 36. (Left) Capsules following removal from HFIR before disassembly. (Right) Sorted tensile samples at top with disassembled capsule and unsorted tensile samples at bottom. 


\section{LIST OF TABLES}

Table 1. Chemical composition of AISI 347 from different suppliers. All values are given in percent by weight. This information was reported in [1].

Table 2. Unirradiated welded AISI 347 samples that were tensile tested.

Table 3. Results of the hydrogen charging. An asterisk by a sample's label means that sample was consumed to measure the hydrogen content after charging. Thick borders separate the samples that were enclosed in the same capsule for hydrogen charging. The hydrogen content is reported as weight parts per million (wppm).

Table 4. Tensile results from room temperature tests of hydrided Zry-4 samples.

Table 5. Tensile properties of Zry-4 as a function of PWHT time and temperature. Average values are given for YS, UTS, UE, and TE.

Table 6. Average grain widths for unwelded, no PWHT, and $48 \mathrm{~h}$ PWHT at $800^{\circ} \mathrm{C}$. The circular intercept method was used in all cases except for ZO44 edge, which used the linear intercept method

Table 7. Matrix of neutron irradiated samples. Capsule name, material, position, number of cycles, and expected flux are shown in the first row of each sub-table.

\section{LIST OF EQUATIONS}

Equation 1

Equation 2

\section{ACKNOWLEDGMENTS}

Support for this research was provided by the US Department of Energy's National Nuclear Security Administration (DOE/NNSA), Office of Material Management and Minimization, Molybdenum-99 Program. The authors would also like to thank Nesrin Cetiner and Doug Stringfield. 


\section{INTRODUCTION}

SHINE Medical Technologies is developing a facility that will produce molybdenum-99 for medical isotope procedures. As part of this facility, a metal tank, called the target solution vessel (TSV), will hold a uranyl sulfite solution. The TSV must withstand neutron irradiation near room temperature and potential corrosion from the aqueous solution. The large cylindrical TSV will be fabricated by welding and will have numerous pipes and connections also attached via welding. The vessel and those pipes will have varying thicknesses so both gas tungsten arc welding (GTAW) and flux-cored arc welding (FCAW) will be necessary to fabricate different sections. The original material under consideration for the TSV was Zircaloy-4 (Zry-4), but it is known to form a hydride which can degrade its mechanical properties. Thus, some investigation here is focused on the effects of hydrogen uptake in the Zry-4. Additionally, the alternative material being considered is AISI 347, a stainless steel. Both materials have little existing data for their neutron irradiation behavior below $100^{\circ} \mathrm{C}$, and both have open questions on the weld behavior under neutron irradiation. Testing has focused on characterizing their weld properties with tensile tests and performing neutron irradiation of samples in the High Flux Isotope Reactor (HFIR) at Oak Ridge National Laboratory (ORNL).

\section{EXPERIMENTAL METHODS}

\subsection{MATERIAL INFORMATION}

\subsubsection{Zircaloy-4}

The Zry-4 used here has a composition of Zr, $1.54 \mathrm{Sn}, 0.21 \mathrm{Fe}$, and $0.11 \mathrm{Cr}$ in wt \% as reported by the manufacturer, ATI Specialty Alloys and Components, for batch no. MIL1526608. During fabrication the plate was hot rolled, annealed at $782 \pm 14^{\circ} \mathrm{C}$ for $105 \mathrm{~min}$, blasted, and pickled by the supplier.

The GTAW (also called tungsten inert gas (TIG) welding) of sample bars was done by Major Tool and Machine Inc. and the post-weld heat treatments (PWHTs) were done at ORNL. An example of the weld tracker sheet for one of the welded bars is included in Appendix A. All tensile samples from the welded test bars were cut so that the tensile direction was parallel to the original rolling direction of the plate, which is perpendicular to the weld seam.

\subsubsection{AISI 347}

AISI 347 was procured from Penn Stainless, Rolled Alloys, and Sandmeyer. A sample from each material was analyzed at Eurofins EAG Materials Science, LLC using ICP (inductively coupled plasma), IGA (instrumental gas analysis) and GD-OES (glow discharge optical emission spectrometry) techniques (Table 1). All three materials are in reasonable agreement with the ASTM A240 standard for AISI 347, listed in the right column of Table 1. The ASTM A240 standard specifies that the Nb content should be at least ten times the carbon content, but no more than $1 \%$, so that the carbon will form $\mathrm{NbC}$ precipitates instead of the detrimental CrC. 
ORNL/SPR-2020/1879

Table 1. Chemical composition of AISI 347 from different suppliers. All values are given in percent by weight. This information was reported in [1].

\begin{tabular}{|l|l|l|l|l|l|}
\hline & & \multicolumn{3}{|l|}{ Suppliers } & \\
\hline \multirow{5}{*}{ Technique } & Elements & Penn Stainless & Rolled Alloys & Sandmeyer & $\begin{array}{l}\text { ASTM } \\
\text { A240 }\end{array}$ \\
\hline \multirow{5}{*}{ ICP-OES } & $\mathrm{Fe}$ & Balance & Balance & Balance & Balance \\
\cline { 2 - 6 } & $\mathrm{Cr}$ & $17.3(\mathrm{wt} \%)$ & $17.5(\mathrm{wt} \%)$ & $17.8(\mathrm{wt} \%)$ & $\begin{array}{l}17-19 \\
(\mathrm{wt} \%)\end{array}$ \\
\cline { 2 - 6 } & $\mathrm{Mn}$ & 1.42 & 1.17 & 1.1 & 2 \\
\cline { 2 - 6 } & $\mathrm{Ni}$ & 9.28 & 9.75 & 9.64 & $9-13$ \\
\cline { 2 - 6 } & $\mathrm{Si}$ & 0.36 & 0.77 & 0.7 & 0.75 \\
\hline \multirow{5}{*}{ IGA } & $\mathrm{C}$ & 0.045 & 0.046 & 0.053 & 0.08 \\
\cline { 2 - 6 } & $\mathrm{O}$ & 0.0020 & 0.0016 & 0.0045 & N/A \\
\cline { 2 - 6 } & $\mathrm{S}$ & 0.0012 & 0.00075 & 0.0015 & 0.030 \\
\hline \multirow{5}{*}{ GDOES } & $\mathrm{P}$ & 0.025 & 0.029 & 0.027 & 0.45 \\
\cline { 2 - 6 } & $\mathrm{Nb}$ & 0.2 & 0.3 & 0.3 & $10 \times \mathrm{C}$ \\
\cline { 2 - 6 } & $\mathrm{Si}$ & 0.36 & 0.77 & 0.7 & 0.75 \\
\cline { 2 - 6 } & $\mathrm{Co}$ & 0.023 & 0.1 & 0.3 & N/A \\
\cline { 2 - 6 } & $\mathrm{Cu}$ & 0.022 & 0.3 & 0.1 & N/A \\
\cline { 2 - 6 } & $\mathrm{Mo}$ & 0.029 & 0.056 & 0.059 & N/A \\
\cline { 2 - 6 } & $\mathrm{V}$ & 0.012 & & & \\
\hline
\end{tabular}

\subsection{MICROSTRUCTURE CHARACTERIZATION}

Polarized light microscopy was used to analyze grains in the Zircaloy-4. Additional microstructural analysis including energy dispersive x-ray spectroscopy (EDS), electron backscatter diffraction (EBSD), and fracture surface analysis was completed with the Tescan MIRA SEM.

The rolling direction of the Zry-4 plate and welded bars were known. The rolling direction of the AISI 347 plates were not indicated by the manufacturers, so tensile samples were prepared in two perpendicular directions, called A and B (Figure 1).

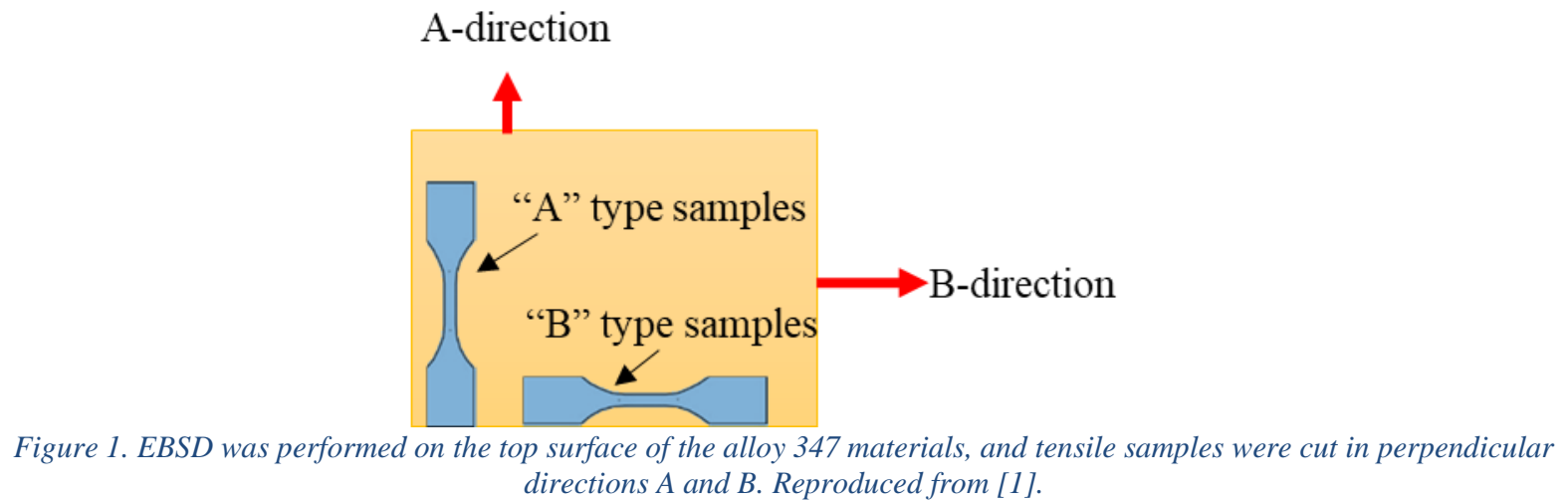




\subsection{MECHANICAL TESTING}

Tensile tests were performed on all materials at room temperature using an MTS Insight electromechanical testing frame. The SS3 type sample geometry was used (Figure 2). The extension rate for all samples (unless noted otherwise) was $0.00762 \mathrm{~mm} / \mathrm{s}$, which is 0.001 $\mathrm{mm} / \mathrm{mm} / \mathrm{s}$ strain rate for this geometry of samples.

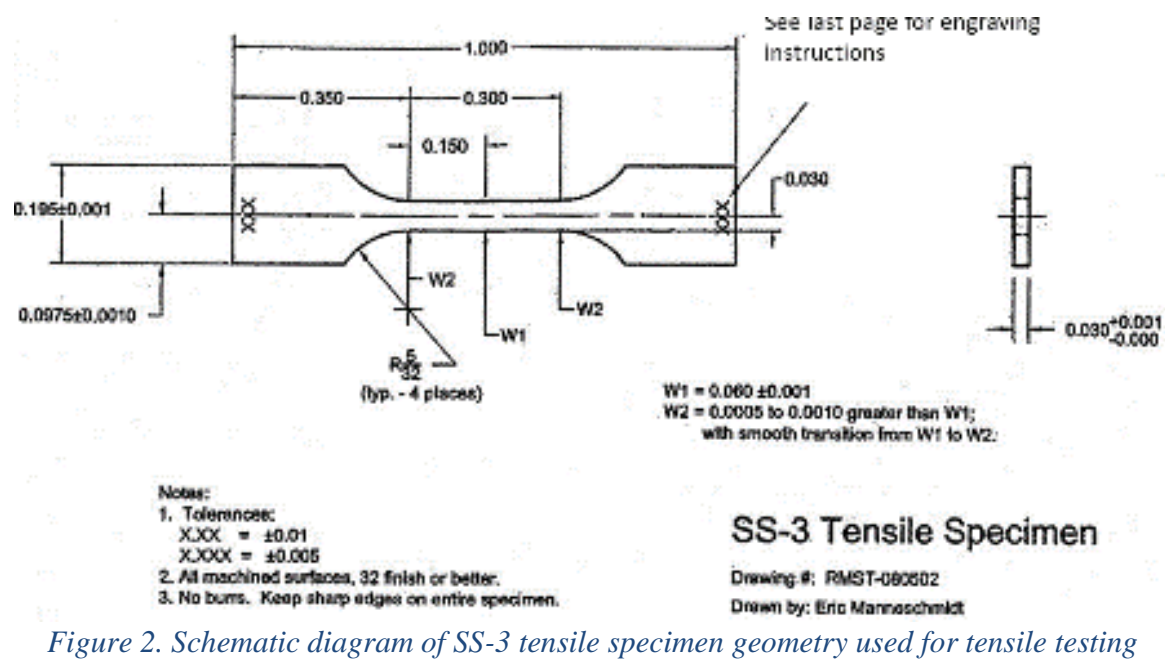

The tensile strain data was collected by recording the extension of the crosshead. An extensometer was not used. To remove the machine compliance that occurs in the strain data, the elastic component of the strain was removed throughout the data sets. Thus, in all images only the engineering plastic strain is plotted. The method of data analysis is described in more detail in Reference [2].

\subsection{HYDROGEN CHARGING}

The hydrogen charging method as described in References $[1,3]$ was used here. The method relies on the dissociation of hydrogen from titanium hydride powder during heating, which then reacts with the zirconium in the Zircaloy-4 to form zirconium hydride, as below.

$$
\begin{gathered}
\mathrm{TiH}_{2}(\mathrm{~s}) \rightarrow \mathrm{Ti}(\mathrm{s})+\mathrm{H}_{2}(\mathrm{~g}) \\
(1-\mathrm{x} / 2) \mathrm{H}_{2}(\mathrm{~g})+\mathrm{Zr} \rightarrow \mathrm{ZrH}_{2}-\mathrm{x}(\mathrm{s})
\end{gathered}
$$

To accomplish this reaction, titanium hydride powder was loosely wrapped in a nickel foil and inserted with three or four SS3 tensile samples in a glass tube (Figure 3). Glass spacers were inserted between each tensile sample to ensure that they did not overlap each other and the full surface area was exposed to the hydrogen. The glass tube was sealed under vacuum, and then heat-treated for 24 hours at $500^{\circ} \mathrm{C}$. After the 24 hour hold, the glass tube is cooled from $500^{\circ}$ to $427^{\circ} \mathrm{C}$ at a $20^{\circ} \mathrm{C} /$ hour rate and held for 30 minutes before being allowed to finally cool to room temperature. 


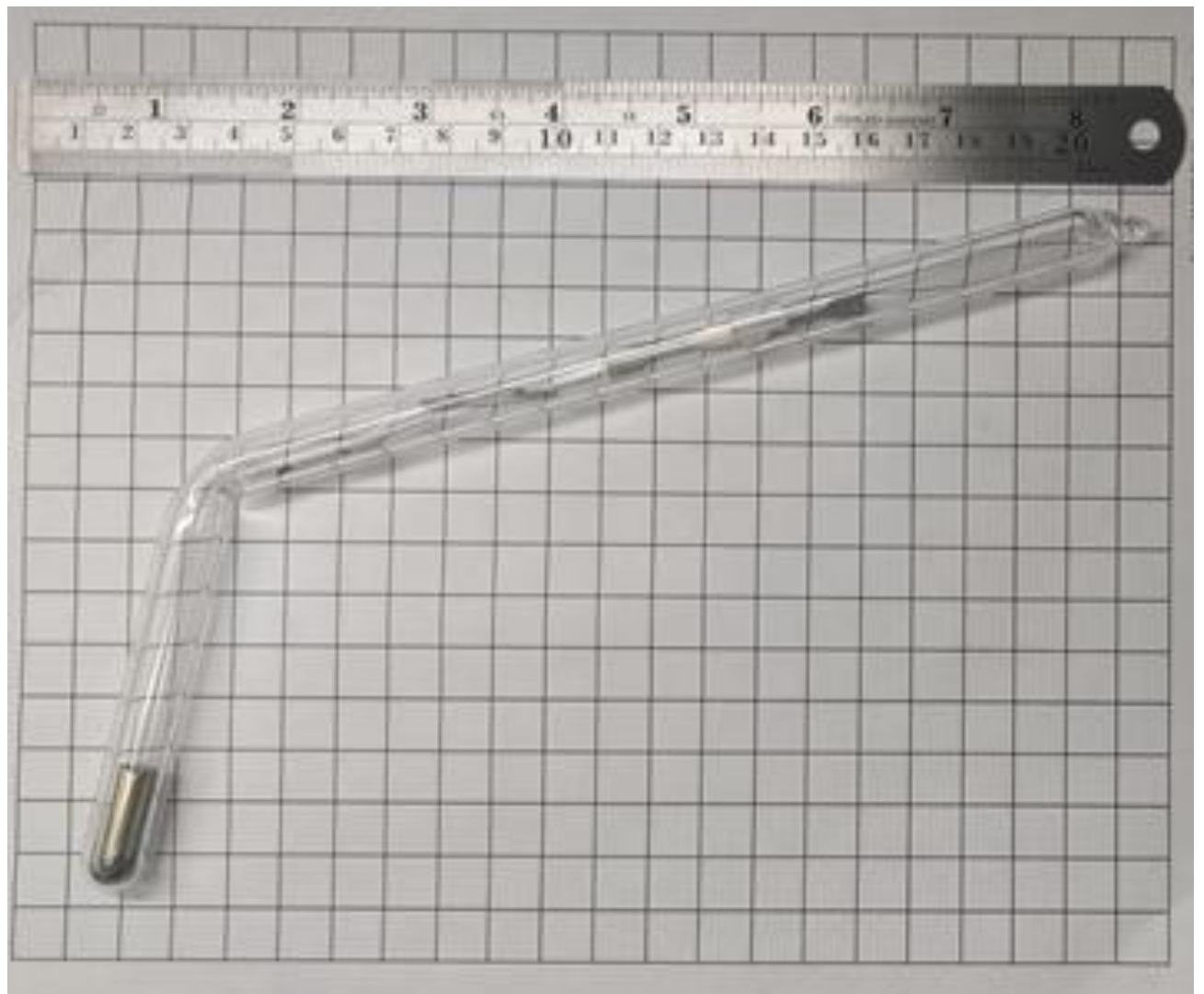

Figure 3. Picture of a glass tube containing four tensile samples in the upper section and a Ni foil pouch with TiH $\mathrm{Powder}^{\mathrm{p}}$ the lower left end.

The amount of powder in each glass tube depended on the desired hydrogen charging amount ( $\mathrm{x}$ in weight $\mathrm{ppm}$ ) and the weight of the samples ( $\mathrm{w}$ in $\mathrm{g}$ ). Using those two factors and atomic constants, the amount of $\mathrm{TiH}_{2}$ powder needed for each tube ( $\mathrm{Y}$ in $\mathrm{g}$ ) was calculated as in Equation 1. For example, a typical Zry-4 SS3 tensile bar weighs $0.41 \mathrm{~g}$, with slight differences from bar to bar because of the machining imperfections. For a hydriding of four such bars to a level of $500 \mathrm{ppm} \mathrm{H}$ would require $0.020 \mathrm{~g}$ of $\mathrm{TiH}_{2}$ powder included in their glass tube.

$$
Y=\frac{x * w}{10^{6}} * \frac{1 \mathrm{~mol} \mathrm{H}}{1.00784 \mathrm{~g} \mathrm{H}} * \frac{1 \mathrm{~mol} \mathrm{TiH}_{2}}{2 \mathrm{~mol} \mathrm{H}} * \frac{50.0238 \mathrm{~g} \mathrm{TiH}_{2}}{1 \mathrm{~mol} \mathrm{TiH}_{2}}=\frac{x * w}{10^{6}} * 24.817 \mathrm{~g} \mathrm{TiH}_{2}
$$

To achieve the accurate amount of powder needed for each set of samples, each sample was weighed on a balance five times and the average of those weights taken. This helped reduce any errors from the balance drifting. For each group of tensile bars that was hydrided, their average weights were summed and used as w in Equation 1 along with the desired hydrogen weight ppm to calculate the desired amount of $\mathrm{TiH}_{2}$ powder. The powder was carefully transferred to a small piece of $\mathrm{Ni}$ foil and weighed five times for an average weight. For these small amounts of powder, it was difficult to transfer the precise amount of powder from the powder bottle to the Ni 
foil. Thus, for each set of samples, the actual included amount of $\mathrm{TiH}_{2}$ powder was recorded along with the goal amount from Equation 1. Despite the challenge, for the 20 sets of samples that were hydrided for this project, all the $\mathrm{TiH}_{2}$ powder weights were within $+0.0003 /-0.0001 \mathrm{~g}$ of the target weight.

The Equation 1 estimate for the hydriding assumes that all the hydrogen dissociates from the $\mathrm{TiH}_{2}$ and all the hydrogen absorbs and bonds with the zirconium. In practice this does not happen and the amount of hydride formation in the samples is strongly influenced by their surface finish. Also, as discussed above, there is some uncertainty in the weights of the samples and powders included in each tube. Thus, one sample out of each set was used for destructive analysis to measure the hydrogen content after the hydriding. These measurements were performed by Eurofins EAG Materials Science, LLC using instrumental gas analysis (IGA). The IGA method heats the sample in a graphite crucible inside a furnace to raise the sample temperature above $2500^{\circ} \mathrm{C}$ and release any contained gas. The released gas is measured to give a reading of how much was contained in the sample. For these experiments, it was assumed that all samples in a set had the same ppm $\mathrm{H}$, so the one measured sample out of each set was taken to be the hydrogen value for all samples in each set. There can be some sample to sample variation in one set, but because the measurement is destructive, it is not possible to measure the hydrogen level in each sample.

\section{RESULTS}

\subsection{WELDING OF AISI 347}

Welded samples were constructed from both the Rolled Alloys and Penn Stainless materials. Tension on samples constructed from these weld bars is the same direction as the " $\mathrm{B}$ " orientation referenced in this and the 2019 report [1]. Due to the different requirements of FCAW and GTAW in the application, different geometries (see Figure 4) were machined via wire electric discharge machining (EDM) for each type of weld. The FCAW used 347LT1-1/-4 flux cored wire, AWS class A5.22, diameter 0.035", and manufactured by Washington Alloy. The GTAW used Washington Alloy weld filler material ER347, AWS class A5.9 in 1/16" diameter close to the root and 3/32" diameter close to the top of the weld. GTAW uses a tungsten electrode which is not consumed during the weld. Both the FCAW and GTAW used argon shield gas.

Welding was carried out by Vacuum Technology Inc. and followed relevant American Welding Society standards [4-6]. Welding guides to track weld settings, pass quality, etc, were created to monitor/document the progress and quality of the weldbars. An example weld tracker document is supplied in Appendix A. 


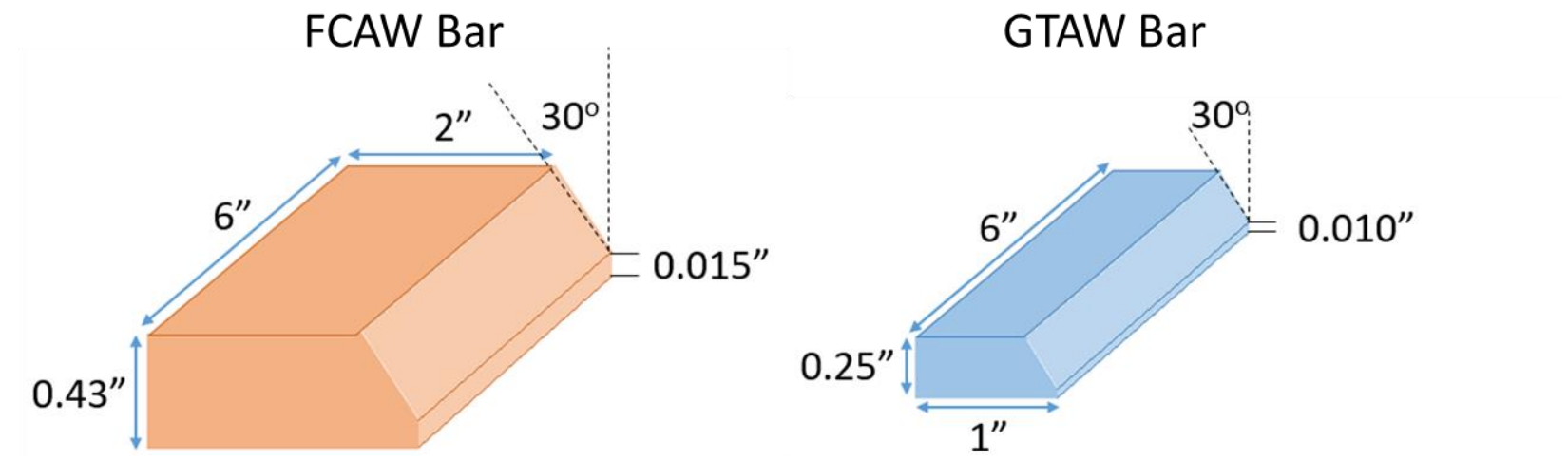

Figure 4. Weld bar geometries. Two bars and filler material are necessary for complete welds.

Figure 5 shows the welding workspace and the clamping used on the narrow GTAW bars. The FCAW bars were wide enough that they were clamped to the table without needing the additional layer. Some images were taken during the welding process to check the weld passes. For example, the GTAW bar number P2 (Penn Stainless bar number 2) is shown during or after each of the six weld passes in Figure 6. Six weld passes were done on each of the GTAW and FCAW bars to complete the welds. The temperatures after the weld passes can be seen in Appendix A.
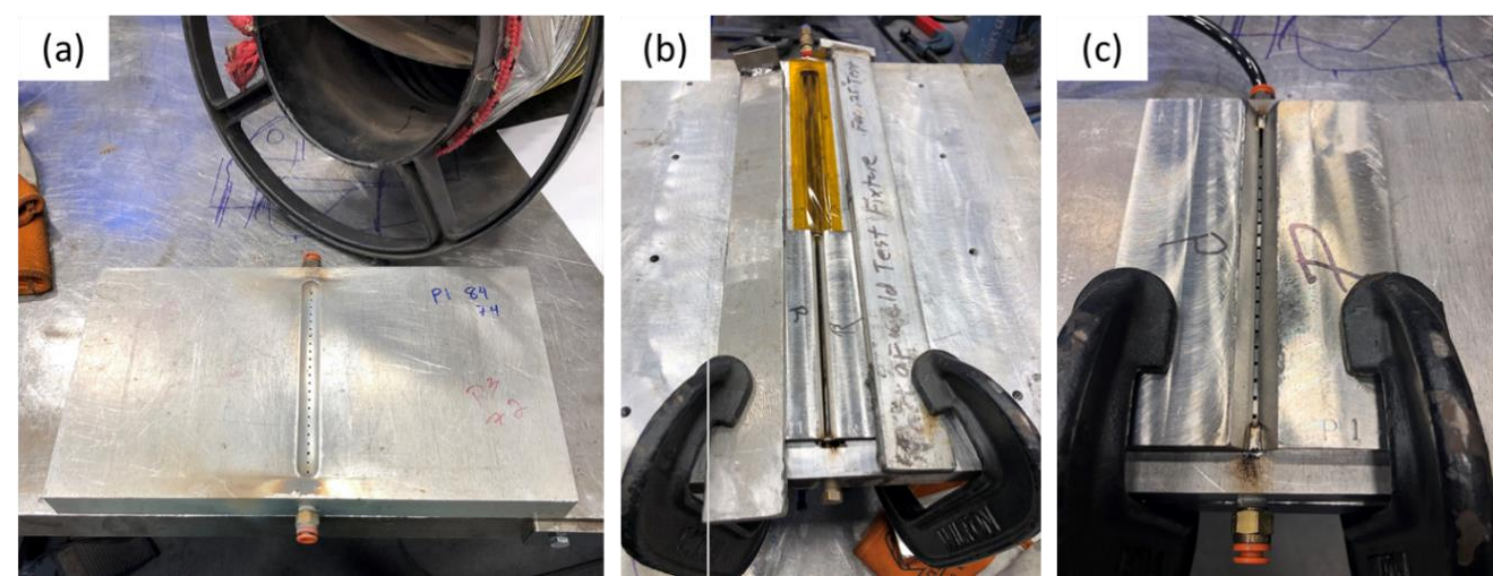

Figure 5. (a) Welding workspace. (b) The GTAW bars had to be clamped with a metal sheet on top because they are narrow. (c) The FCAW bars were directly clamped to the table. 

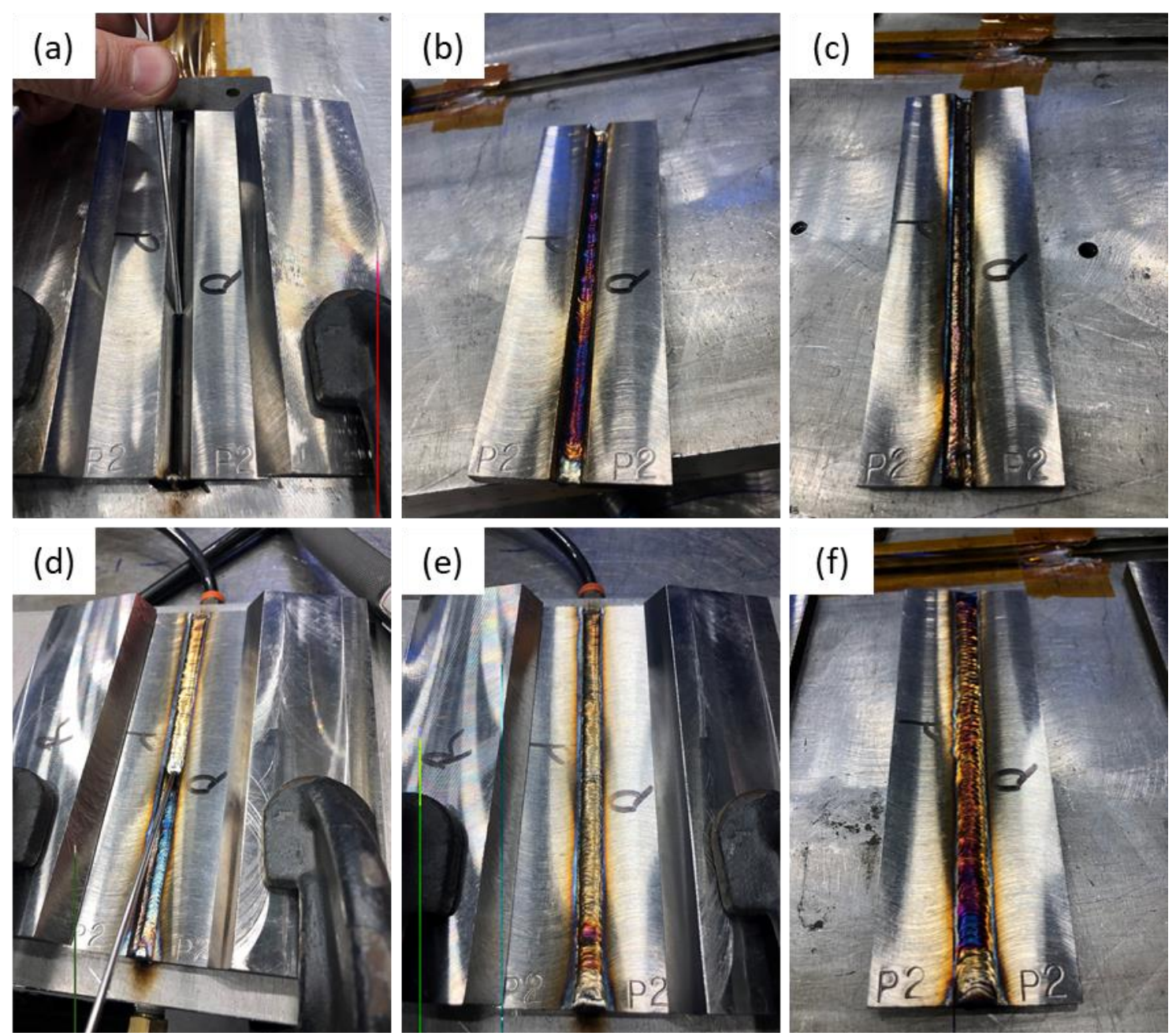

Figure 6. Penn Stainless GTAW bar number P2 is shown after or during each of the six weld passes, starting at (a) and ending with $(f)$.

Three weld bars for each material/weld technique combination were produced. Photos of the bars used to construct samples are shown in Figure 7. Radiographs (Figure 8) were taken of all bars to identify welds with the fewest number of defects and areas to avoid during machining. These images were acquired with a Comet X-ray heat unit. Captures were taken at 120/130 kV with $13 \mathrm{~mA}$, and a focal spot source size of $5.5 \mathrm{~mm}$ over single exposures of 30 seconds. 


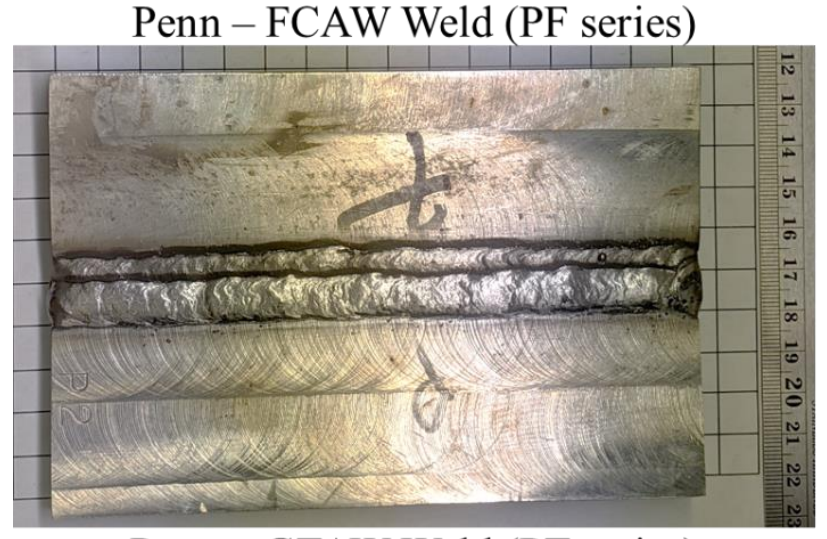

Penn - GTAW Weld (PT series)

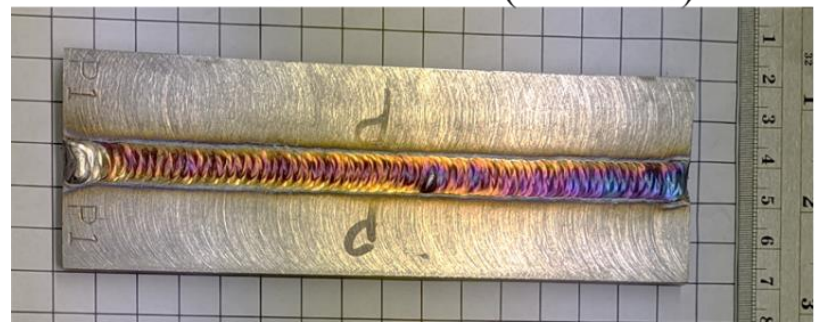

Figure 7. Photographs of welded 347 stainless bars used to manufac
Rolled Alloys - FCAW Weld (RF series)

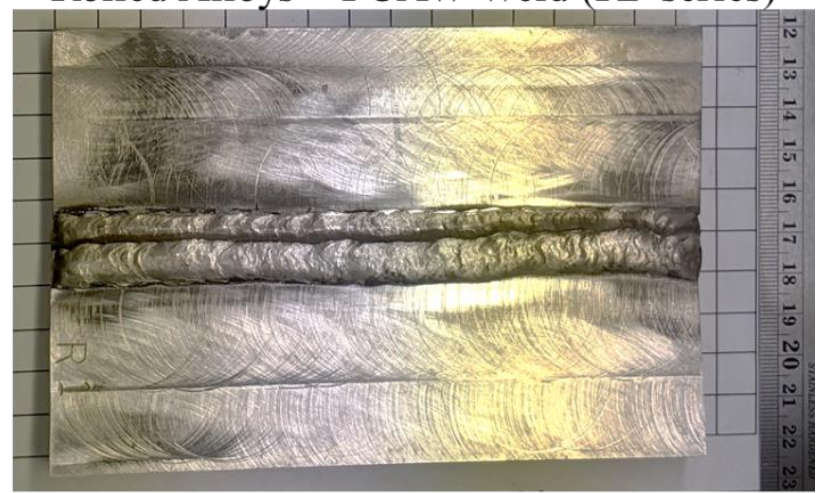

Rolled Alloys - GTAW Weld (RT series)

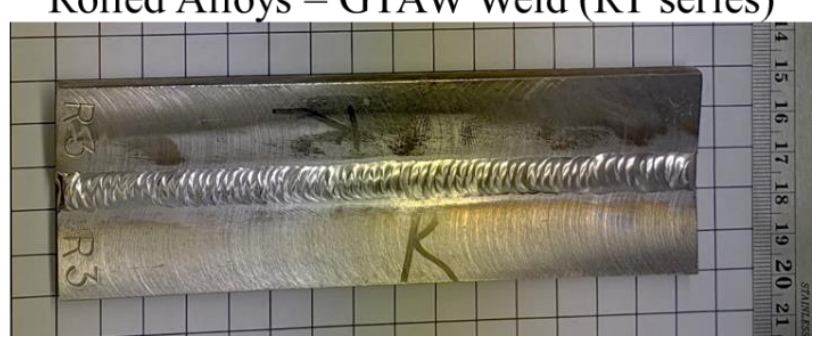

Penn - FCAW Weld (PF series)

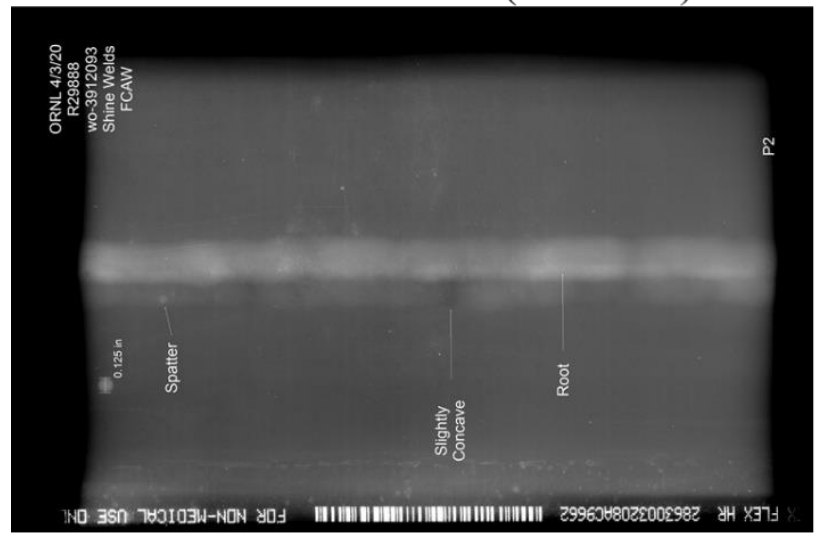

Penn - GTAW Weld (PT series)
Rolled Alloys - FCAW Weld (RF series)

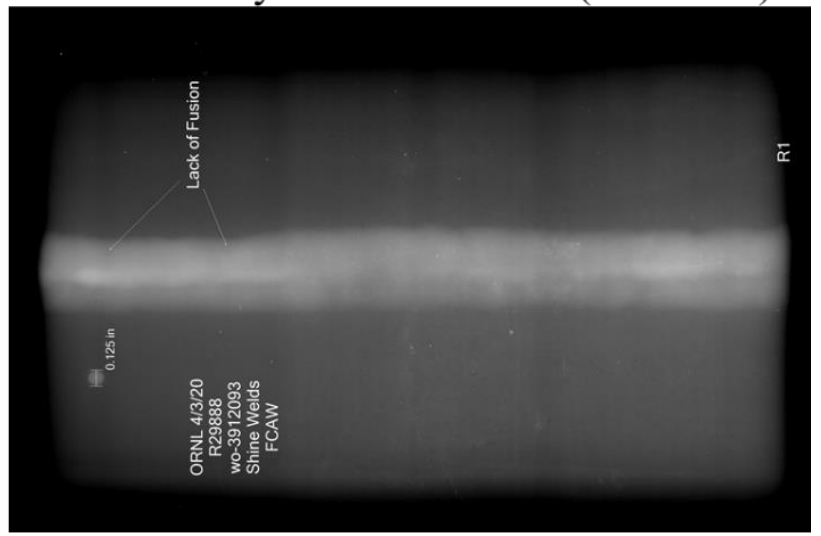

Rolled Alloys - GTAW Weld (RT series)

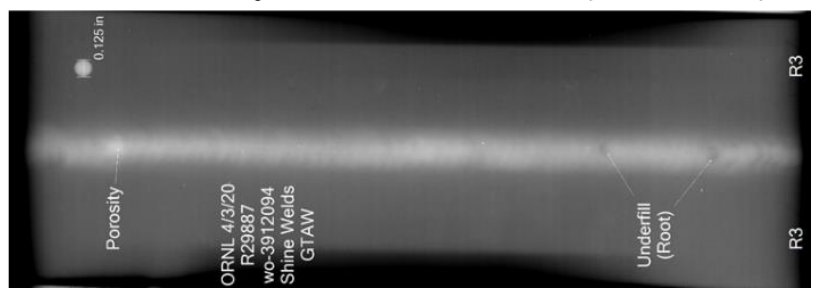

Figure 8. Radiographs of welded 347 bars used to manufacture tensile samples. Annotations indicate weld defects to be avoided during machining or artefacts from imaging.

Tensile samples and long coupons (to investigate microstructure) were machined from weld bars using EDM. Figure 9 shows an example machining layout for these samples. Samples 
were not machined from areas with any weld defects noted in the radiography or from within 0.25 inches from the bar edge. Symmetric tensile bars and coupon samples were cut such that the fusion zone (FZ) was in the center of the sample (the center of the gauge for the weldbars). Because the width of the heat affected zone (HAZ) was unknown, asymmetric samples were cut with the gauge adjacent to the FZ to potentially capture the HAZ and base metal (BM) in the gauge. Additionally, because any change in the dimensions of the FZ, HAZ, and BM as a function of depth were unknown, the depth of samples were tracked during machining. When samples are machined, thick "liftouts" in the tensile or coupon geometry are cut which span the bar from top to bottom (weld face to root). Individual samples are then cut from these liftouts, like slicing a loaf of bread. The last two digits of any individual sample ID correlate first to the liftout number and second to the depth ( 1 being the sample closest to the weld top). See Figure 9 .

\section{Coupon}
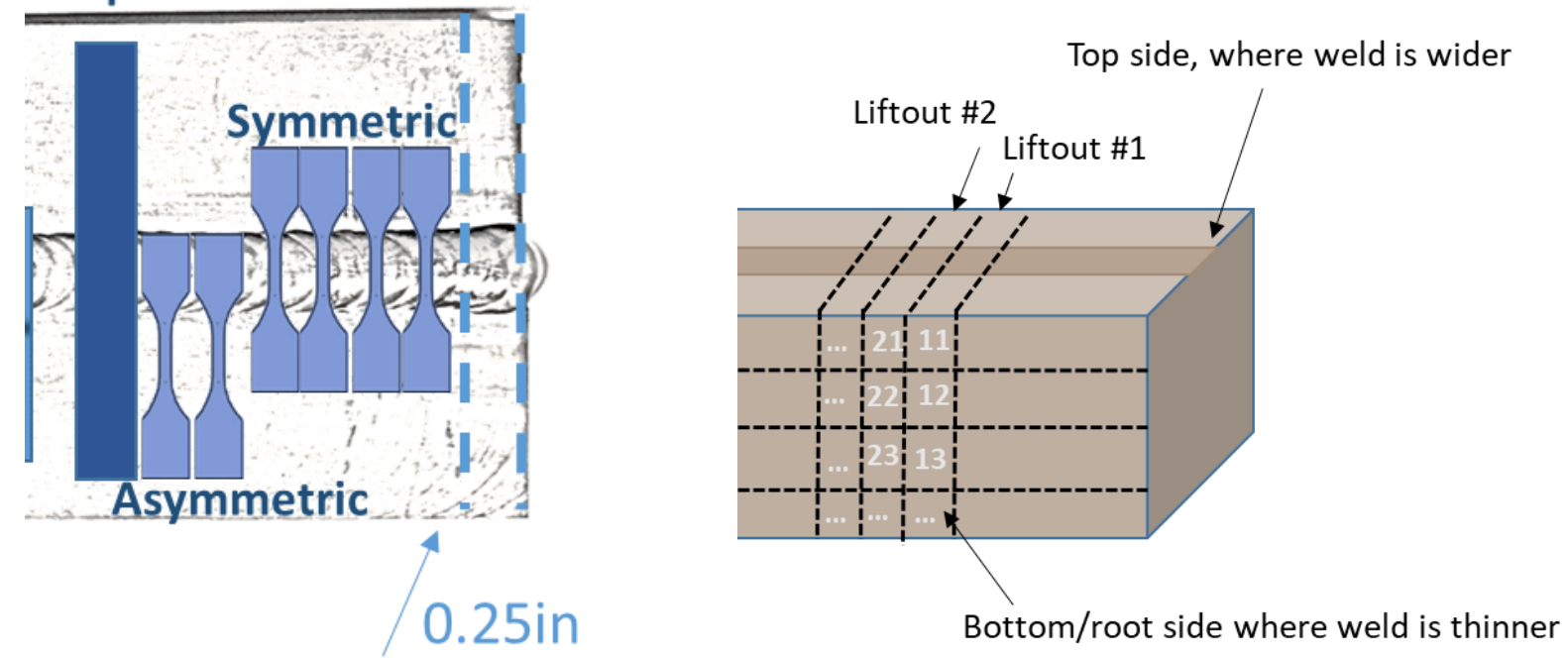

Figure 9.(Left) Example sample machining layout for a GTAW weldbar. (Right) Schematic for machining/tracking samples by the depth from which the sample was taken.

The tensile data focuses on 8 different varieties of tensile specimens consisting of the 2 material types, 2 welding conditions, and 2 symmetry conditions, i.e. FZ for symmetric and HAZ for asymmetric. The sample naming convention is as follows. First character R for Rolled Alloys or P for Penn Stainless; second character F for FCAW or T for GTAW type; third character $\mathrm{S}$ for symmetric or A for asymmetric cut from the weld; fourth character number indicates which liftout; and fifth character indicates which layer within the liftout (Table 1). While liftout number did not influence the mechanical behavior of the material, the depth number did for only the symmetric condition. With increasing depth number, the specimens are being cut closer to the root of the weld. The trend of tensile behavior with depth is shown in Figure 10 for Penn GTAW symmetric specimens on liftout \#4. At the weld face, the specimens have yield stresses (YS) around 60-70\% that of specimens at the weld root. The ultimate tensile strength (UTS) does not vary significantly from weld face to root, but the uniform elongation (UE) at this strength maximum decreases closer to the root, signifying that localized necking occurs at smaller strain values. The total elongation (TE) minus the UE, called post-uniform elongation, does not change significantly with depth. This data shows that the weld face has a smaller onset of plastic deformation but undergoes an amount of strain hardening such that the 
ORNL/SPR-2020/1879

UTS at the weld face is similar to that of the UTS at the weld root. Stress-strain curve behavior is shown in Figure 11.

Table 2. Unirradiated welded AISI 347 samples that were tensile tested.

\begin{tabular}{|l|l|l|l|l|}
\hline Sample ID & Supplier & Type of weld & $\begin{array}{l}\text { Symmetric or } \\
\text { Asymmetric }\end{array}$ & Layer \\
\hline RFS14 & Rolled & FCAW & Sym & 4 \\
\hline RFS24 & Rolled & FCAW & Sym & 4 \\
\hline RFA14 & Rolled & FCAW & Asym & 4 \\
\hline RFA24 & Rolled & FCAW & Asym & 4 \\
\hline RTS24 & Rolled & GTAW & Sym & 4 \\
\hline RTS34 & Rolled & GTAW & Sym & 4 \\
\hline RTA14 & Rolled & GTAW & Asym & 4 \\
\hline RTA24 & Rolled & GTAW & Asym & 4 \\
\hline PFS14 & Penn & FCAW & Sym & 4 \\
\hline PFS24 & Penn & FCAW & Sym & 4 \\
\hline PFA14 & Penn & FCAW & Asym & 4 \\
\hline PFA24 & Penn & FCAW & Asym & 4 \\
\hline PTA24 & Penn & GTAW & Asym & 4 \\
\hline PTA34 & Penn & GTAW & Asym & 4 \\
\hline PTS14 & Penn & GTAW & Sym & 4 \\
\hline PTS24 & Penn & GTAW & Sym & 1 \\
\hline PTS41 & Penn & GTAW & Sym & 2 \\
\hline PTS42 & Penn & GTAW & Sym & 3 \\
\hline PTS43 & Penn & GTAW & Sym & 4 \\
\hline PTS44 & Penn & GTAW & Sym & Sym \\
\hline PTS45 & Penn & GTAW & Sym & \\
\hline
\end{tabular}

The tensile strength and elongation for the 8 varieties are reported in Figure 12 and the representative tensile curves in Figure 13 and Figure 14. The values of strength and elongation are taken as averages of two specimens of each variety. These two specimens are from separate liftouts while keeping the depth constant (for this case, a depth \#4 was chosen). For strength and elongation, there were no major differences between FCAW and GTAW specimen performances. Between suppliers, Penn Stainless did not differ from Rolled Alloys in the symmetric condition. In the asymmetric condition however, Penn showed larger UTS and slightly less elongation. In general, the asymmetric condition showed a stark contrast to the symmetric condition in YS and UE. Similar to the difference between weld face and weld root, asymmetric tended to have lower YS like the weld face and higher UE, while symmetric tended to have higher YS like the weld root and lower UE. Also like the contrast between weld face and root, there was no major variation in UTS and post-uniform elongation between symmetric and asymmetric. The only major exception is that RTS (Rolled Alloys GTAW symmetric cut) showed a much larger elongation than the other symmetric specimens (Figure 13). 
ORNL/SPR-2020/1879

(a)

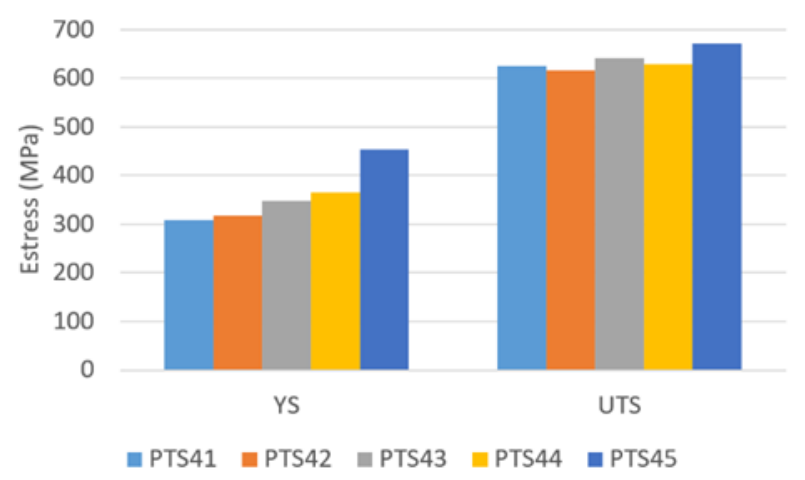

(b)

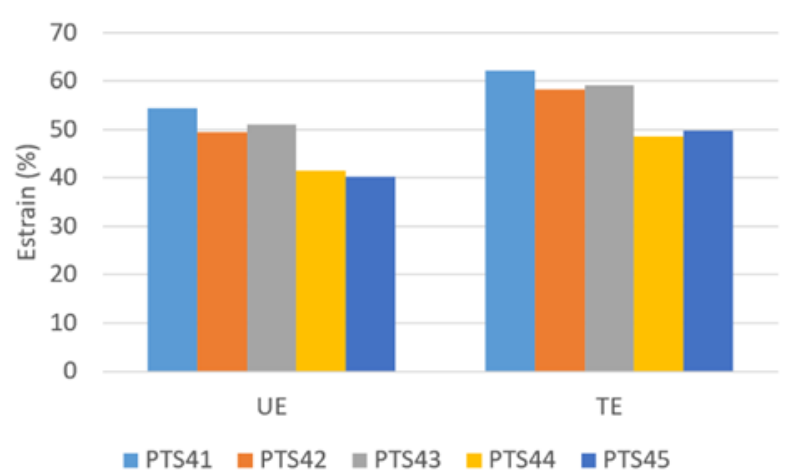

Figure 10. (a) Tensile yield stress (YS) and ultimate strength (UTS) and (b) tensile uniform elongation (UE) and total elongation (TE) for symmetric Penn GTAW specimens from depth 1 (weld face) to depth 5 (weld root).

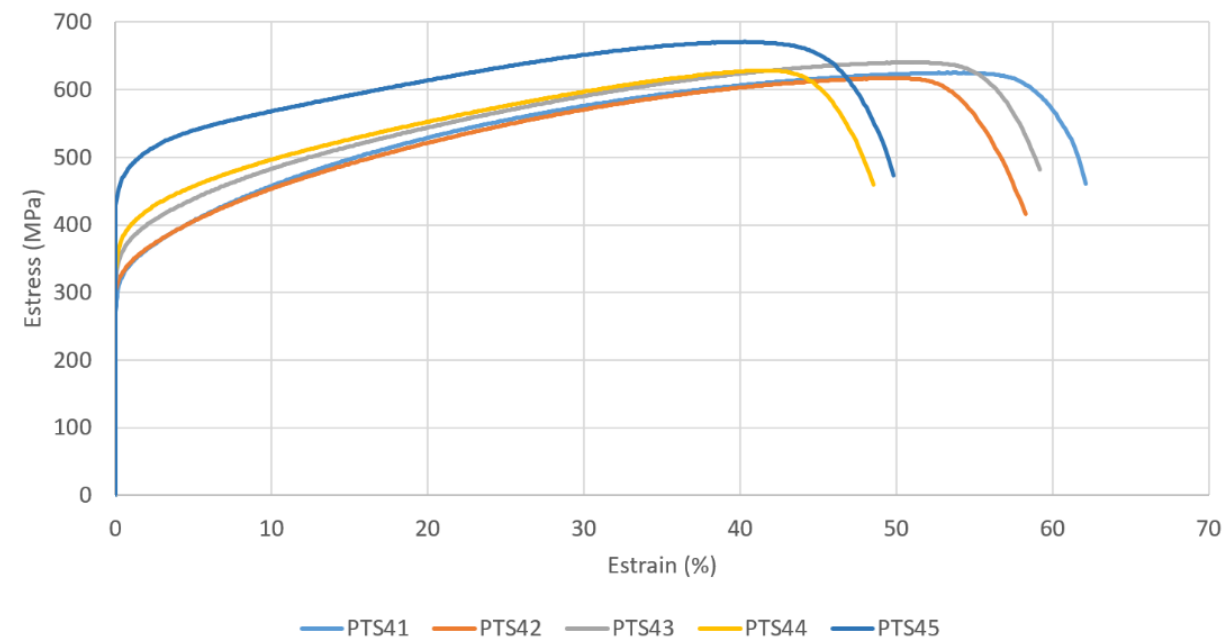

Figure 11. Tensile curves for symmetric Penn GTAW specimens from depth 1 (weld face) to depth 5 (weld root).
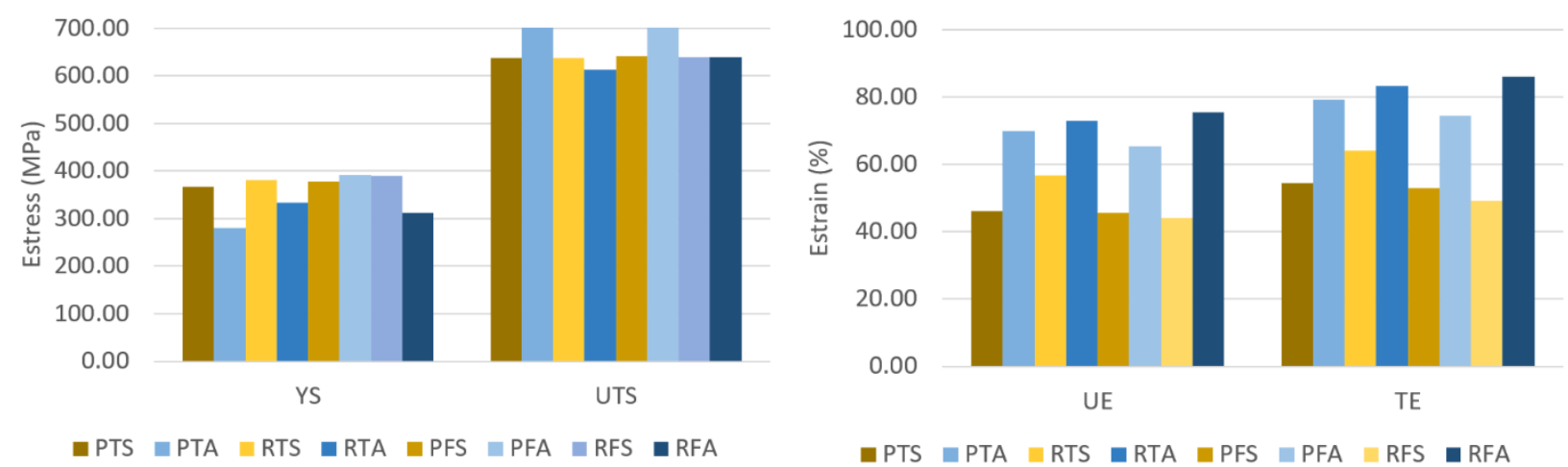

Figure 12. Tensile yield stress (YS) and ultimate strength (UTS) and tensile uniform elongation (UE) and total elongation (TE) for 8 different material varieties of AISI 347 welds. 
ORNL/SPR-2020/1879

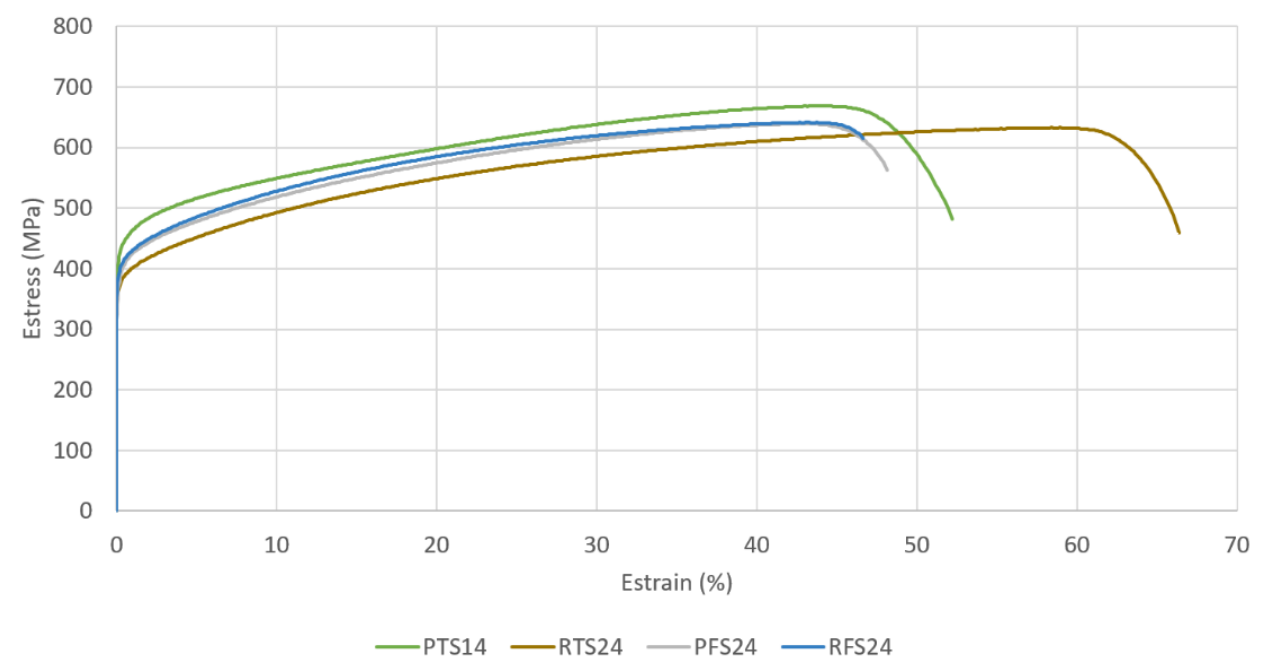

Figure 13. Tensile curves for symmetric Penn and Rolled GTAW and FCAW welds.

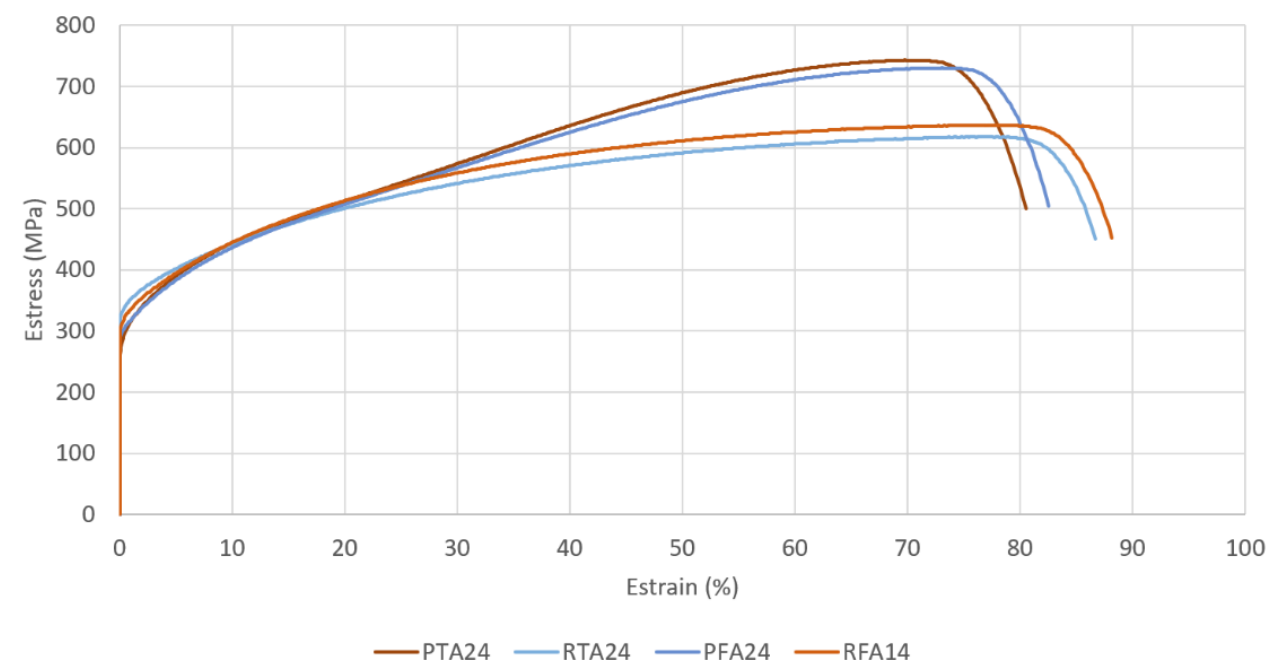

Figure 14. Tensile curves for asymmetric Penn and Rolled GTAW and FCAW welds.

Representative fracture surfaces from all 8 sets of welded tensile samples are shown in Figure 15. Although all analysis at this point is preliminary, both symmetric and asymmetric sample fracture surfaces are dominated by microvoid coalescence, a behavior expected of AISI 347 and indicative of desirable ductile fracture. Significant variation exists in the apparent reduction of area amongst the samples, and this will be investigated further.

Limited microstructural analysis has been performed on coupon samples to investigate the size of the HAZ and FZ for different welds and at various depths. Example composite SEM images can be seen in Figure 16 with rough estimations of the boundaries between the FZ/HAZ and the HAZ/BM. FZs of these samples consist of large $(>50 \mu \mathrm{m})$ grains, while HAZs have grains between the sizes of those in the BM and FZ (increased in size due to growth from the heat of welding). Analysis here is also preliminary, but it suggests FZs between $3.5-5.5 \mathrm{~mm}$ wide and BM-to-BM widths of $8.5 \mathrm{~mm}$ at most. This, however, is implausible given that the FZ alone 
for FCAW welds should be around $12 \mathrm{~mm}$ near the top (layer 1) of the welds. Investigation is ongoing to identify the source of this inconsistency.
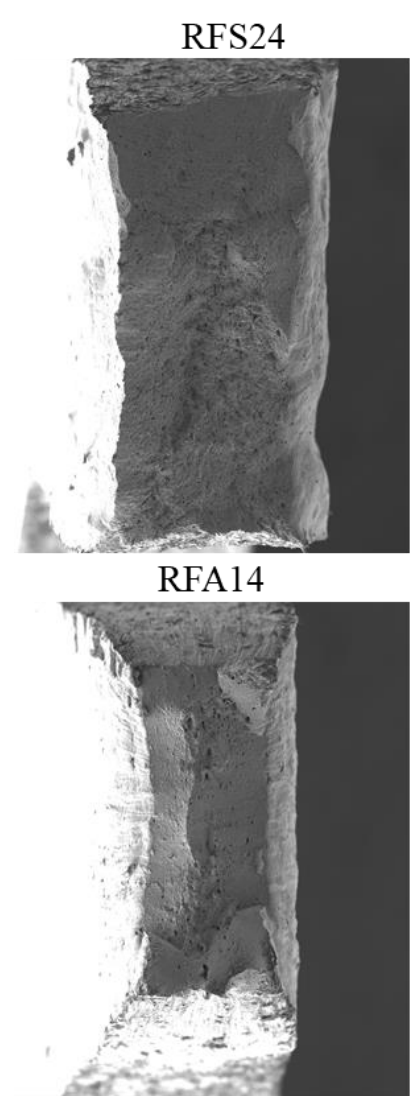

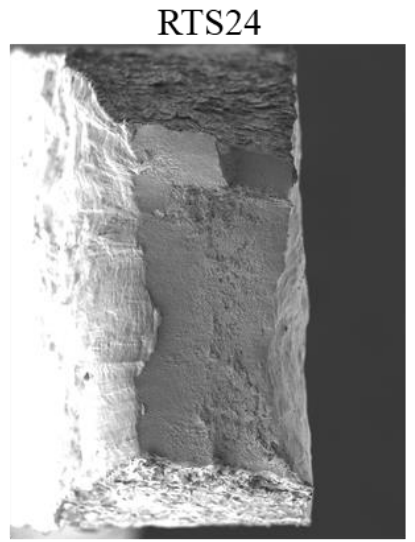

RTA24

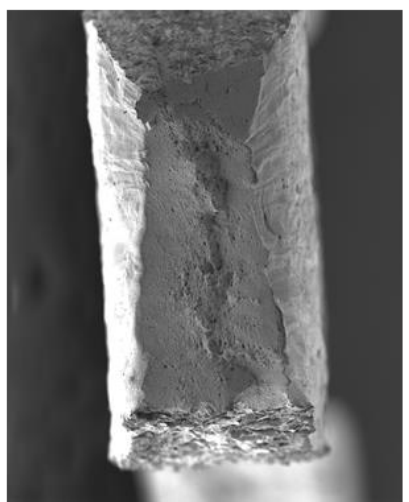

PFS24

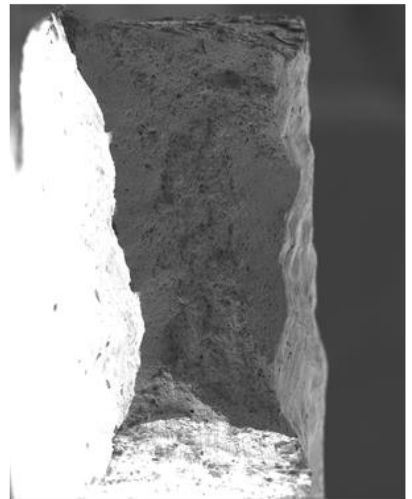

PFA24

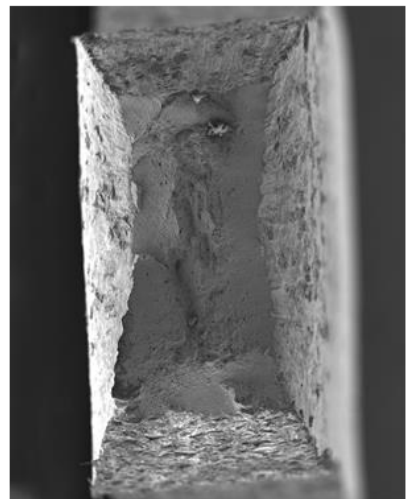

PTS14

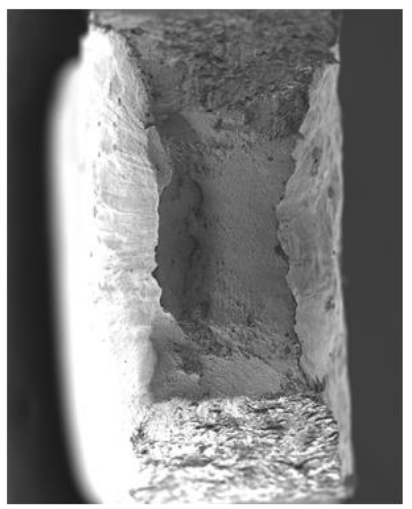

PTA24

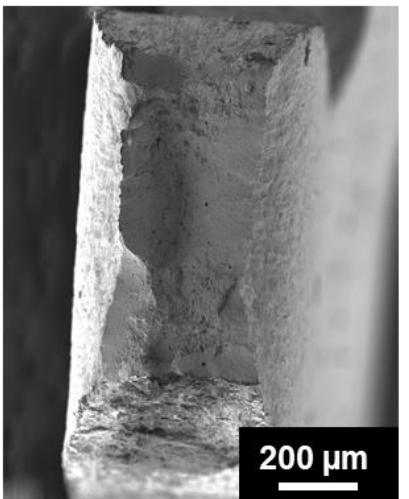

Figure 15. Representative fracture surfaces from all weld/cut combinations.

RFC1

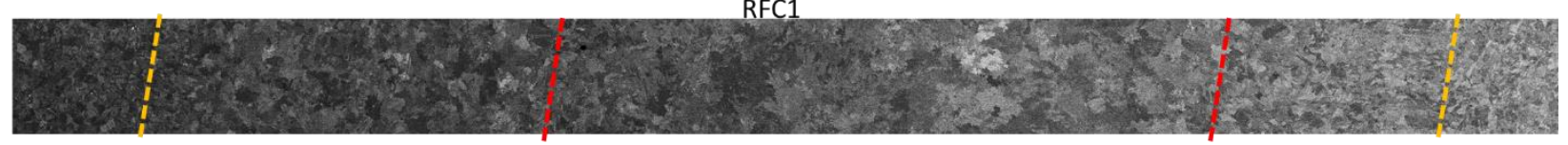

RFC5

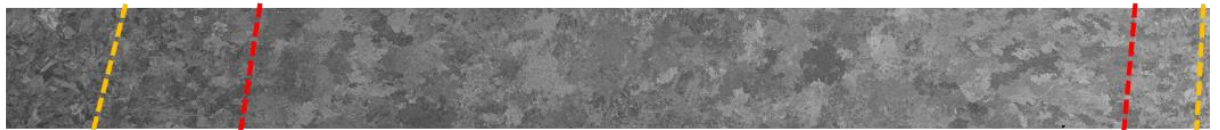

PTC1

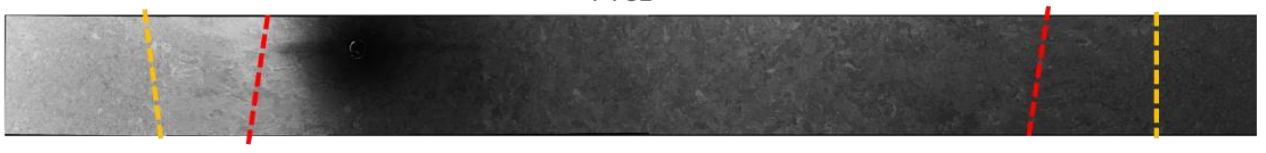

PTC4

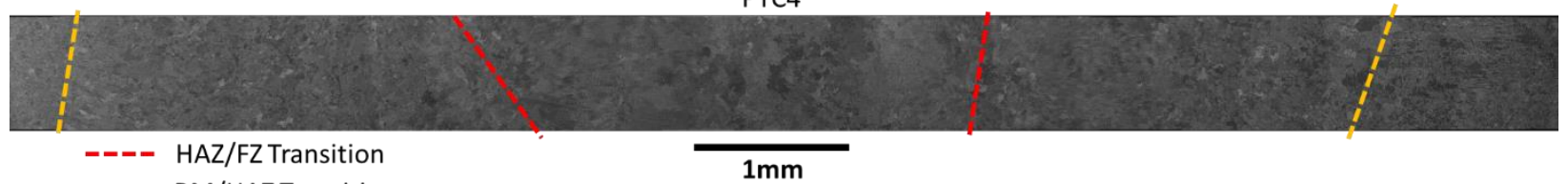

$==-=$ BM/HAZTransition

Figure 16. Composite SEM images from coupon samples from two weldbars. Preliminary analysis on the width of the FZ and HAZ is shown with dotted lines. RFC1 and RFC5 Rolled Alloys welded material sectioned from the weld face and weld root, respectively. PTC1 and PTC4 Penn Stainless welded material sections from the weld face and near the weld root, respectively. 


\subsection{EXPLOSIVE WELDED PLATE}

A bimetal composite plate consisting of an alloy SA-516-70N base metal approximately 2 inches thick and AISI 347 stainless steel cladding layer of $\sim 1 \mathrm{~mm}$ thickness was fabricated by NobleClad via explosion welding. The interface appears as a waveform due to the fast heating and pressure of the explosion weld "jet" and the zones in the crests and troughs of the waveform are vortexes or eddies created by rotational movement of the material during mixing [7].

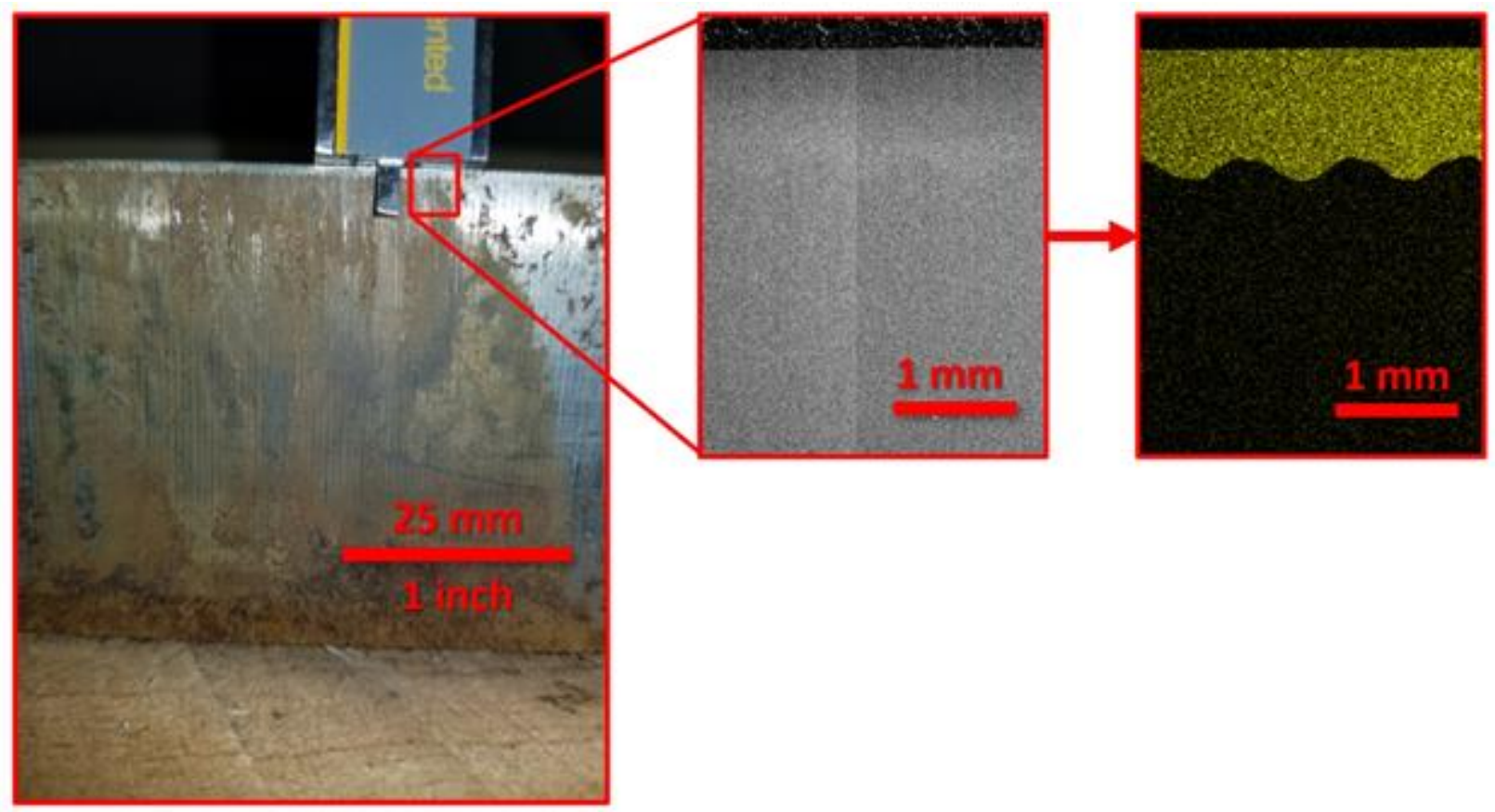

Figure 17. Picture of the side of the explosion weld plate. The zoomed in feature shows an SEM micrograph of the weld interface. EDS mapping of the Cr signal gives a better contrast of the waveform at the interface.

There was minimal interdiffusion near the boundary such that these zones retained essentially the chemical composition of the parent plates as measured by EDS mapping (Figure 17). The height difference between crest and trough was measured to be $0.17 \mathrm{~mm}$ and the cladding layer retains a uniform thickness of $0.96 \mathrm{~mm}$ at each end of the plate. The thickness of the base plate is sufficiently large (about 2") as to have no limitation on the thickness of base material used in mechanical testing.

The bond-shear strength will be measured by tensile-shear testing. The tensile samples are made in the geometry of an SS-3 (Figure 2), with rectangular notches cut into each layer on opposing sides of the gauge section (Figure 18). The thickness of the layers, the notch width, and the shear area with overlap are not parameters of the material properties alone but also the strength of the interface [8]. By varying the layer thickness and notch placement, one can force the failure to occur in different layers in the tensile tests and learn the characteristics of the interface. However, some interface properties must be known before fabricating the tensileshear samples. Therefore, rectangular shear test specimens will be made in accordance with ASTM A264 standard for testing the shear strength (Figure 19) of Stainless Chromium-Nickel Steel-Clad Plates to directly probe the shear strength of the interface [9]. The purpose of these shear strength tests is to determine the notch placement in the tensile samples. The rectangular 
shear specimens are too large of a volume of material to be irradiated in HFIR. Additionally, error in bond-shear strength calculations for these tests is magnified for thin-cladding materials and should only be used quantitatively for thick-cladding layers. These specimens are relatively difficult to machine to precise tolerances for the cladding lip that is to be sheared off in testing [10]. The machining to a depth of the interface is another challenge when the interface is difficult to locate without a microscope and the machined depth may be off by a significant percentage of the thickness of the cladding material. Therefore, this test is solely used as an interfacial strength marker for tensile-shear testing.

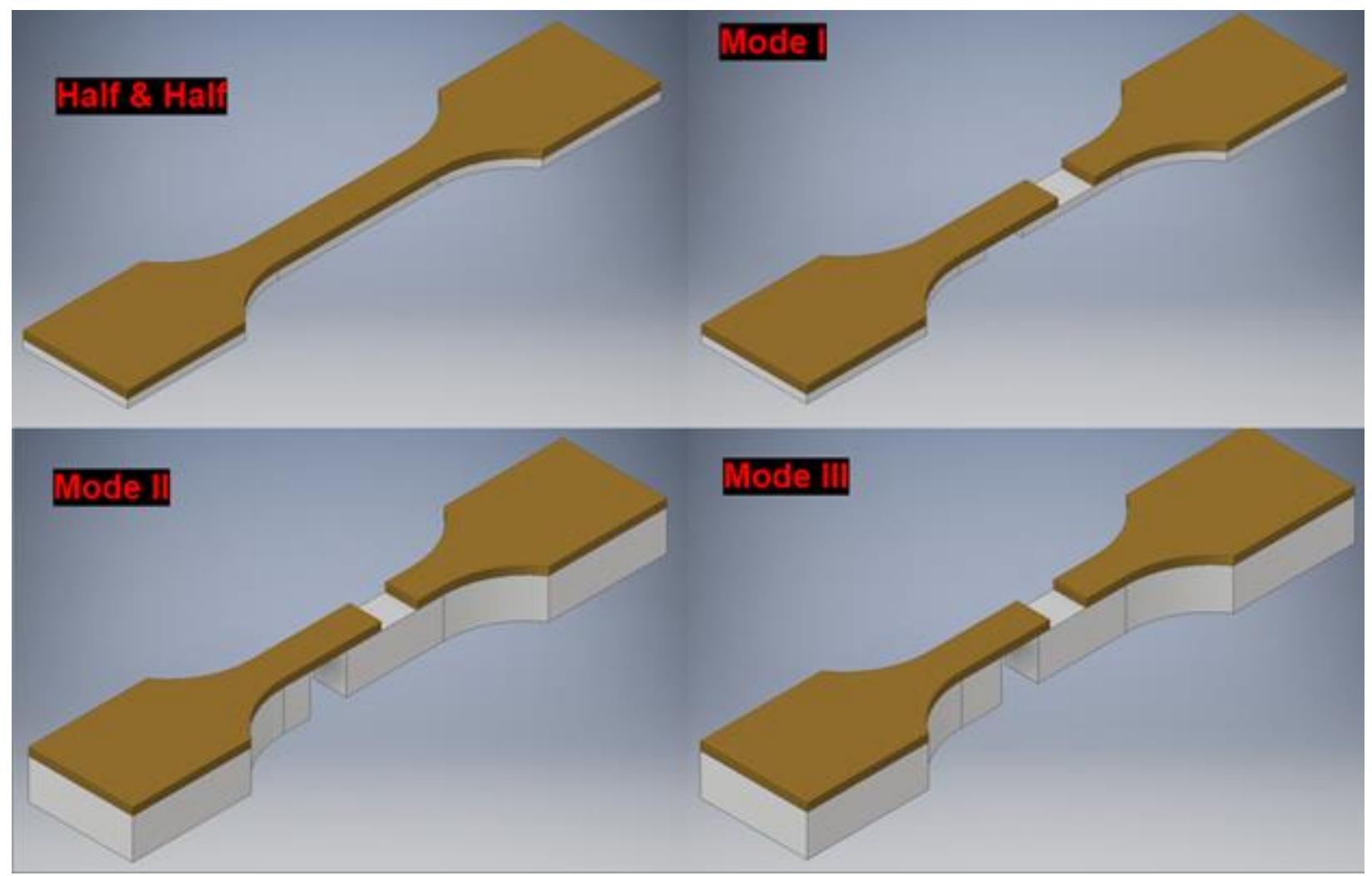

Figure 18. CAD model of the tensile specimens for tensile-shear testing. Each mode determines whether the break will occur in the base metal (light grey-colored), cladding metal (brass-colored), or directly at the interface by varying notch placement. Not pictured are SS-3 specimens for control tests of each metal. 

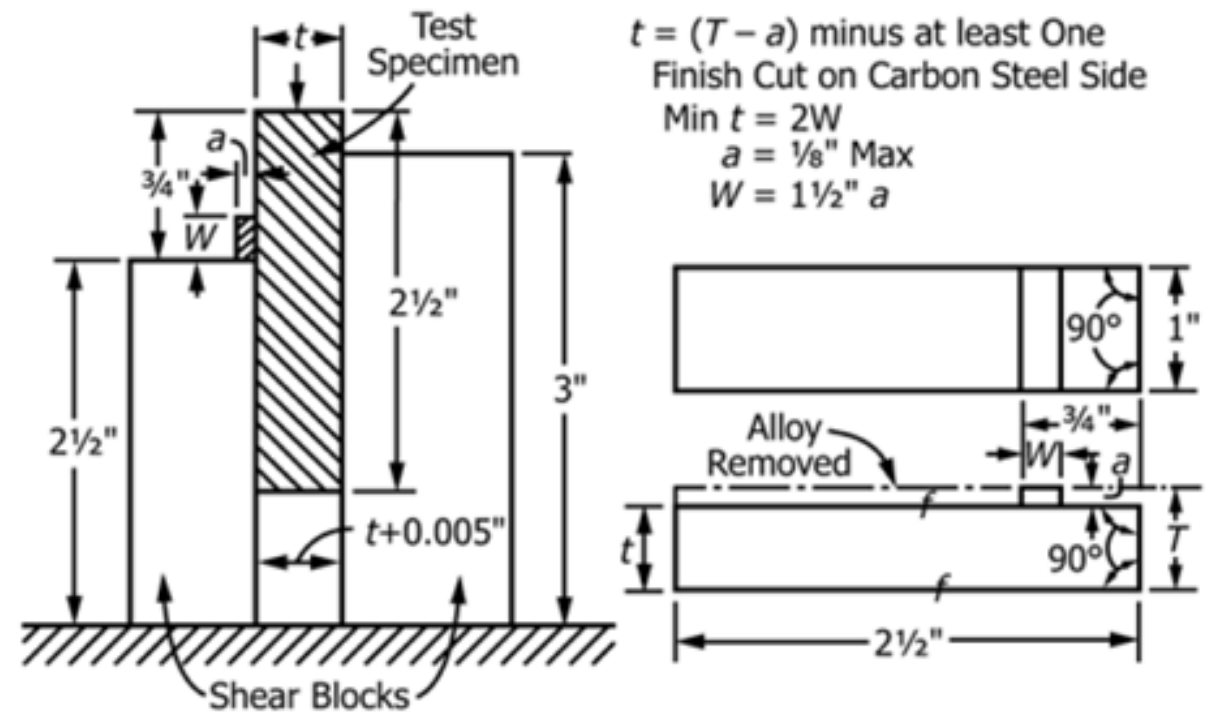

Shear Blocks shall be Bolted Firmly Together against

Filler Piece which Provide Space $0.005^{\prime \prime}$ Wider than $t$ of Specimen

Figure 19. Schematic diagram of shear strength test fixture and specimen (left) and shear specimen (right)[9].

(a)

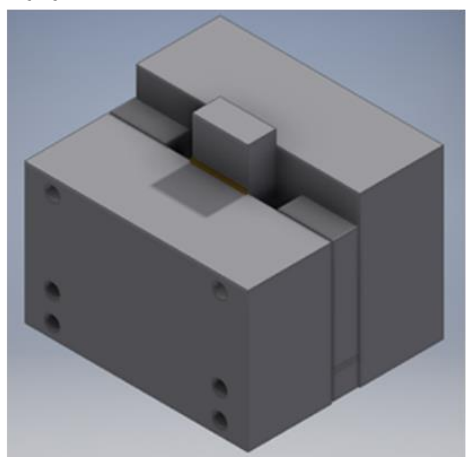

(b)

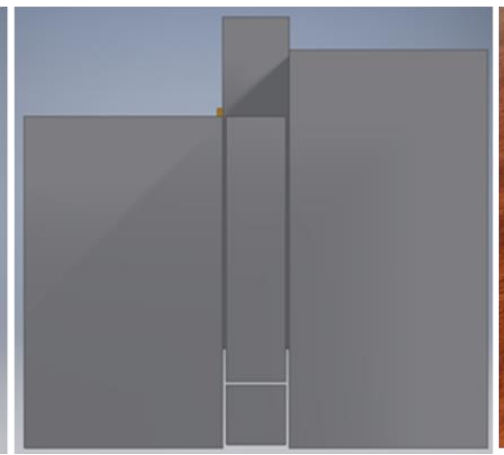

(c)

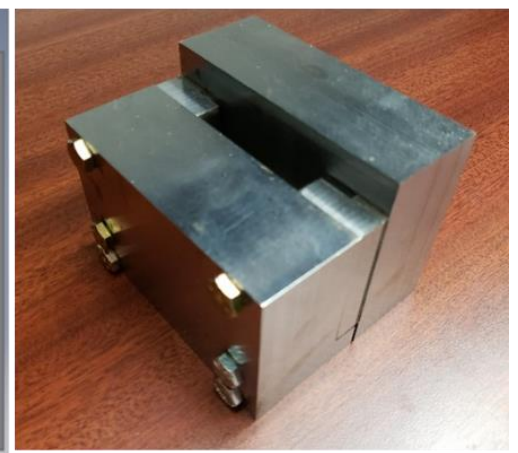

Figure 20. (a) CAD model of shear strength test fixture and specimen (a) orthographic view and (b) Side view showing small specimen lip (brass-colored) overhanging the front "shear block". (c) image of the completed fixture.

The shear strength test from ASTM A264 will be tested in the fixture made from the base metal material and shown in Figure 20. In addition to interface bond strength, the composite will be tested under non-uniform stresses in a three-point bend test to observe lamination failure and the quality of the bond with respect to the flexural properties of the material. Uniaxial tensile strength will capture the uniform stress in both layers of the bimetal as well as in the direction of the weld. Hardness testing will be performed in a track pattern across the interface on the tabs of irradiated SS-3 tensile specimens to determine the quality of the bond. Charpy V-notch specimens will be used to determine the impact strength and fracture of the base metal and cladding layer with the notch made on the base metal side.

The strength and ductility of the explosion weld composite was evaluated by tensile tests. 
These tests were performed on an SS-3 specimen consisting of approximately half thickness base metal and half cladding metal, with the direction of force parallel to the bond. Keeping the force in the same direction for the microstructure, full thickness SS-3 base metal specimen and cladding metal specimens were also tested. The results of the tensile strength and elongation are shown in Figure 21. For each of the three conditions, the specimens showed very little strain hardening as shown by the small UE needed to reach the UTS. For the cladding metal, the necking region was fairly consistent with previous 347 stainless steel tensile tests that were performed. The low alloy carbon steel base metal showed similar ductility to the 347 cladding stainless steel with about $60 \%$ of the YS and UTS. Notably, the explosion welded composite showed a decreased ductility but higher strength than the stainless steel alone. The possible deformation mechanism still needs to be investigated.
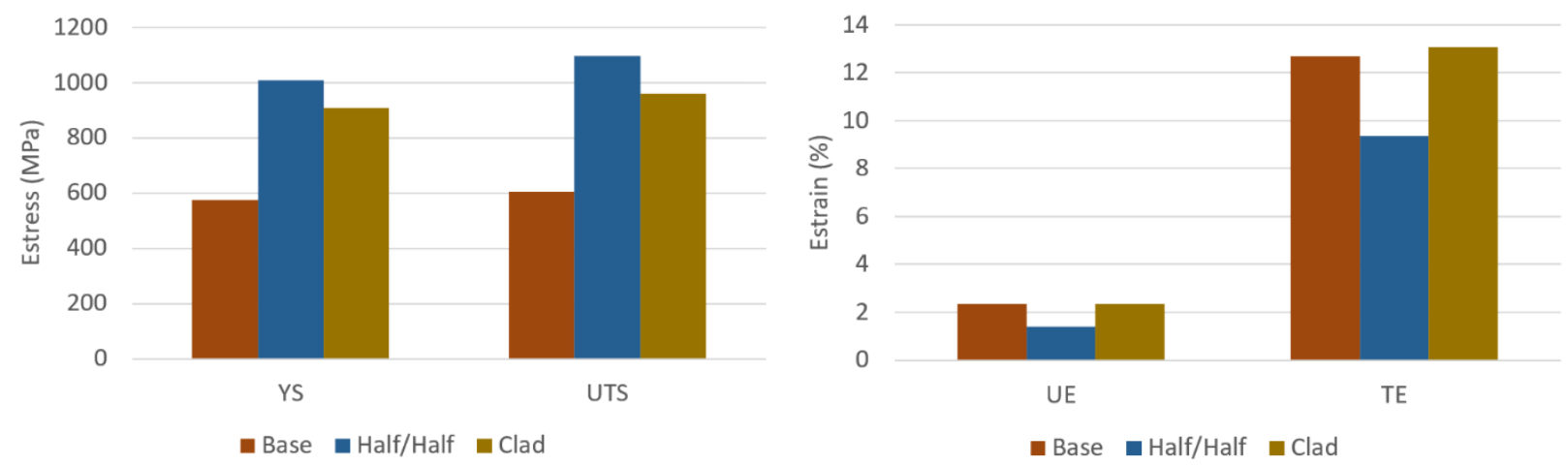

Figure 21. Tensile yield strength (YS) and ultimate strength (UTS) and tensile uniform elongation (UE) and total elongation (TE) for explosion weld materials.

Two specimens of each of the three varieties were tested. The label " $\mathrm{B}$ " was given for base metal, the label "F" or "FCFB" for the composite weld, and the label "G" or "GCGB" for the cladding metal. Tensile curves of 5 representative specimens are shown in Figure 22. One of the cladding specimens was not tested due to a machining error. We can see that the cladding and base metal show similar behavior in the necking region. The composite shows a much steeper decrease in engineering stress in the necking region, possibly due to a different plastic deformation mechanism. 
ORNL/SPR-2020/1879

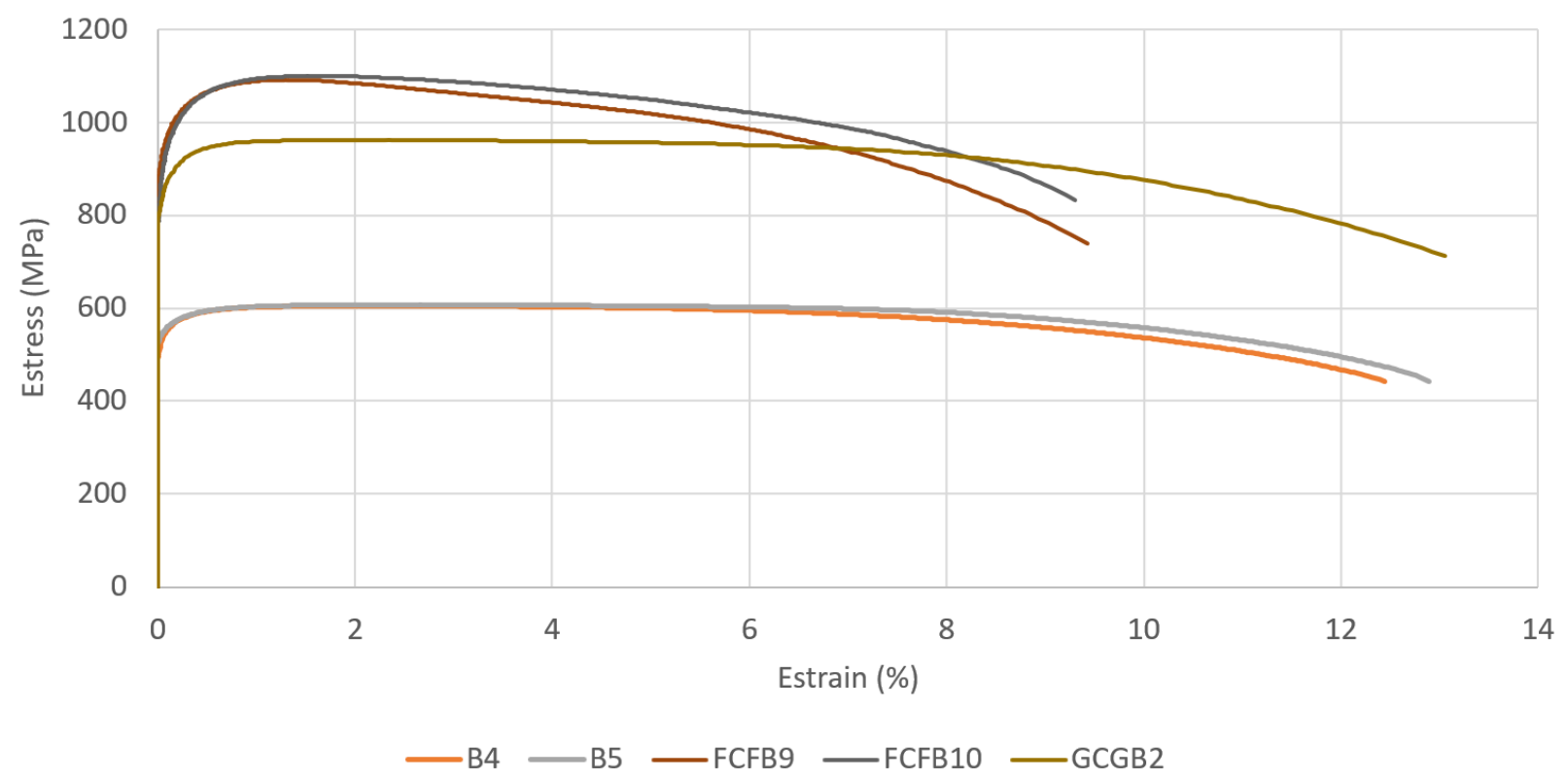

Figure 22. Tensile curves for explosion weld materials. Sample labels starting with B are base metal, $F$ are approximately half clad and half base metal, and $G$ are clad alone.

Representative fracture surfaces of the tested explosion weld materials are shown in Figure 23. Microstructural characterization is still needed for these materials. However, we can see that the ductile fracture of the cladding is characteristic of other AISI 347 fracture surfaces. The base metal surface has a much rougher fracture surface with larger pore sizes. The composite is a clear mixture of both, where it is apparent that the cracks initiated on the much weaker base metal material and lead to the cladding layer to fail last. EDS of the chromium signal can confirm where the exact location of the wavy explosion weld interface lies and will be later done. 
B4

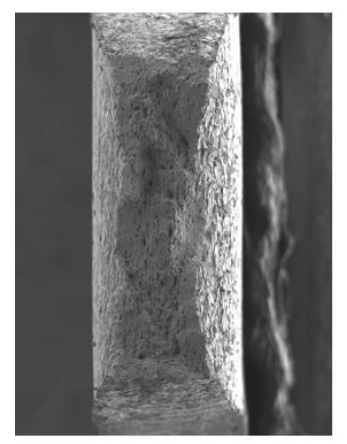

B5

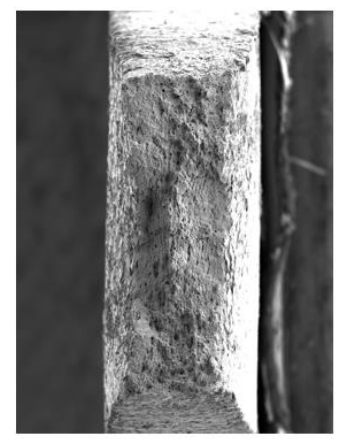

FCFB9

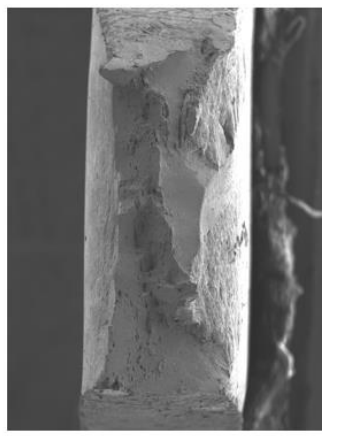

FCFB10 GCGB2
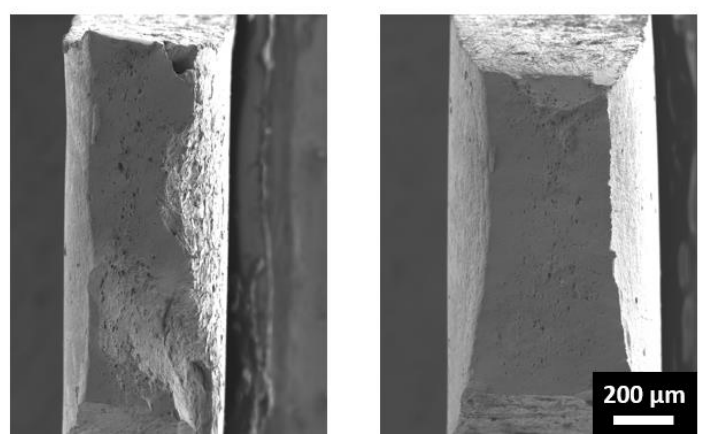

Figure 23. Fracture surfaces of the base metal (B4, B5), half cladding half base metal (FCFB9 and FCFB10), and the cladding 347 layer (GCGB2).

\subsection{HYDROGEN CHARGED ZIRCALOY-4}

The hydrogen charging of the Zry-4 was done in batches, with three or four tensile samples put in each glass for the charging. One sample from each set was used for destructive hydrogen content analysis, and these samples are indicated with an asterisk in Table 1. All other samples in the same set as the analyzed sample were assumed to have the same hydrogen content. From previous hydrogen charging trials, it is known that there is sample to sample variation within a set. For example, Z33 was measured to have $560 \mathrm{ppm} \mathrm{H}$ and Z34 was measured to have $520 \mathrm{ppm} \mathrm{H}$ even though they were in the same glass tube for the hydrogen charging. Thus, the uncertainty on the hydrogen content values are at least $+/-20 \mathrm{ppm} \mathrm{H}$. However, since the hydrogen charging measurement is destructive to the sample, it is impossible to measure the hydrogen content in each sample. The trend is that the measured hydrogen amounts are less than the target amounts, which is reasonable considering the method used. As described in the Methods section, the amount of $\mathrm{TiH}_{2}$ powder used for the $\mathrm{H}$ charging is calculated assuming all of the $\mathrm{H}$ is desorbed from the $\mathrm{TiH}_{2}$ and absorbed in the Zircaloy-4, but in fact this process is not $100 \%$ efficient. 
ORNL/SPR-2020/1879

Table 3. Results of the hydrogen charging. An asterisk by a sample's label means that sample was consumed to measure the hydrogen content after charging. Thick borders separate the samples that were enclosed in the same capsule for hydrogen charging. The hydrogen content is reported as weight parts per million (wppm).

\begin{tabular}{|c|c|c|c|c|}
\hline $\begin{array}{l}\text { Sample } \\
\text { ID }\end{array}$ & Weld & Post-weld heat treatment & $\begin{array}{l}\text { Target H } \\
\text { (wppm) }\end{array}$ & $\begin{array}{l}\text { H measured } \\
\text { (wppm) }\end{array}$ \\
\hline $\mathrm{Z}-11^{*}$ & None & None & 250 & 200 \\
\hline Z-12 & None & None & 250 & 200 \\
\hline Z-13 & None & None & 250 & 200 \\
\hline Z-16* & None & None & 250 & 220 \\
\hline $\mathrm{Z}-17$ & None & None & 250 & 220 \\
\hline Z-18 & None & None & 250 & 220 \\
\hline $\mathrm{Z}-19 *$ & None & None & 250 & 230 \\
\hline $\mathrm{Z}-20$ & None & None & 250 & 230 \\
\hline Z-49 & None & None & 250 & 230 \\
\hline $\mathrm{Z}-50$ & None & None & 250 & 230 \\
\hline Z-100* & None & None & 500 & 370 \\
\hline Z-101 & None & None & 500 & 370 \\
\hline Z-102 & None & None & 500 & 370 \\
\hline Z-103 & None & None & 500 & 370 \\
\hline Z-104 & None & None & 500 & 410 \\
\hline Z-105* & None & None & 500 & 410 \\
\hline Z-106 & None & None & 500 & 410 \\
\hline Z-107 & None & None & 500 & 410 \\
\hline Z-108 & None & None & 500 & 470 \\
\hline Z-109 & None & None & 500 & 470 \\
\hline Z-110* & None & None & 500 & 470 \\
\hline Z-111 & None & None & 500 & 470 \\
\hline Z-112 & None & None & 500 & 510 \\
\hline Z-113 & None & None & 500 & 510 \\
\hline Z-114* & None & None & 500 & 510 \\
\hline Z-115 & None & None & 500 & 510 \\
\hline $\mathrm{ZN}-01 *$ & GTAW & $5 \mathrm{~h}$ ramp; $1 \mathrm{hr}$ at $600^{\circ} \mathrm{C}$ & 250 & 270 \\
\hline $\mathrm{ZN}-02$ & GTAW & $5 \mathrm{~h}$ ramp; $1 \mathrm{hr}$ at $600^{\circ} \mathrm{C}$ & 250 & 270 \\
\hline $\mathrm{ZN}-03$ & GTAW & $5 \mathrm{~h}$ ramp; $1 \mathrm{hr}$ at $600^{\circ} \mathrm{C}$ & 250 & 270 \\
\hline $\mathrm{ZN}-04$ & GTAW & $5 \mathrm{~h} \mathrm{ramp} ; 1 \mathrm{hr}$ at $600^{\circ} \mathrm{C}$ & 250 & 270 \\
\hline $\mathrm{ZN}-05$ & GTAW & $5 \mathrm{~h}$ ramp; $1 \mathrm{hr}$ at $600^{\circ} \mathrm{C}$ & 250 & 150 \\
\hline $\mathrm{ZN}-06$ & GTAW & $5 \mathrm{~h}$ ramp; $1 \mathrm{hr}$ at $600^{\circ} \mathrm{C}$ & 250 & 150 \\
\hline $\mathrm{ZN}-07$ & GTAW & $5 \mathrm{~h}$ ramp; $1 \mathrm{hr}$ at $600^{\circ} \mathrm{C}$ & 250 & 150 \\
\hline $\mathrm{ZN}-08 *$ & GTAW & $5 \mathrm{~h}$ ramp; $1 \mathrm{hr}$ at $600^{\circ} \mathrm{C}$ & 250 & 150 \\
\hline $\mathrm{ZN}-09$ & GTAW & $5 \mathrm{~h}$ ramp; $1 \mathrm{hr}$ at $600^{\circ} \mathrm{C}$ & 250 & 200 \\
\hline $\mathrm{ZN}-10 *$ & GTAW & $5 \mathrm{~h}$ ramp; $1 \mathrm{hr}$ at $600^{\circ} \mathrm{C}$ & 250 & 200 \\
\hline
\end{tabular}


ORNL/SPR-2020/1879

\begin{tabular}{|c|c|c|c|c|}
\hline $\mathrm{ZN}-11$ & GTAW & $5 \mathrm{~h}$ ramp; $1 \mathrm{hr}$ at $600^{\circ} \mathrm{C}$ & 250 & 200 \\
\hline $\mathrm{ZN}-12$ & GTAW & $5 \mathrm{~h}$ ramp; $1 \mathrm{hr}$ at $600^{\circ} \mathrm{C}$ & 250 & 200 \\
\hline $\mathrm{ZN}-13$ & GTAW & $5 \mathrm{~h}$ ramp; $1 \mathrm{hr}$ at $600^{\circ} \mathrm{C}$ & 250 & 180 \\
\hline $\mathrm{ZN}-14$ & GTAW & $5 \mathrm{~h}$ ramp; $1 \mathrm{hr}$ at $600^{\circ} \mathrm{C}$ & 250 & 180 \\
\hline $\mathrm{ZN}-15^{*}$ & GTAW & $5 \mathrm{~h}$ ramp; $1 \mathrm{hr}$ at $600^{\circ} \mathrm{C}$ & 250 & 180 \\
\hline $\mathrm{ZN}-16$ & GTAW & $5 \mathrm{~h}$ ramp; $1 \mathrm{hr}$ at $600^{\circ} \mathrm{C}$ & 250 & 180 \\
\hline $\mathrm{ZN}-17$ & GTAW & $5 \mathrm{~h}$ ramp; $1 \mathrm{hr}$ at $600^{\circ} \mathrm{C}$ & 500 & 400 \\
\hline $\mathrm{ZN}-18$ & GTAW & $5 \mathrm{~h}$ ramp; $1 \mathrm{hr}$ at $600^{\circ} \mathrm{C}$ & 500 & 400 \\
\hline $\mathrm{ZN}-19 *$ & GTAW & $5 \mathrm{~h}$ ramp; $1 \mathrm{hr}$ at $600^{\circ} \mathrm{C}$ & 500 & 400 \\
\hline $\mathrm{ZN}-20$ & GTAW & $5 \mathrm{~h}$ ramp; $1 \mathrm{hr}$ at $600^{\circ} \mathrm{C}$ & 500 & 400 \\
\hline $\mathrm{ZN}-21$ & GTAW & $5 \mathrm{~h}$ ramp; $1 \mathrm{hr}$ at $600^{\circ} \mathrm{C}$ & 500 & 390 \\
\hline $\mathrm{ZN}-22$ & GTAW & $5 \mathrm{~h}$ ramp; $1 \mathrm{hr}$ at $600^{\circ} \mathrm{C}$ & 500 & 390 \\
\hline $\mathrm{ZN}-23$ & GTAW & $5 \mathrm{~h}$ ramp; $1 \mathrm{hr}$ at $600^{\circ} \mathrm{C}$ & 500 & 390 \\
\hline $\mathrm{ZN}-24 *$ & GTAW & $5 \mathrm{~h}$ ramp; $1 \mathrm{hr}$ at $600^{\circ} \mathrm{C}$ & 500 & 390 \\
\hline $\mathrm{ZN}-25$ & GTAW & $5 \mathrm{~h}$ ramp; $1 \mathrm{hr}$ at $600^{\circ} \mathrm{C}$ & 500 & 370 \\
\hline $\mathrm{ZN}-26$ & GTAW & $5 \mathrm{~h}$ ramp; $1 \mathrm{hr}$ at $600^{\circ} \mathrm{C}$ & 500 & 370 \\
\hline $\mathrm{ZN}-27^{*}$ & GTAW & $5 \mathrm{~h}$ ramp; $1 \mathrm{hr}$ at $600^{\circ} \mathrm{C}$ & 500 & 370 \\
\hline $\mathrm{ZN}-28$ & GTAW & $5 \mathrm{~h}$ ramp; $1 \mathrm{hr}$ at $600^{\circ} \mathrm{C}$ & 500 & 370 \\
\hline $\mathrm{ZN}-29 *$ & GTAW & $5 \mathrm{~h}$ ramp; $1 \mathrm{hr}$ at $600^{\circ} \mathrm{C}$ & 500 & 340 \\
\hline $\mathrm{ZN}-30$ & GTAW & $5 \mathrm{~h}$ ramp; $1 \mathrm{hr}$ at $600^{\circ} \mathrm{C}$ & 500 & 340 \\
\hline $\mathrm{ZN}-31$ & GTAW & $5 \mathrm{~h}$ ramp; $1 \mathrm{hr}$ at $600^{\circ} \mathrm{C}$ & 500 & 340 \\
\hline $\mathrm{ZN}-32$ & GTAW & $5 \mathrm{~h}$ ramp; $1 \mathrm{hr}$ at $600^{\circ} \mathrm{C}$ & 500 & 340 \\
\hline ZO-01 & GTAW & None & 250 & 160 \\
\hline $\mathrm{ZO}-02$ & GTAW & None & 250 & 160 \\
\hline $\mathrm{ZO}-03 *$ & GTAW & None & 250 & 160 \\
\hline ZO-04 & GTAW & None & 250 & 160 \\
\hline $\mathrm{ZO}-05^{*}$ & GTAW & None & 250 & 200 \\
\hline ZO-06 & GTAW & None & 250 & 200 \\
\hline ZO-07 & GTAW & None & 250 & 200 \\
\hline ZO-08 & GTAW & None & 250 & 200 \\
\hline ZO-09 & GTAW & None & 250 & 220 \\
\hline ZO-10 & GTAW & None & 250 & 220 \\
\hline $\mathrm{ZO}-11 *$ & GTAW & None & 250 & 220 \\
\hline ZO-12 & GTAW & None & 250 & 220 \\
\hline ZO-13 & GTAW & None & 250 & 200 \\
\hline ZO-14 & GTAW & None & 250 & 200 \\
\hline ZO-15 & GTAW & None & 250 & 200 \\
\hline ZO-16* & GTAW & None & 250 & 200 \\
\hline ZO-17 & GTAW & None & 500 & 380 \\
\hline ZO-18 & GTAW & None & 500 & 380 \\
\hline ZO-19 & GTAW & None & 500 & 380 \\
\hline
\end{tabular}


ORNL/SPR-2020/1879

\begin{tabular}{|l|l|l|l|l|}
\hline ZO-20* & GTAW & None & 500 & 380 \\
\hline ZO-21* & GTAW & None & 500 & 370 \\
\hline ZO-22 & GTAW & None & 500 & 370 \\
\hline ZO-23 & GTAW & None & 500 & 370 \\
\hline ZO-24 & GTAW & None & 500 & 370 \\
\hline ZO-25 & GTAW & None & 500 & 380 \\
\hline ZO-26* & GTAW & None & 500 & 380 \\
\hline ZO-27 & GTAW & None & 500 & 380 \\
\hline ZO-28 & GTAW & None & 500 & 380 \\
\hline ZO-29 & GTAW & None & 500 & 340 \\
\hline ZO-30 & GTAW & None & 500 & 340 \\
\hline ZO-31 & GTAW & None & 500 & 340 \\
\hline ZO-32* & GTAW & None & 500 & 340 \\
\hline
\end{tabular}

Three variables were considered in the hydrogen charging experiments: base metal or welded; as-welded or welded and with a PWHT of 5 hour ramp up to $600^{\circ} \mathrm{C}$ and a 1 hour hold at $600^{\circ} \mathrm{C}$; and differing amounts of hydrogen content. Tensile SS3 samples of each type were tensile tested at room temperature using an extension rate of $0.00762 \mathrm{~mm} / \mathrm{s}$. The summary of their yield stress (YS), ultimate tensile strength (UTS), uniform elongation (UE), and total elongation (TE) is shown in Table 4. Tensile results from room temperature tests of hydrided Zry-4 samples..

Table 4. Tensile results from room temperature tests of hydrided Zry-4 samples.

\begin{tabular}{|c|c|c|c|c|c|c|c|}
\hline $\begin{array}{l}\text { Sample } \\
\text { ID }\end{array}$ & Weld & PWHT & $\begin{array}{l}\text { Measured } \\
\mathrm{H}\end{array}$ & $\begin{array}{l}\mathrm{YS} \\
(\mathrm{MPa})\end{array}$ & $\begin{array}{l}\text { UTS } \\
(\mathrm{MPa})\end{array}$ & $\begin{array}{l}\mathrm{UE} \\
(\%)\end{array}$ & TE $(\%)$ \\
\hline Z120 & $\mathrm{BM}$ & No & 0 & 401 & 554 & 12.6 & 22.8 \\
\hline Z12 & $\mathrm{BM}$ & No & 200 & 416 & 569 & 11.4 & 20.7 \\
\hline $\mathrm{Z} 50$ & $\mathrm{BM}$ & No & 230 & 420 & 578 & 12.1 & 25.9 \\
\hline Z102 & $\mathrm{BM}$ & No & 370 & 423 & 597 & 12.0 & 20.6 \\
\hline Z109 & $\mathrm{BM}$ & No & 470 & 427 & 565 & 4.6 & 4.6 \\
\hline Z115 & $\mathrm{BM}$ & No & 510 & 435 & 527 & 1.2 & 1.2 \\
\hline ZO38 & Weld & No & 0 & 446 & 554 & 8.3 & 16.5 \\
\hline ZO06 & Weld & No & 200 & 485 & 592 & 6.7 & 9.4 \\
\hline ZO15 & Weld & No & 200 & 490 & 589 & 5.6 & 7.3 \\
\hline ZO18 & Weld & No & 380 & 474 & 500 & 0.4 & 0.4 \\
\hline $\mathrm{ZO} 25$ & Weld & No & 380 & 493 & 593 & 3.3 & 3.4 \\
\hline ZN36 & Weld & 5h ramp, $1 \mathrm{~h} 600 \mathrm{C}$ & 0 & 461 & 557 & 6.7 & 14.4 \\
\hline ZN12 & Weld & 5h ramp, 1h 600C & 200 & 475 & 582 & 6.6 & 7.7 \\
\hline ZN13 & Weld & 5h ramp, 1h 600C & 180 & 478 & 584 & 7.1 & 9.4 \\
\hline ZN17 & Weld & 5h ramp, 1h 600C & 400 & 480 & 594 & 4.5 & 4.5 \\
\hline ZN21 & Weld & 5h ramp, 1h 600C & 390 & 480 & 588 & 8.1 & 10.6 \\
\hline
\end{tabular}


The base metal samples have relatively high total elongations of $20-26 \%$ for the control case with no hydrogen charging and the cases with up to $370 \mathrm{ppm} \mathrm{H}$. However, there is an apparent change in the behavior for the samples that has hydrogen amounts of 470 and $510 \mathrm{ppm}$ which show 4.6 and 1.2\% elongation, respectively (Table 3 and Figure 24). Also, there is a slight increase in UTS for all of the hydrogen charged samples versus the control sample. Figure 25 shows the fracture surfaces of the samples up to $370 \mathrm{ppm} \mathrm{H}$ and agrees with the tensile results that the microstructure is similar and shows ductile dimples for these three samples. There may be a change in the microstructure between the $370 \mathrm{ppm} \mathrm{H}$ and the $470 \mathrm{ppm} \mathrm{H}$ that causes the sudden drop in elongation. This will be explored further in the future.

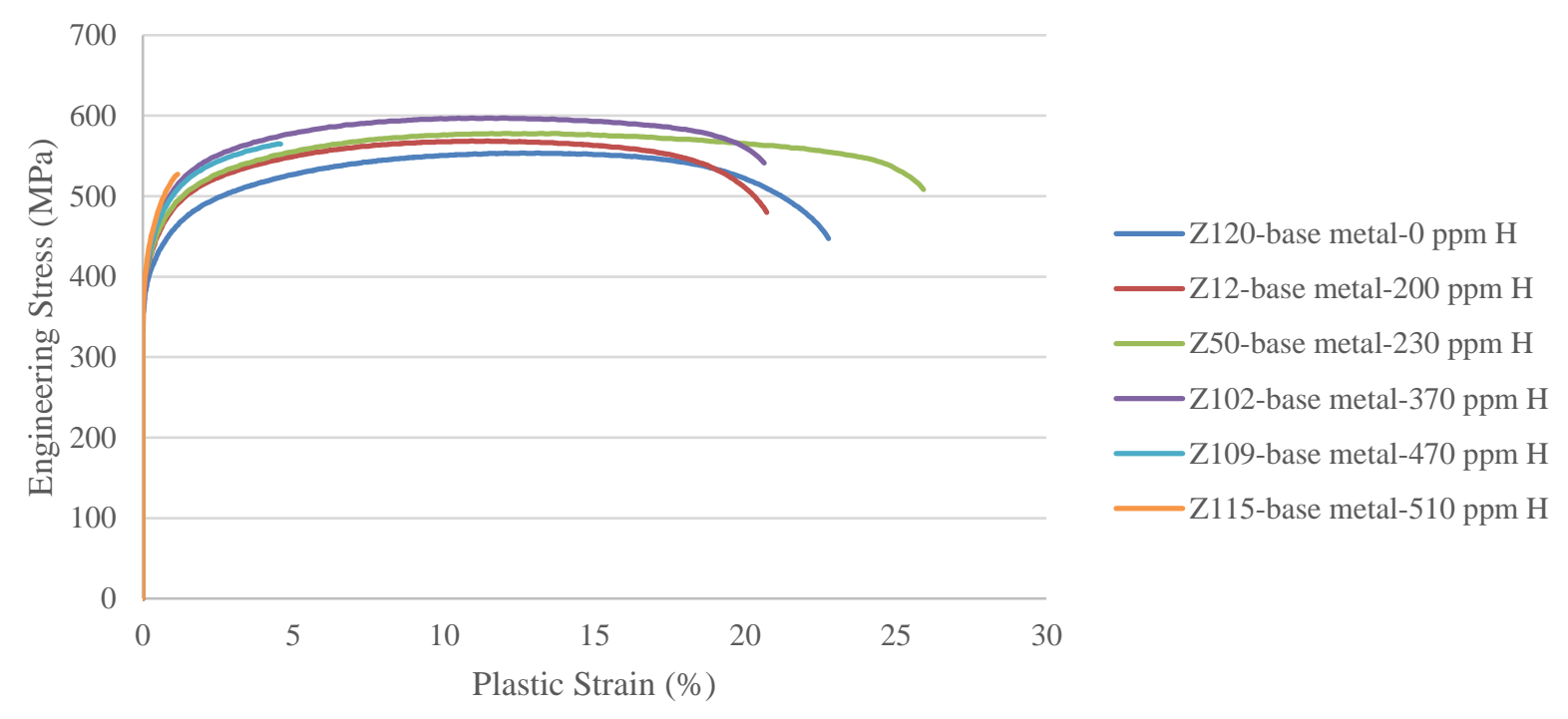

Figure 24. Tensile data for base metal (no weld) Zry-4 with varying amounts of hydrogen charging.

(a) Z120-base metal-0 ppm H

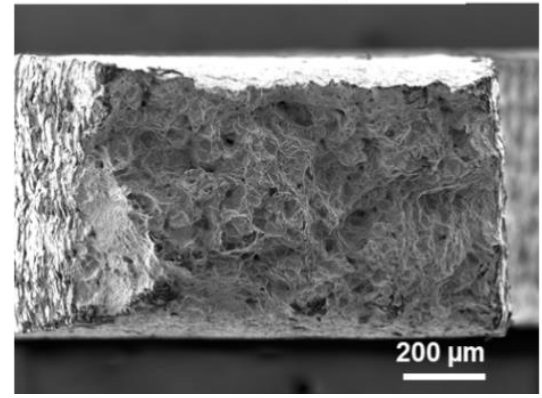

(b) Z12-base metal-200 ppm H

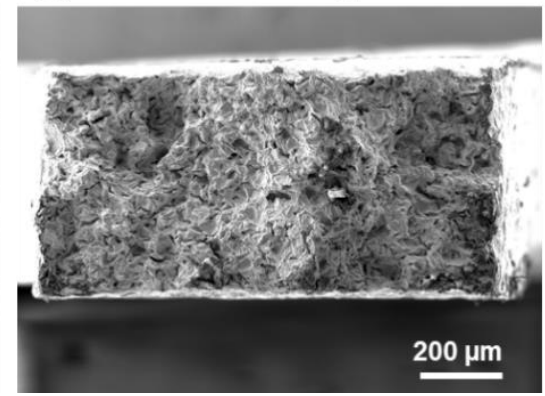

(c) Z102-base metal- $370 \mathrm{ppm} \mathrm{H}$

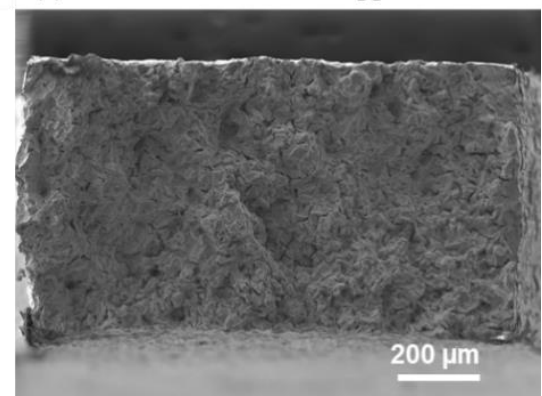

Figure 25. Fracture surfaces of Zircaloy-4 base metal with increasing amounts of hydrogen charging, (a) 0 ppm H, (b) 200 ppm H, (c) $370 \mathrm{ppm} \mathrm{H}$.

The samples that were welded and did not receive a PWHT (the ZO series) show a clear trend of decreasing elongation with increasing amount of hydrogen. There is also a spread in the elongation values here with the two samples charged to $200 \mathrm{ppm} \mathrm{H}$ having 9.4 and $7.3 \% \mathrm{TE}$ and the two samples charged to $380 \mathrm{ppm} \mathrm{H}$ having 3.4 and $0.4 \%$ TE (Table 3 and Figure 26). As with the base metal samples, the hydrogen charging slightly increased the UTS of all the welded samples. On the fracture surfaces of the welded samples, Figure 27, there is a clear trend of the reduction of area matching the amount of ductility, with $\mathrm{ZO} 25$ having no noticeable reduction in area since it had $0.4 \% \mathrm{TE}$. Also, the character of the fracture surface changes with decreasing 
ductility and increasing amounts of hydrogen content. The control sample with no hydrogen has height variation on the surface and many ductile dimples (Figure 27a), while ZO18 and ZO25 (Figure 27c and d) which had significantly reduced ductility have more flat surfaces and evidence of brittle cleavage.

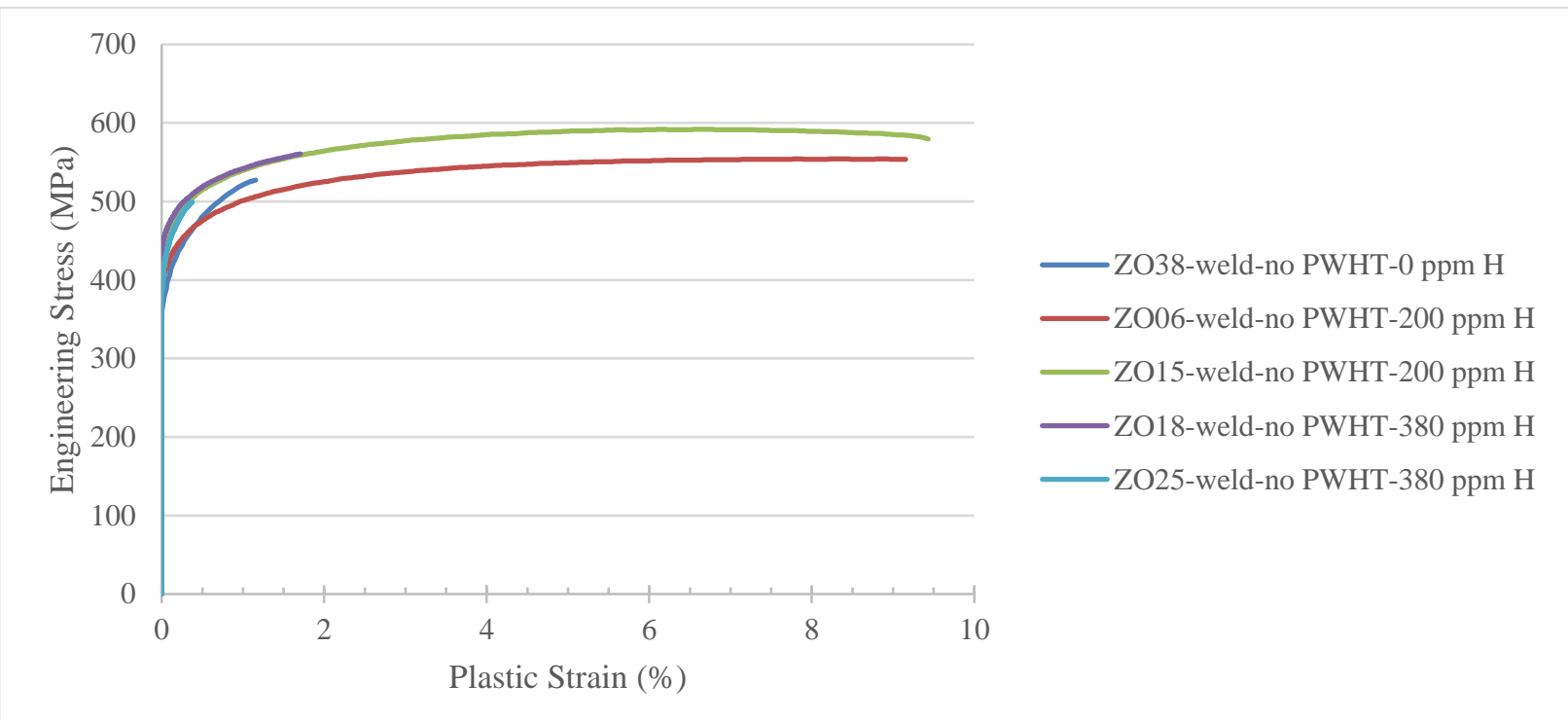

Figure 26. Tensile data from Zry-4 samples that were welded and had varying amounts of hydrogen charging. 
(a) ZO38-weld no PWHT-0 ppm H

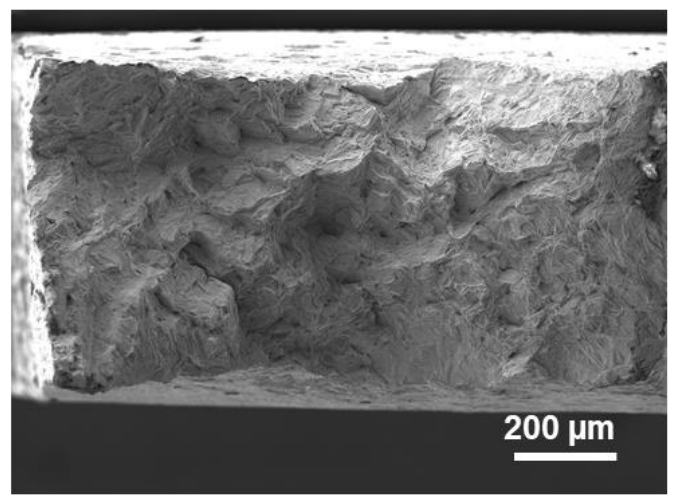

(c) ZO18-weld no PWHT-380 ppm H

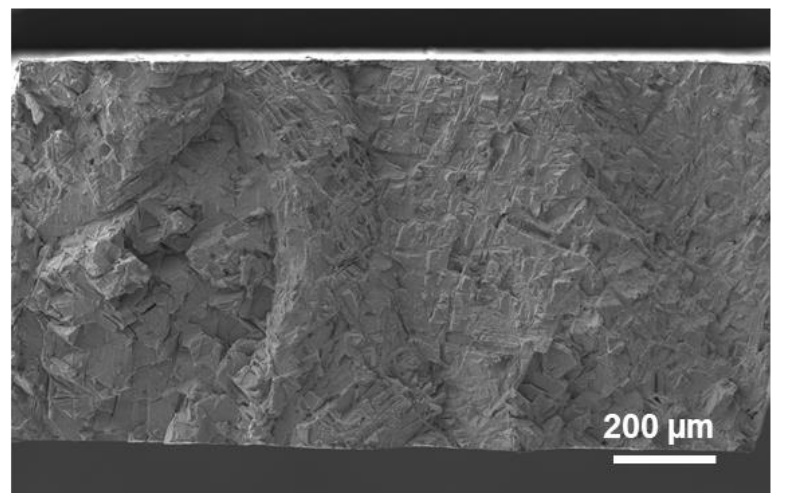

(b) ZO15-weld no PWHT-200 ppm H

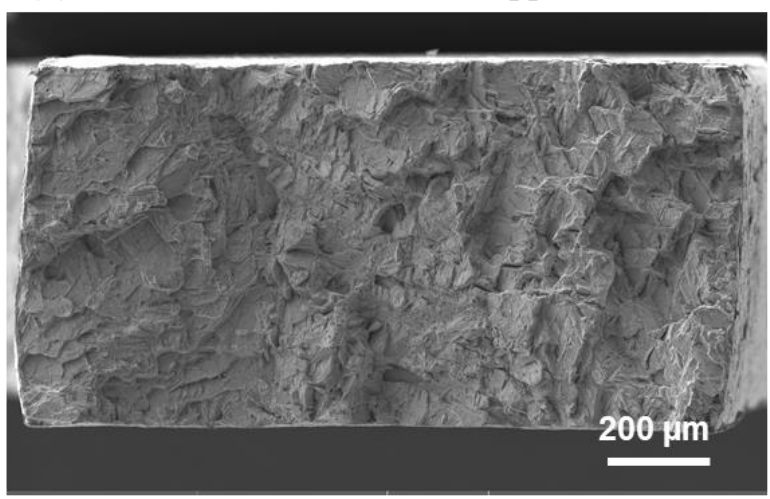

(d) ZO25-weld no PWHT-380 ppm H

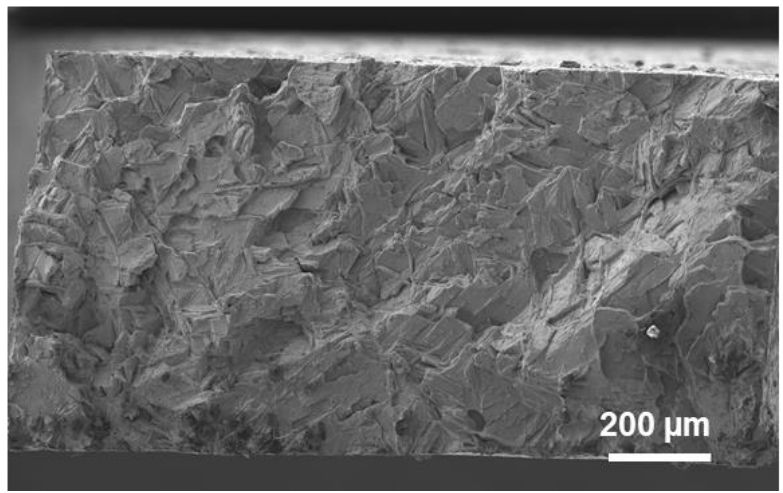

Figure 27. Fracture surfaces of Zircaloy-4 welded without a PWHT and increasing amounts of hydrogen charging: (a) 0 ppm H, (b) $200 \mathrm{ppm} \mathrm{H,} \mathrm{(c)} 380 \mathrm{ppm} \mathrm{H,} \mathrm{(d)} 380 \mathrm{ppm} \mathrm{H}$.

The samples that were welded and PWHT with a 5 hour ramp and a 1 hour hold at $600^{\circ} \mathrm{C}$ (the ZN series) had similar and slightly better elongation than the no PWHT samples (Table 3 and Figure 28). The welded control sample with no hydrogen, ZN36, had 14.4\% TE while the similar welded control sample without PWHT, ZO38, had 16.5\% TE. This illustrates the small gains from the PWHT and the large spread in elongation values for the welded and welded plus PWHT samples. Any one sample from the welded or welded plus PWHT series may not show the trend, but as a whole there was statistically noticeable increase in TE with PWHT as compared to the no PWHT samples. More detail on the effects of the PWHT are covered in the following sections.

As for the effects of the hydrogen charging, the welded and PWHT samples with hydrogen did slightly better than the welded without PWHT samples with hydrogen. The lowest elongation of the welded and PWHT samples was 4.5\% versus the lowest elongation for the welded without PWHT samples was $0.4 \%$. Still, the progression of the fracture surfaces for the welded with PWHT samples shows the same trend of ductile dimples for the control sample but more angular and brittle features as the hydrogen content increased (Figure 29). 
ORNL/SPR-2020/1879

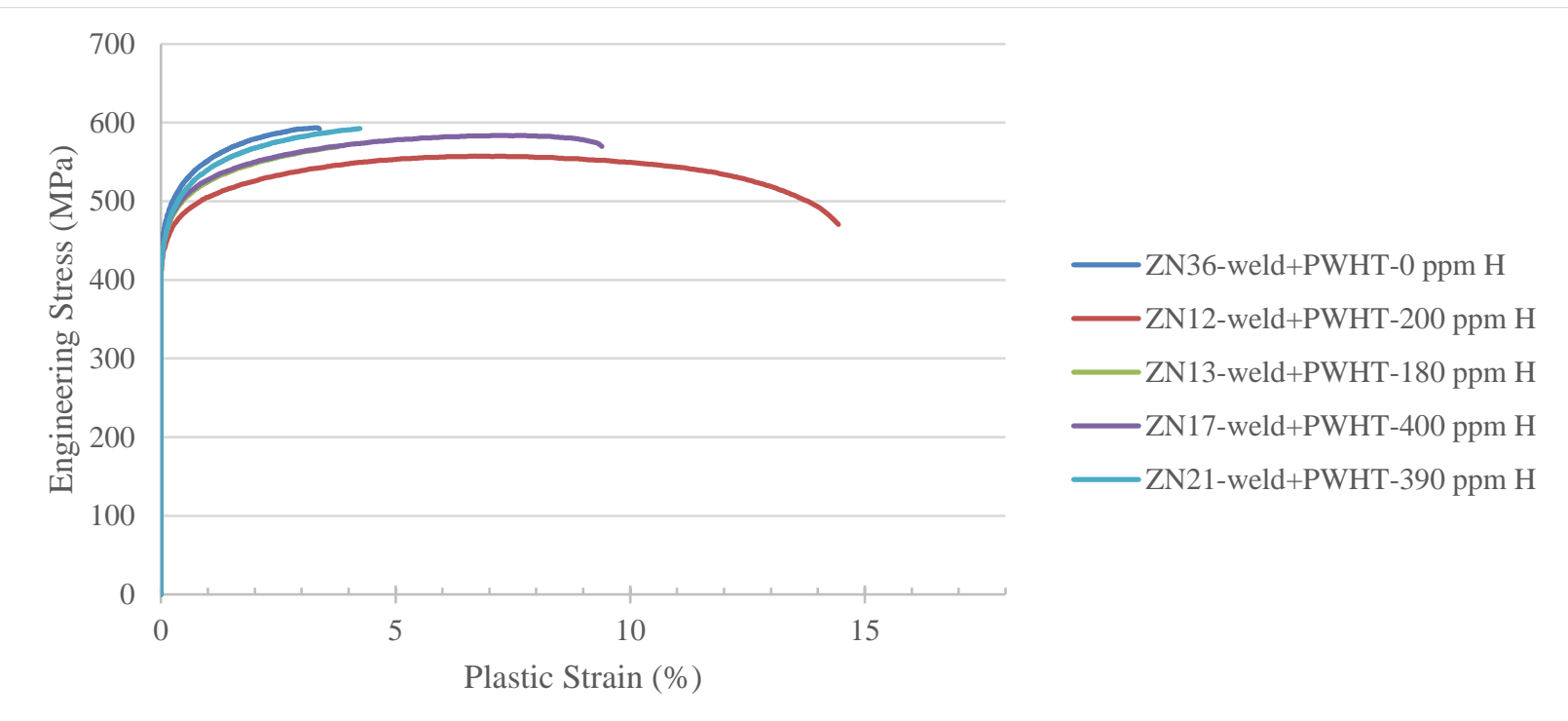

Figure 28. Tensile data from Zry-4 samples that were welded, PWHT at $600^{\circ} \mathrm{C}$, and hydrogen charged to various levels.

(a) ZN36-weld+PWHT-0 ppm H

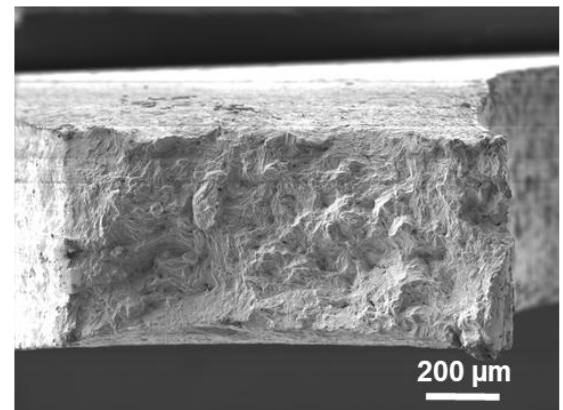

(b) ZN12-weld+PWHT-200 ppm H

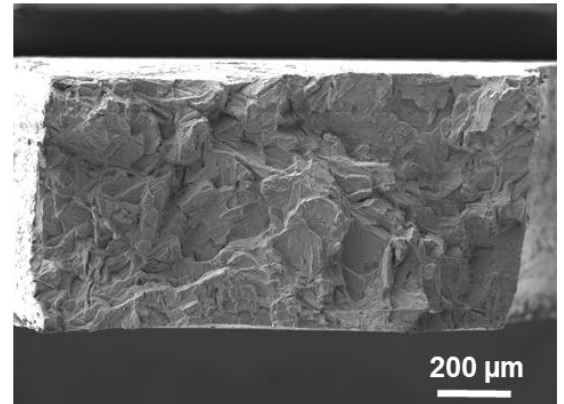

(c) ZN17-weld+PWHT-400 ppm H

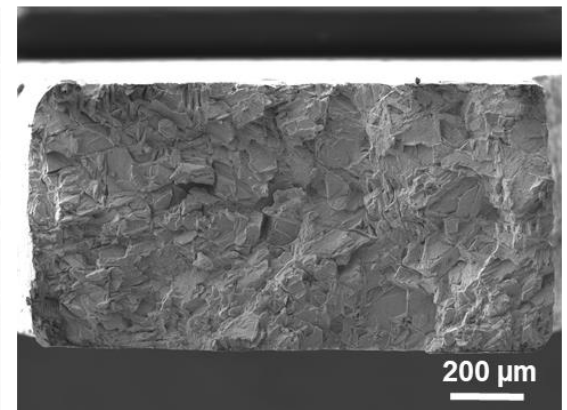

Figure 29. Fracture surfaces of Zry-4 welded and PWHT with varying amounts of hydrogen charging: (a) 0 ppm $H$, (b) 200 ppm $\mathrm{H}$, (c) $400 \mathrm{ppm} \mathrm{H}$.

\subsection{POST-WELD HEAT TREATMENT ZIRCALOY-4}

Over the past several years, a range of PWHTs were performed on unirradiated, welded ZZry-4 [1, 11, 12]. Tensile data, fracture surfaces, and microstructural imaging was all taken. Limited microstructural data taken recently, combined with new analysis on this data has yielded significant insight into the PWHT-ductility relationship. Attention here is paid to optimizing total elongation as a function of PWHT time/temperature, microstructural evolution with PWHT, and potential effects of second phase precipitates.

The range of samples considered in this new analysis is presented in Table 5, which directly compares PWHT conditions with tensile results for yield strength (YS), ultimate tensile strength (UTS), ultimate elongation (UE), and total elongation (TE). Colors in the table and further in this section are used to identify cases which consider different independent variables. Black/Grey is used for the control cases with either unwelded Zry-4 or welded material with no PWHT. Green is used for case $1-1$ hour PWHTs over temperatures ranging from $450-800^{\circ} \mathrm{C}$, 
ORNL/SPR-2020/1879

purple is used for case $2-\mathrm{PWHTs}$ at $538^{\circ} \mathrm{C}\left(1000^{\circ} \mathrm{F}\right)$ between $0.5-24$ hours, and orange is used for case $3-$ PWHTs at $800^{\circ} \mathrm{C}$ between $1-48$ hours.

Table 5. Tensile properties of Zry-4 as a function of PWHT time and temperature. Average values are given for YS, UTS, UE, and TE.

\begin{tabular}{rllllllll}
$\begin{array}{r}\text { Sample } \\
\text { Code/Codes }\end{array}$ & $\begin{array}{c}\text { Time } \\
(\mathrm{hr})\end{array}$ & $\begin{array}{c}\text { Temp } \\
\left({ }^{\circ} \mathrm{C}\right)\end{array}$ & $\begin{array}{l}\text { Tests } \\
(\#)\end{array}$ & $\begin{array}{l}Y S \\
(\mathrm{MPa})\end{array}$ & $\begin{array}{l}\text { UTS } \\
(\mathrm{MPa})\end{array}$ & $\begin{array}{l}\text { UE } \\
(\%)\end{array}$ & $\begin{array}{l}\text { TE } \\
(\%)\end{array}$ \\
\hline$Z$ & Base Metal & 4 & 372 & 521 & 13.2 & 24.6 \\
$Z T / Z A T$ & No PWHT & 9 & 471 & 585 & 6.8 & 12.4 \\
$Z B T$ & 1 & 450 & 4 & 466 & 579 & 6.8 & 13.1 \\
$Z F A$ & 1 & 500 & 11 & 447 & 571 & 7.2 & 13.3 \\
$Z C T$ & 1 & 538 & 4 & 469 & 594 & 7.7 & 13.9 \\
$Z F B$ & 1 & 600 & 12 & 473 & 588 & 7.7 & 14.6 \\
$Z D T$ & 1 & 650 & 4 & 493 & 601 & 7.5 & 13.7 \\
$Z F C$ & 1 & 700 & 11 & 473 & 586 & 8.2 & 16.0 \\
$Z F D$ & 1 & 750 & 10 & 470 & 574 & 7.6 & 15.7 \\
$Z F E / Z I B$ & 1 & 800 & 7 & 485 & 584 & 7.3 & 16.5 \\
$Z E A$ & 0.5 & 538 & 3 & 481 & 578 & 5.2 & 10.5 \\
$Z C T$ & 1 & 538 & 4 & 469 & 594 & 7.7 & 13.9 \\
$Z E B$ & 1.5 & 538 & 3 & 473 & 583 & 7.2 & 13.4 \\
$Z E C$ & 2 & 538 & 3 & 464 & 567 & 5.6 & 10.5 \\
$Z E D$ & 3 & 538 & 3 & 470 & 579 & 6.2 & 12.6 \\
$Z E E$ & 10 & 538 & 3 & 491 & 601 & 6.8 & 14.0 \\
$Z G E / Z H B$ & 24 & 538 & 11 & 498 & 605 & 7.3 & 14.7 \\
$Z G A$ & 12 & 800 & 4 & 487 & 581 & 6.5 & 14.2 \\
$Z G D$ & 18 & 800 & 3 & 481 & 576 & 7.7 & 14.7 \\
$Z G C$ & 48 & 800 & 4 & 372 & 391 & 6.5 & 13.7
\end{tabular}

\subsubsection{Optimizing Total Elongation with PWHT}

The highest average total elongation (16.5\%) across all data is achieved with a PWHT of $800^{\circ} \mathrm{C}$ for 1 hour. This represents a recovery of roughly $1 / 3$ the lost TE from welding $(24.6 \%$ unwelded to $12.4 \%$ following welding).

Analysis of total elongation as a function of PWHT time and temperature is shown in Figure 30. There is a clear increasing trend in TE with temperature for case of 1 hour PWHTs with increasing temperature. Results are less clear for the cases where PWHT time is varied while temperature is held constant. Generally, however, longer PWHTs at $538^{\circ} \mathrm{C}$ increase average TE, while the opposite is true at $800^{\circ} \mathrm{C}$. 
ORNL/SPR-2020/1879
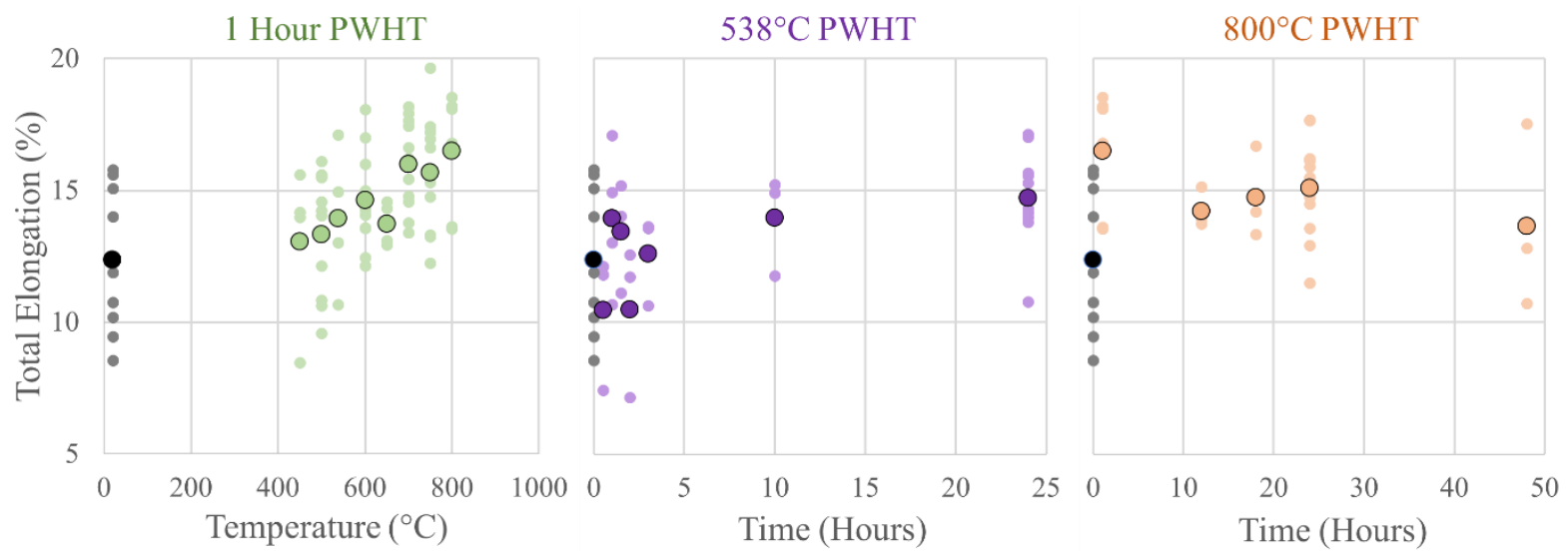

Figure 30. Total Elongation as a function of hold temperature or time. Average values are shown with large/dark icons and individual data points are shown with small/light icons. The black/grey markers at the left-hand side in each case represents the weld bar with no PWHT.

Comparisons of fracture surfaces from unwelded, welded no PWHT, and 1 hour PWHT over a range of temperatures are shown in Figure 31. All failures occurred in the fusion zone of the welded samples. Several important observations can be made from this comparison. Failure in the unwelded base metal appears dominated by microvoid coalescence - where voids nucleate, grow, and coalesce at the areas of highest stress and leave a dimpled surface after fracture. Following welding, the dimples become much smaller and are interspersed by areas more consistent with intergranular fracture - where cracks propagate along grain boundaries. Combinations of intergranular and coalescent behavior are observed across case 1 fracture surfaces. However, intergranular failure appears more prevalent in the lower PWHT temperature cases, suggesting a transition to the desirable coalescent behavior. A clear reduction in area is also seen as PWHT temperature increases for case 1 samples. 


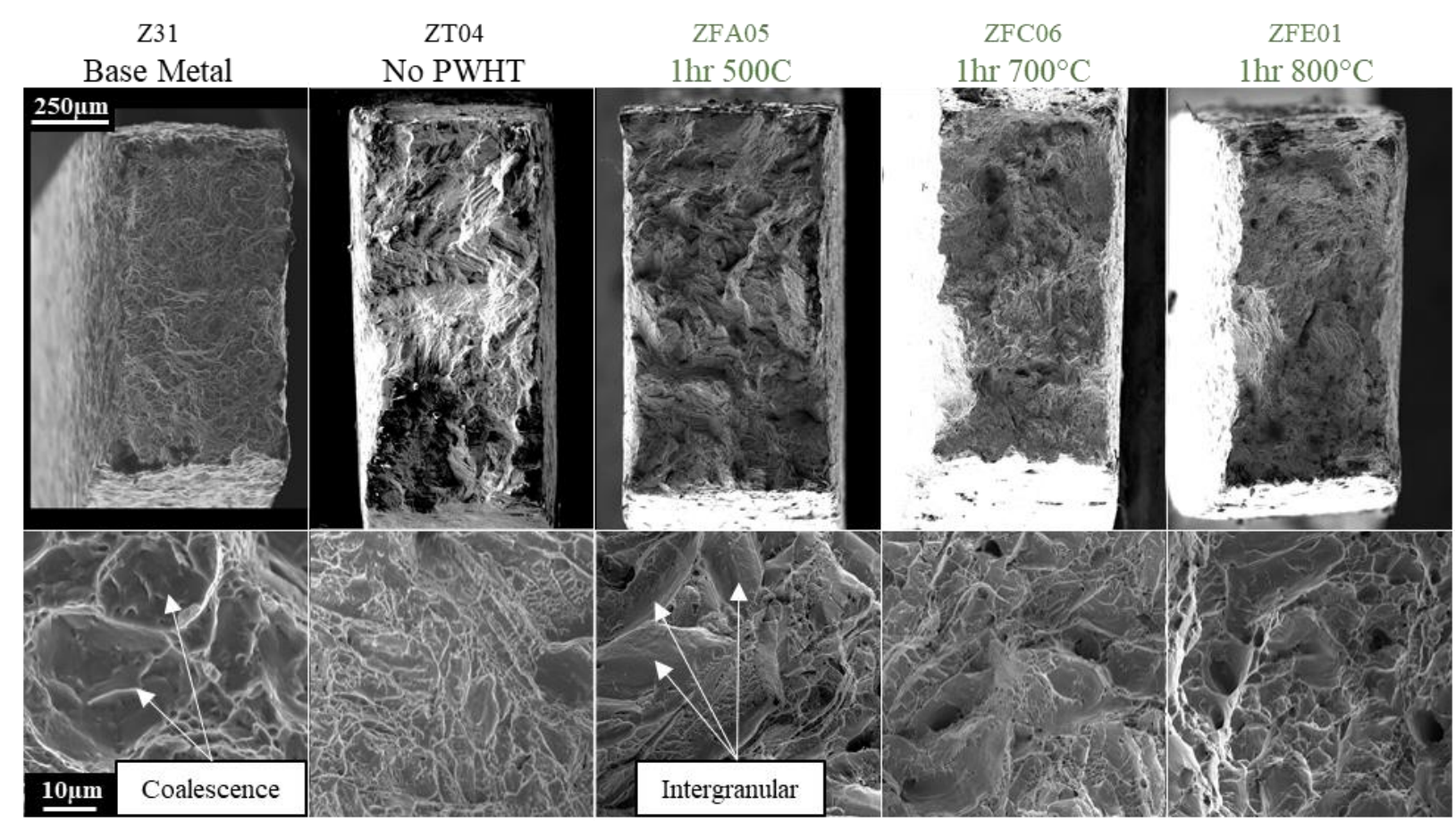

Figure 31. SEM micrographs of fracture surfaces Base metal, no PWH,T and 1-hour PWHT holds over a range of temperatures. Whole bar surfaces are shown above higher magnification images. Examples are pointed out for coalescent and intergranular failures.

\subsubsection{Microstructural Evolution of PWHT}

Following the fusion welding of any material, three distinct microstructural areas emerge: the FZ, HAZ, and BM. As reported previously, welds for this work resolve into a FZ dominated by fine, elongated grains in a basketweave Widmanstätten geometry and a HAZ with larger grains where some lath-like structures exist but are not exclusive. The BM is composed of fine, equiaxed grains.

To further investigate evolution of the microstructure during PWHT, a single welded sample (ZO44) was polished, imaged by polarized light microscopy, underwent an $800^{\circ} \mathrm{C}, 48$ hour PWHT, was polished as shallowly as possible, and imaged again. Microstructures in identical areas for this sample are shown in Figure 32 and grain sizes are reported in Table 4. Observations between the as-welded and PWHT samples include:

1) Large $(>100 \mu \mathrm{m})$ grain formation at the sample edge in the $\mathrm{FZ}$ and in the $\mathrm{BM}$ (the sample edge at the heat affected zone was not imaged)

2) Little-to-no difference in grain size in the majority of the FZ and HAZ following PWHT

3) A moderate amount of grain growth may occur in the base metal. 

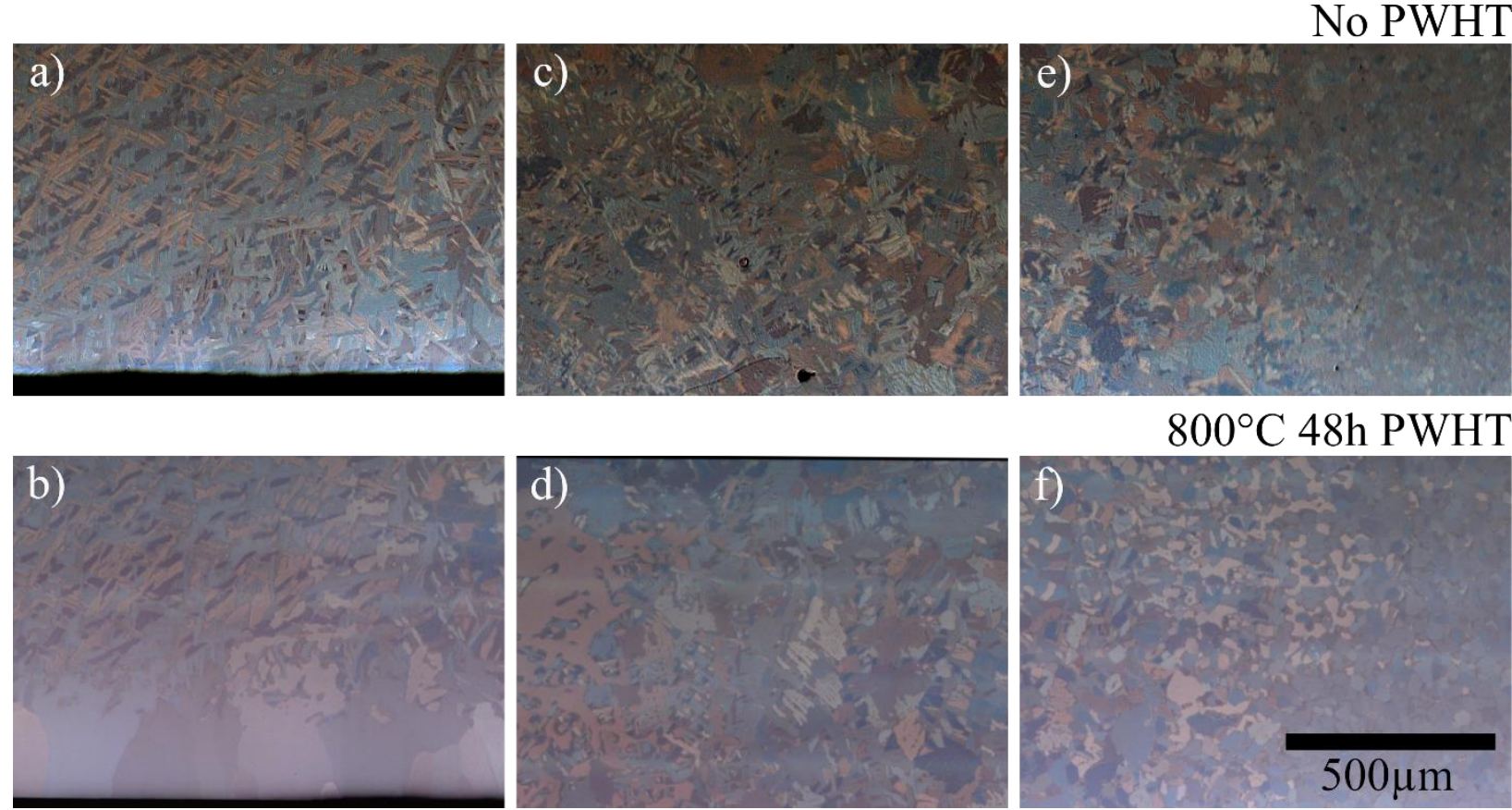

$800^{\circ} \mathrm{C} 48 \mathrm{~h}$ PWHT

Figure 32. Composite polarized light micrographs showing the same areas in a sample (ZO44) with no PWHT (top) and following an $800^{\circ} \mathrm{C}, 48$ hour PWHT (bottom). a) and b) show the fusion zone with the sample edge at the bottom of the images, c) and d) show the transition from the HAZ (right) to the fusion zone (left), and e) and f) show the transition from the base metal (right) to the HAZ (left).

Table 6. Average grain widths for unwelded, no PWHT, and $48 \mathrm{~h} P W H T$ at $800^{\circ} \mathrm{C}$. The circular intercept method was used in all cases except for ZO44 edge, which used the linear intercept method.

\begin{tabular}{r|llll} 
Sample & PWHT & Base metal & HAZ & Fusion \\
& Time $(\mathrm{hr})$ & $(\mu \mathrm{m})$ & $(\mu \mathrm{m})$ & zone $(\mu \mathrm{m})$ \\
\hline Z35 & Unwelded & 16.0 & - & - \\
ZO44 & No PWHT & 17.4 & 24.5 & 22.2 \\
ZO44 bulk & 48 & 22.6 & 25.7 & 24.2 \\
ZO44 edge & 48 & 128.5 & - & 131.3
\end{tabular}

In addition, several PWHT conditions which produced extremely large grains in the HAZ were identified. All cases involved PWHT times of at least 24 hours at $800^{\circ} \mathrm{C}$. These large grains fit the criteria of an undesirable morphology of Zry-4 known as blocky alpha, which is distinguished by large $(>300 \mu \mathrm{m})$ grains with irregular, wavy boundaries $[9,10]$. Examples of 
blocky alpha identified in the HAZ of welded Zry-4 samples following PWHT are shown in Figure 33.

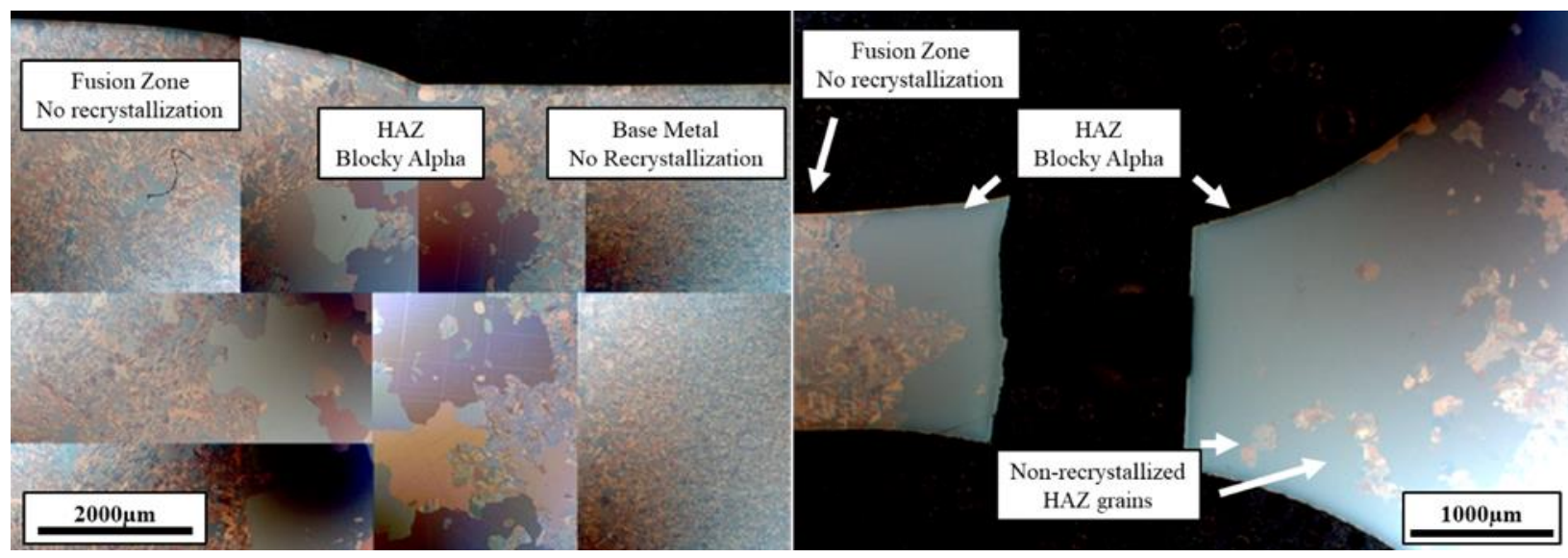

Figure 33. (Left) Polarized light composite image of a weldbar $\left(P W H T 48 \mathrm{hr}, 800^{\circ} \mathrm{C}\right)$ cross-section showing large grains in the HAZ, which fit the criteria for blocky alpha. (Right) polarized light micrograph of a tested tensile sample (ZGB2, PWHT 24hr, $800^{\circ} \mathrm{C}$ ) showing a large single grain in the failure area.

\subsubsection{Second Phase Precipitates}

The effects of second phase precipitates (SPPs), which have been largely neglected in the earlier work, may have significant effects on the PWHT changes to elongation observed. SPPs in Zry-4 form from the alloying elements $\mathrm{Fe}$ and $\mathrm{Cr}$ and precipitate at grain boundaries. The size and distribution of SPPs are dependent on the thermal history of the material. With conventionally processed Zry-4, the change in size of SPPs is often modelled with the Second Order Cumulative Annealing Parameter (SOCAP) [11]:

$$
\text { SOCAP }=D^{3}-D_{0}^{3}=\left[\left(K / T^{2}\right) \exp (--Q / R T)\right] t
$$

Where D is the final SPP diameter, D0 is the initial diameter, $\mathrm{T}$ is annealing temperature, and $\mathrm{t}$ is annealing time. $\mathrm{Q} / \mathrm{R}=18700 \mathrm{~K}$ and $\mathrm{K}=1.11 \cdot 10-11 \mathrm{~m} 3 \mathrm{~s}-1 \mathrm{~K} 2$. Although SPPs have not been directly measured in this work, if we plot the SOCAP values for the PWHTs performed in this work against average TE, we find that the data groups reasonably into an increasing trend of TE with SOCAP up to a value of 1E-21. Following this, there is potentially an inverse relationship, but the amount of data is sparse. Practically, this could point to a relationship between ductility 
ORNL/SPR-2020/1879

and SPP size/density and may merit further investigation.

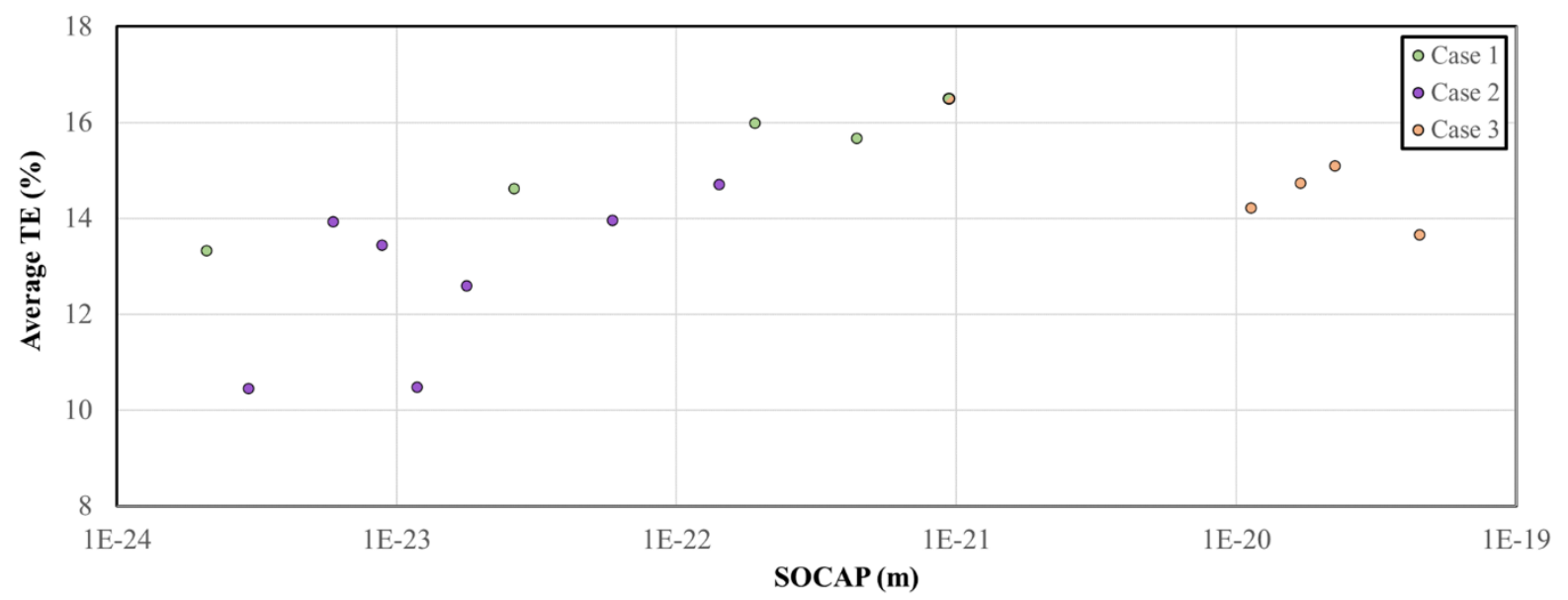

Figure 34. SOCAP relationship with TE for this work.

\subsection{NEUTRON IRRADIATION}

The process of irradiating tensile samples in HFIR is partially complete. Four sets of samples (32 samples total) have been irradiated, transferred to hot cells, and unloaded in preparation for testing. Four more sets of samples (44 samples total) will be irradiated in the next HFIR cycle, which will occur after the reactor is cleared for startup following an unplanned outage. The testing matrix for Zry-4 contains 3 independent variables: weld state (unwelded, welded-as-is, and welded with $600^{\circ} \mathrm{C} / 1 \mathrm{hr}$ PWHT), neutron fluence (1E20 or 1E21), and hydrogen content $(0, \sim 250 \mathrm{ppm}$, or $\sim 500 \mathrm{ppm})$. The testing matrix for AISI 347 consists of 4 independent variables: manufacturer (primarily Rolled Alloys and Penn Stainless), cut direction (only tested for Penn Stainless with no welding), weld type (none, FCAW or GTAW), and neutron fluence (1E20 or 1E21). Four explosion welded samples are also included in the test matrix with the single variable of neutron fluence. Sample details for can be seen in Table 7.

Table 7. Matrix of neutron irradiated samples. Capsule name, material, position, number of cycles, and expected flux are shown in the first row of each sub-table.

\begin{tabular}{|l|l|l|}
\hline \multicolumn{3}{|c|}{$\begin{array}{c}\text { Irradiated Capsule SHINE 11 - Zircaloy } 4 \\
\text { HT-4 - 0.05 cycles - 1E20 n/cm² }\end{array}$} \\
\hline \multicolumn{1}{|c|}{ Weld State } & Hydrogen (ppm) & Sample ID \\
\hline Base metal & 0 & Z1-19 \\
\hline Base metal & 0 & Z1-21 \\
\hline Base metal & 230 & Z-20 \\
\hline Base metal & 230 & Z-49 \\
\hline Welded as-is & 0 & ZO-35 \\
\hline Welded as-is & 0 & ZO-36 \\
\hline Welded PWHT & 0 & ZN-37 \\
\hline Welded PWHT & 0 & ZN-38 \\
\hline
\end{tabular}

\begin{tabular}{|l|l|l|}
\hline \multicolumn{3}{|c|}{$\begin{array}{c}\text { Irradiated Capsule SHINE 12 - Zircaloy } 4 \\
\text { HT-7 - 0.53 cycles - 1E21 n/cm }\end{array}$} \\
\hline Weld State & Hydrogen (ppm) & Sample ID \\
\hline Base metal & 0 & Z1-17 \\
\hline Base metal & 0 & Z1-19 \\
\hline Base metal & 220 & Z-17 \\
\hline Base metal & 220 & Z-18 \\
\hline Welded as-is & 0 & ZO-33 \\
\hline Welded as-is & 0 & ZO-34 \\
\hline Welded PWHT & 0 & ZN-33 \\
\hline Welded PWHT & 0 & ZN-34 \\
\hline
\end{tabular}

\begin{tabular}{|c|c|c|}
\hline \multicolumn{3}{|c|}{ Irradiated Capsule SHINE 13 - AISI 347 } \\
HT-6 - 0.05 cycles - 1E20 n/cm $\mathbf{~ f l u x ~}$ \\
\hline Manufacturer & Cut Direction & Sample ID \\
\hline Rolled alloys & a direction & RA-09 \\
\hline
\end{tabular}

\begin{tabular}{|l|l|l|}
\hline \multicolumn{3}{|c|}{ Irradiated Capsule SHINE 14 - AISI 347 } \\
HT-7 - 0.53 cycles - 1E21 n/cm² flux \\
\hline Manufacturer & Cut Direction & Sample ID \\
\hline Rolled alloys & a direction & RA-12 \\
\hline
\end{tabular}


ORNL/SPR-2020/1879

\begin{tabular}{|l|l|l|}
\hline Rolled alloys & a direction & RA-11 \\
\hline Sandmeyer & a direction & SA-05 \\
\hline Sandmeyer & a direction & SA-07 \\
\hline Penn & a direction & PA-04 \\
\hline Penn & a direction & PA-06 \\
\hline Penn & b direction & PB-04 \\
\hline Penn & b direction & PB-06 \\
\hline
\end{tabular}

\begin{tabular}{|l|l|l|}
\hline Rolled alloys & a direction & RA-13 \\
\hline Sandmeyer & a direction & SA-08 \\
\hline Sandmeyer & a direction & SA-11 \\
\hline Penn & a direction & PA-07 \\
\hline Penn & a direction & PA-08 \\
\hline Penn & b direction & PB-07 \\
\hline Penn & b direction & PB-08 \\
\hline
\end{tabular}

\begin{tabular}{|l|l|l|}
\hline \multicolumn{3}{|c|}{$\begin{array}{l}\text { Unirradiated Capsule SHINE } 21 \text { - Zircaloy } 4 \\
\text { HT-4 - } \mathbf{0 . 0 5} \text { cycles - 1E20 n/cm² }\end{array}$} \\
\hline \multicolumn{1}{|c|}{ Weld Stax } \\
\hline Base metal & Hydrogen $(\mathbf{p p m})$ & Sample ID \\
\hline Base metal & 510 & Z108 \\
\hline Welded as-is & 200 & Z112 \\
\hline Welded as-is & 200 & ZO-07 \\
\hline Welded as-is & 380 & ZO-08 \\
\hline Welded as-is & 380 & ZO-17 \\
\hline Weld PWHT & 200 & ZO-19 \\
\hline Weld PWHT & 200 & ZN-09 \\
\hline Weld PWHT & 400 & ZN-11 \\
\hline Weld PWHT & 400 & ZN-18 \\
\hline
\end{tabular}

\begin{tabular}{|l|l|l|}
\hline \multicolumn{3}{|c|}{ Unirradiated Capsule SHINE 22 - Zircaloy 4} \\
HT-3 - 0.53 cycles - 1E21 n/cm flux $^{\mid}$ \\
\hline \multicolumn{1}{|c|}{ Weld State } & Hydrogen $(\mathbf{p p m})$ & Sample ID \\
\hline Base metal & 470 & Z111 \\
\hline Base metal & 510 & Z113 \\
\hline Welded as-is & 200 & ZO-13 \\
\hline Welded as-is & 200 & ZO-14 \\
\hline Welded as-is & 380 & ZO-27 \\
\hline Welded as-is & 380 & ZO-28 \\
\hline Weld PWHT & 180 & ZN-14 \\
\hline Weld PWHT & 180 & ZN-16 \\
\hline Weld PWHT & 390 & ZN-22 \\
\hline Weld PWHT & 390 & ZN-23 \\
\hline
\end{tabular}

\begin{tabular}{|l|l|l|}
\hline \multicolumn{3}{|c|}{$\begin{array}{c}\text { Unirradiated Capsule SHINE } 23 \text { - AISI 347 } \\
\text { HT-6 - 0.05 cycles - 1E20 n/cm }\end{array}$ flux } \\
\hline Manufacturer & \multicolumn{1}{|c|}{ Weld Type } & Sample ID \\
\hline Rolled alloys & GTAW & RTS21 \\
\hline Rolled alloys & GTAW & RTS23 \\
\hline Rolled alloys & FCAW & RFS21 \\
\hline Rolled alloys & FCAW & RFS25 \\
\hline Rolled alloys & FCAW & RFS11 \\
\hline Penn & GTAW & PTS11 \\
\hline Penn & GTAW & PTS13 \\
\hline Penn & FCAW & PFS11 \\
\hline Penn & FCAW & PFS15 \\
\hline Penn & FCAW & PFS41 \\
\hline 347 to 70 Noble & explosion weld & FC/FB1 \\
\hline 347 to 70 Noble & explosion weld & FC/FB3 \\
\hline
\end{tabular}

\begin{tabular}{|l|l|l|}
\hline \multicolumn{3}{|c|}{$\begin{array}{l}\text { Unirradiated Capsule SHINE 24 - AISI 347 } \\
\text { HT-7 - 0.53 cycles - 1E21 n/cm } \\
\text { flux }\end{array}$} \\
\hline Manufacturer & \multicolumn{1}{|c|}{ Weld Type } & Sample ID \\
\hline Rolled alloys & GTAW & RTS31 \\
\hline Rolled alloys & GTAW & RTS33 \\
\hline Rolled alloys & FCAW & RFS31 \\
\hline Rolled alloys & FCAW & RFS35 \\
\hline Rolled alloys & FCAW & RFS45 \\
\hline Penn & GTAW & PTS31 \\
\hline Penn & GTAW & PTS33 \\
\hline Penn & FCAW & PFS35 \\
\hline Penn & FCAW & PFS21 \\
\hline Penn & FCAW & PFS25 \\
\hline 347 to 70 Noble & explosion weld & FC/FB4 \\
\hline 347 to 70 Noble & explosion weld & FC/FB5 \\
\hline
\end{tabular}

A schematic view of the irradiation capsules used is shown in Figure 35. Figure 35. Perforated capsule design used in this work. Exploded view (top), from left to right, shows perforated housing, spacer, samples, and endcap. Cross-sectional view (bottom) shows the same as assembled with dimensions given in $\mathrm{mm}$. Samples irradiated and unloaded in preparation for tensile testing can be seen in Figure 36. Capsule endcaps were cut off following irradiation to remove samples. No corrosion or other visible damage is observed on the samples, which have been identified and sorted for tensile testing. 


\section{Exploded View}
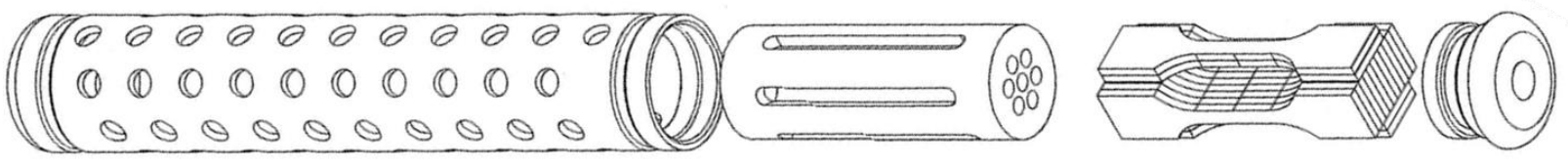

\section{Cross-section}

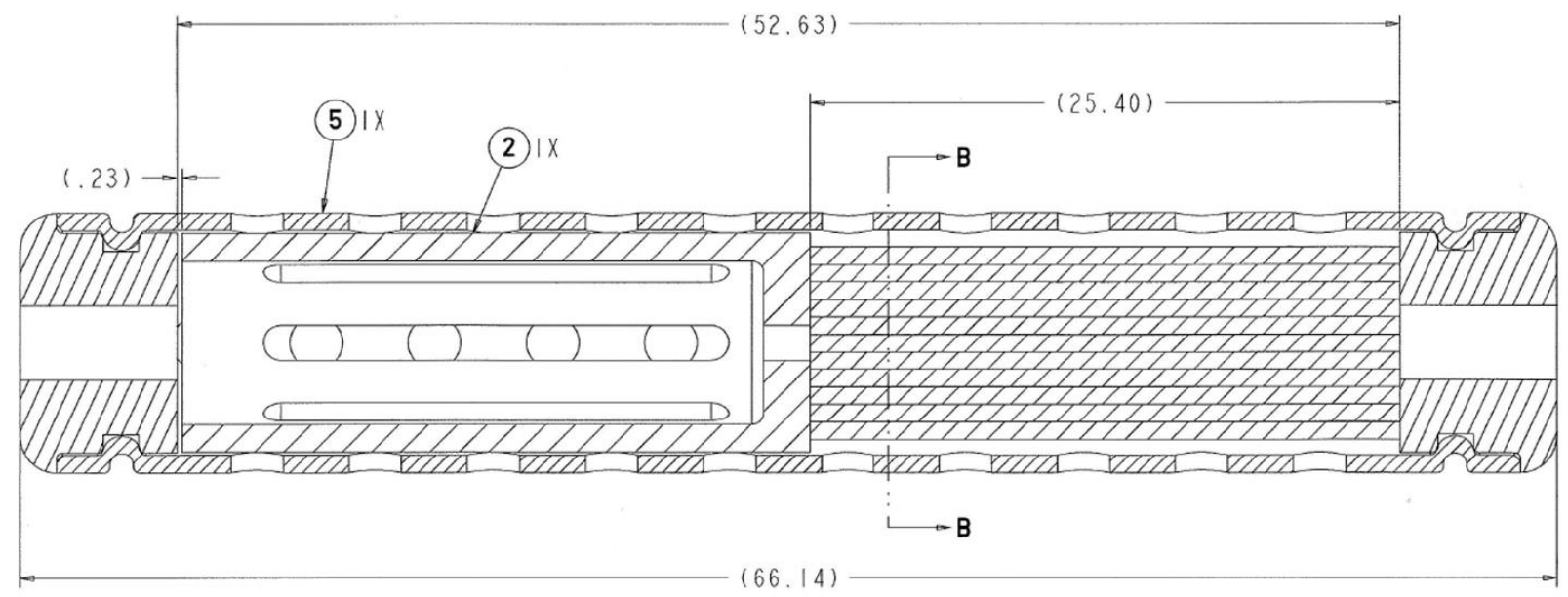

Figure 35. Perforated capsule design used in this work. Exploded view (top), from left to right, shows perforated housing, spacer, samples, and endcap. Cross-sectional view (bottom) shows the same as assembled with dimensions given in mm.

Post-irradiation capsules

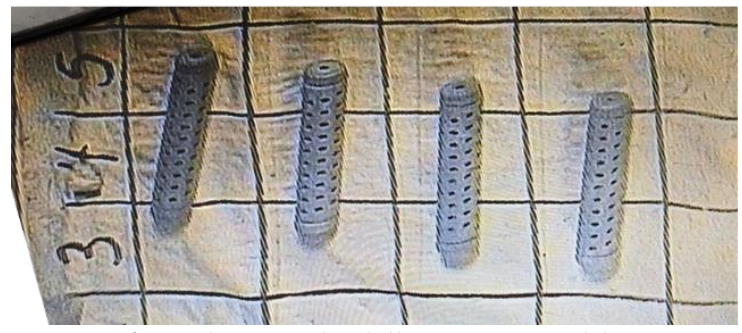

Figure 36. (Left) Capsules following removal from HFIR before disassembly. (Right) Sorted tensile samples at top with disassembled capsule and unsorted tensile samples at bottom.
Disassembled Capsules

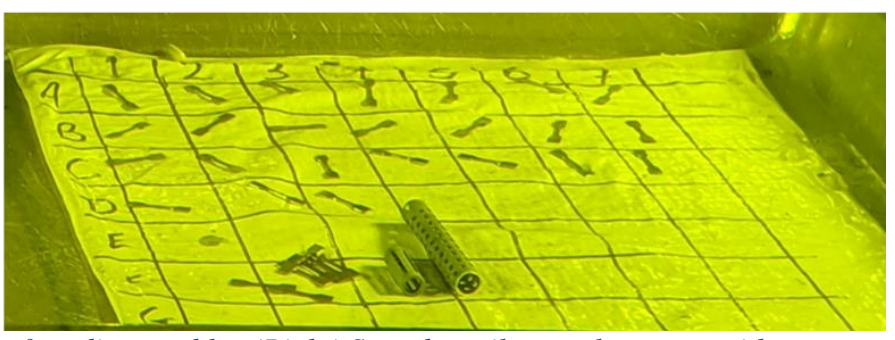

\section{SUMMARY AND FUTURE WORK}

The FY20 research for the Shine TSV project focused on property collection for welded Zry-4 with and without hydrogen charging and on welded AISI 347. For the hydrogen charged Zry-4, there was a trend of reduced ductility with increasing amounts of hydrogen content. The welded, PWHT, and hydrogen charged Zircaoloy-4 samples had slightly more ductility than the welded and hydrogen charged samples that did not receive the PWHT. However, as shown in the analysis of the welded and PWHT Zry-4 samples, there is a large spread in the ductility values of those samples. Despite the spread, there was a noticeable trend of increasing ductility with increasing PWHT temperature, although in the best case the PWHT only increases the ductility by a few percent compared to the no PWHT case. 
For the AISI 347, material from two suppliers was used in the welding trials-Rolled Alloys and Penn Stainless. The base metal of Rolled Alloys had a larger average grain size than that from Penn Stainless. Four variables were considered for the weld tests: the base metal microstructure, FCAW or GTAW type of welding, depth within the weld, and symmetric or asymmetric positioning of the sample relative to the weld line.

Samples of the hydrogen charged Zry-4, the base metal AISI 347 from three suppliers (Rolled Alloys, Penn Stainless, and Sandmeyer Steel), and the welded AISI from two suppliers (Rolled Alloys and Penn Stainless) were included in the irradiation capsules. The first four capsules completed irradiation in FY20. The remaining four capsules will be irradiated in FY21. The focus of FY21 will be testing and analyzing the irradiated materials and comparing their behavior with the unirradiated behavior.

\section{REFERENCES}

[1] L.M. Garrison, J.R. Echols, K. Bawane, B. Eckhart, C. Bryan, Zircaloy-4 and Stainless Steel 347 Property Data and Microstructures Related to the Structural Material for the Target Solution Vessel and Support Lines of SHINE, Oak Ridge National Laboratory, ORNL/SPR-2019/1356, (2019).

[2] L.M. Garrison, Y. Katoh, N.A.P. Kiran Kumar, Mechanical properties of single-crystal tungsten irradiated in a mixed spectrum fission reactor, Journal of Nuclear Materials 518 (2019) 208-225.

[3] C.M. Silva, E.G. Lindquist, J.W. McMurray, C. Bryan, Brittle nature and the related effects of zirconium hydrides in Zircaloy-4, Materials Science \& Engineering A 767 (2019) 138396. [4] American Welding Society, "Specification for Stainless Steel Flux Cored and Metal Cored Welding Electrodes and Rods." (2012) AWS A5.22/A5.22M:2012

[5] American Welding Society, "Welding Consumables-Wire Electrodes, Strip Electrodes, Wires, and Rods for Arc Welding of Stainless and Heat Resisting." (2017) AWS A5.9/A5.9M:2017 (ISO 14343:2009 MOD)

[6] American Welding Society, "Guide for the Joining of Solid Solution for Austenitic Stainless Steels." (2019) AWS G2.3M/G2.3:2019

[7] I.A. Bataev, D. Lazurenko, S. Tanaka, K. Hokamoto, A.A. Bataev, Y. Guo, A.M. Jorge Jr., High cooling rates and metastable phases at the interfaces of explosively welded materials, Acta Materialia 135 (2017) 277-289.

[8] C.X. Chen, M.Y. Liu, B.X. Liu, F.X. Yin, Y.C. Dong, X. Zhang, F.Y. Zhang, Y.G. Zhang, Tensile shear sample design and interfacial shear strength of stainless steel clad plate, Fusion Engineering and Design 125 (2017) 431-441.

[9] ASTM, "Standard Specification for Stainless Chromium-Nickel Steel-Clad Plate." (2019) A264 - 12

[10] R. Blickensderfer, J.M. Burrus, A Multistep Shear Test for Bond Strength of Claddings, Journal of Testing and Evaluation 12(1) (1984) 3-12.

[11] L. Garrison, C. Silva, B. Eckhart, C. Bryan, Evaluation of Zircaloy-4 Welding and Hydrogen Charging Effects for Use as the Structural Material for the Target Solution Vessel and Support Lines of SHINE, Oak Ridge National Laboratory, ORNL/TM-2018/1035, (2018). 
ORNL/SPR-2020/1879

[12] C. Silva, C. Bryan, Evaluation of Zircaloy-4 as the structural material for the Target Solution Vessel and support lines of SHINE - Sample preparation for the third-round neutron irradiation, Oak Ridge National Laboratory, ORNL/TM-2017/482, (2017). 
ORNL/SPR-2020/1879

APPENDIX A: WELDBAR TRACKERS

Example Zircaloy-4 Weld Tracker Sheet

$$
T I G-6(z f \ldots)
$$

\section{Welding Tracker for Zr4 HFIR Irradiation Coupons}
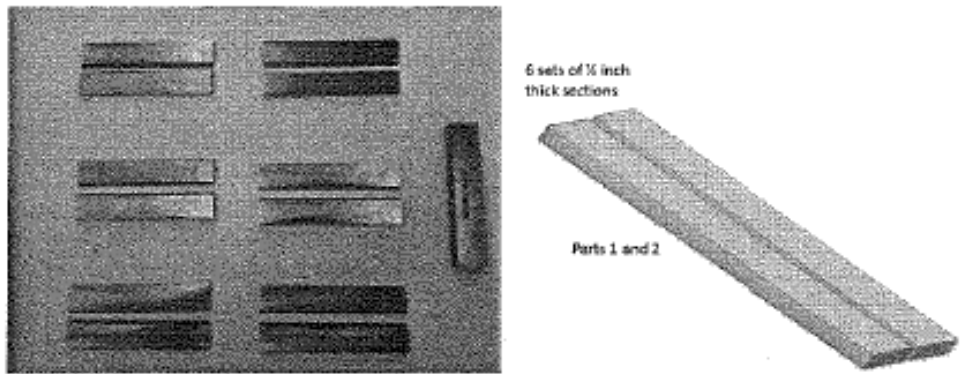

Figure 1: Machined coupon sections

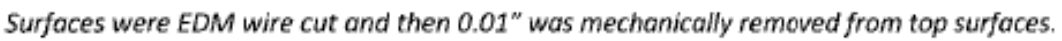
Grooves have been milled (no thermal cutting involved).

\section{Mandatory Standards:}

\begin{tabular}{|l|l|l|}
\hline \hline [1] & AWS G2.5/G2.5M:2012 & $\begin{array}{l}\text { Guide for the Fusion Welding of Zirconium and } \\
\text { Zirconium Alloys }\end{array}$ \\
\hline [2] & AWS A5.24/A5.24M:201 & $\begin{array}{l}\text { Specification for Zirconium and Zirconium-Alloy Welding } \\
\text { Electrodes and Rods }\end{array}$ \\
\hline
\end{tabular}

Start date: $6 / 08 / 2017 \quad$ Start time: $12: 00$ AM

Lead Weld Technician: Kenny Appleby

Inspector: Turner DeHon

Coupon number: TWO (Four coupons in total)

Before photo:

Photo of each weld pass:

After photo:

Starting Notes:
YES / NO

YES / NO

YES / NO

Signature Weld Lead Leter Signature Inspector

1 of 5 


\section{Coupon Joint Preparation:}

1. All coupon surfaces must be chemically cleaned in preparation for the weld.

2. Handle with clean cotton gloves after cleaning. Do not handle with hands.

3. Allow coupons to dry in a dry and clean environment free from humidity and dirt.

4. Groove angle $60^{\circ}$ Root Face KNIFE Root Opening $0.093^{\circ}$

\section{Envirenment:}

1. Work area must be clean and protected from dirt, smoke and airborne contaminants from welding, cutting and grinding operations.

2. Work area must be protected from wind drafts that can interfere with inert gas shielding.

3. All equipment and fixtures must be free from moisture.

4. Take notice of the material identification and storage as well as the special notes on inert gas protection and welding procedures stipulated in the guide [1].

\section{Equipment and Welding Technique:}

Circle Technique: GTAW / PAW

Electrode Filler Material Specification: $\underline{Z} \mathbf{r} 4$ Electrode diameter: $\underline{0.093^{\prime \prime}}$

Amperage settings: 90-168 Voltage: 10.8-14.2 Travel Speed: 2 2-5 (IPM) Inter Pass temp: $\leq 100^{\circ}$

Weld Filler Manufacturer: ATI Specialty Alloys AWS Class: Zircalov 4 Diameter: $0.093^{m}$ Heat

\#251642

Shielding gas used: Argon / Helium (cross selected)

Gas Purity: $99.9999 \%$; Moisture content: $\leq 1.0$ ppm; Dew point Moisture content: $-60^{\circ}\left[{ }^{\circ} \mathrm{F}\right] /\left[{ }^{\circ} \mathrm{C}\right]$

Torch Gas Flow Rate setting: 45

Trail Gas Flow Rate setting: $\quad 20$ (psi)

Backing Gas Flow Rate setting: $30 \quad$ (CFH)

Trail Cup dimensions $2.00^{\prime \prime} \times 6.00^{\prime \prime}$ Backing Fixture description_Aluminum block with SST shims to prevent material cross contact, stainless steel purge diffuser under weld area

Trailing shield material: Stainless Steel

Signature Weld Lead $2 \mathrm{c}$ Signature inspector $\triangle \mathrm{R}$ 
ORNL/SPR-2020/1879

Instructions:

1. Inspect filler rods and make sure that it is in a clean condition and free from contaminants like lubrication. Handle filler only with clean cotton gloves after cleaning

2. Before starting the arc, pre-purged the torch, trailing shield as well as the backup shielding gas hoses and devices.

3. Allow a timed pre-flow of argon gas to remove moisture inside of the torch.

4. The torch shield should be positioned over the part and held for 5 to 10 seconds before the arc is initiated to allow an inert gas blanket to form.

5. Allow 30 seconds of torch shielding gas post flow to protect the weld after the arc has extinguishę.

6. Several weld passes may be required. Each weld pass should be visually inspected for surface color in the as-deposited condition.

7. If interpass color is not bright, as shown in example A or B welding should be stopped. The shielding problem should be corrected and unacceptable area should be repaired.

First weld pass:

Color: Bright no color Repair required: YES / No

Weld temperature $\left[{ }^{\circ} \mathrm{F}\right] /\left[^{\circ} \mathrm{C}\right]: \quad$ Preheat temp: $79.5^{\circ}$

After 5 minutes $129.2-131.1^{\circ}$ after 20 minutes $96.3-96.7^{\circ}$ after 40 minutes N/A

\section{Second weld pass:}

Starting temperature: $\underline{96.3^{\circ}}\left[{ }^{\circ} \mathrm{F}\right] /\left[^{\circ} \mathrm{C}\right]$

Color: Bright with slight straw in $\mathrm{HAZ}$ of start

Repair required: YES / No

Weld temperature $\left[{ }^{\circ} \mathrm{F}\right] /\left[^{\circ} \mathrm{C}\right]$ :

After 5 minutes $126.2-130.1^{\circ}$ after 20 minutes $95.1-95.5^{\circ}$ after 40 minutes N/A

\section{Third weld pass:}

Starting temperature: $95.1^{\circ}\left[{ }^{\circ} \mathrm{F}\right] /\left[{ }^{\circ} \mathrm{C}\right]$

Color: Bright no color $\quad$ Repair required: YES / No

Weld temperature $\left[\left[^{\circ} \mathrm{F}\right] /\left[^{\circ} \mathrm{C}\right]\right.$ :

After 5 minutes $\underline{121,0-123,3^{\circ}}$ after 20 minutes $\underline{95.5-95.7^{\circ}}$ after 40 minutes $\_$N/A

Signature Weld Lead tywe Signature Inspector of $\mathrm{S}$ 
ORNL/SPR-2020/1879

\section{Fourth weld pass:}

Starting temperature: $\underline{95.5^{\circ}}\left[{ }^{\circ} \mathrm{F}\right] /\left[{ }^{\circ} \mathrm{C}\right]$

Color: Bright no color $\quad$ Repair required: YES / No

Weld temperature $\left[{ }^{\circ} \mathrm{F}\right] /\left[{ }^{\circ} \mathrm{C}\right]$ :

After 5 minutes $121.2-123.6^{0}$ after 20 minutes $\underline{93.2 \cdot 94.5^{0}}$ after 40 minutes $\mathrm{N} / \mathrm{A}$

\section{Fifth weld pass:}

Starting temperature: $\left[{ }^{\circ} \mathrm{F}\right] /\left[{ }^{\circ} \mathrm{C}\right]$

Color: Repair required: YES / No

Weld temperature $\left[{ }^{\circ} \mathrm{F}\right] /\left[^{\circ} \mathrm{C}\right]$ :

After 5 minutes after 20 minutes after 40 minutes

\section{Sixth weld pass:}

Starting temperature: $\left[{ }^{\circ} \mathrm{F}\right] /\left[{ }^{\circ} \mathrm{C}\right]$

Color: Repair required: YES / No

Weld temperature $\left[{ }^{\circ} \mathrm{F}\right] /\left[^{\circ} \mathrm{C}\right]$ :

After 5 minutes after $\mathbf{2 0}$ minutes after 40 minutes

Post Weld Heat Treatment (PWHT)

PWHT \#:

Start date of PWHT: Time:

Number days after completion of weld: [days]

Method: Vacuum furnace / heat blanket / wraps

Temperature of heat treatment: $\left[{ }^{\circ} \mathrm{F}\right] /\left[{ }^{\circ} \mathrm{C}\right] ; \quad$ Duration of heat treatment: [hours] Cooling rate: $\left[{ }^{\circ} \mathrm{F}\right] /\left[^{\circ} \mathrm{C}\right]$ per hour

Signature Weld Lead $K \cup A$ 
ORNL/SPR-2020/1879

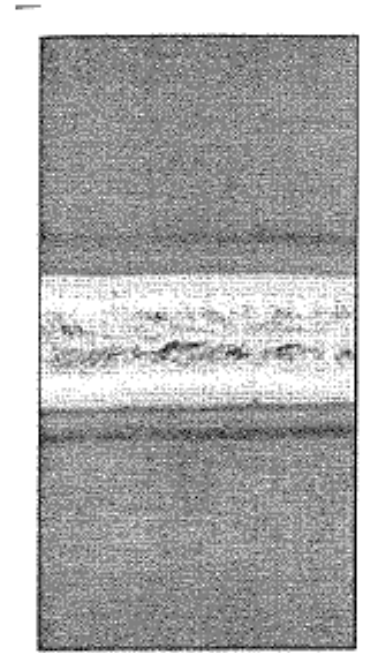

(A)

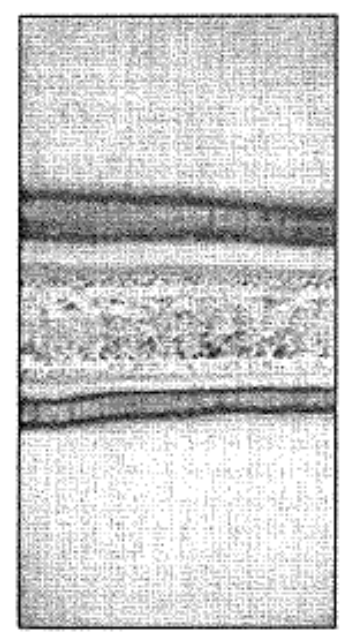

(D)

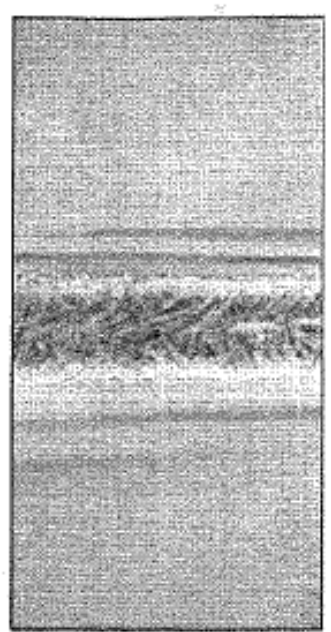

(B)

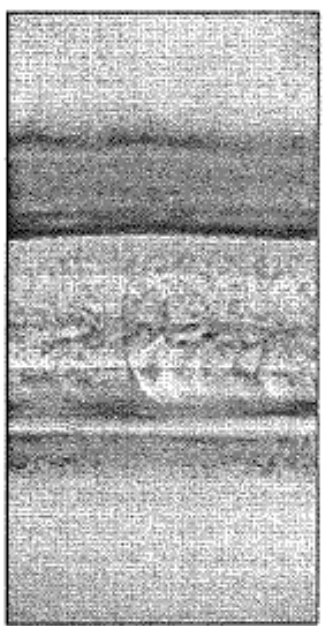

(E)

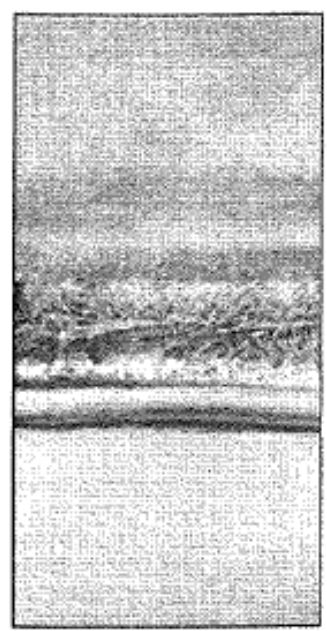

(c)

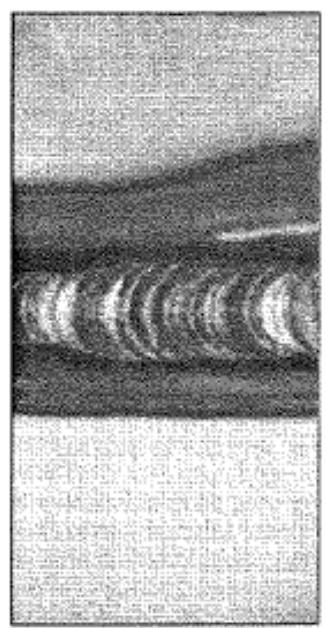

(F)

Notes:

(A) and (B)-Siver to light stravi.

(C) and (D)-Dark straw to blue.

(E) and (F) - Dark blue, gray, or white.

Figure 2: Weld bead coloration and discoloration in Zirconium

Source: Welding Handbook, Materials and Applications, $9^{\text {th }}$ Ed, Vol 5, Part2 by American Welding Society

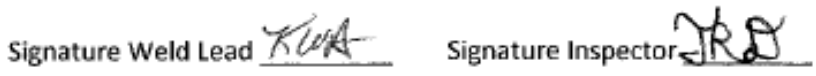

5 of 5 
ORNL/SPR-2020/1879

Example Weld Tracker Sheet for FCAW on stainless steel 347

FCAW Welding of U.43" 'Thick Stainless Steel 347 HFIR Irradiation Coupons

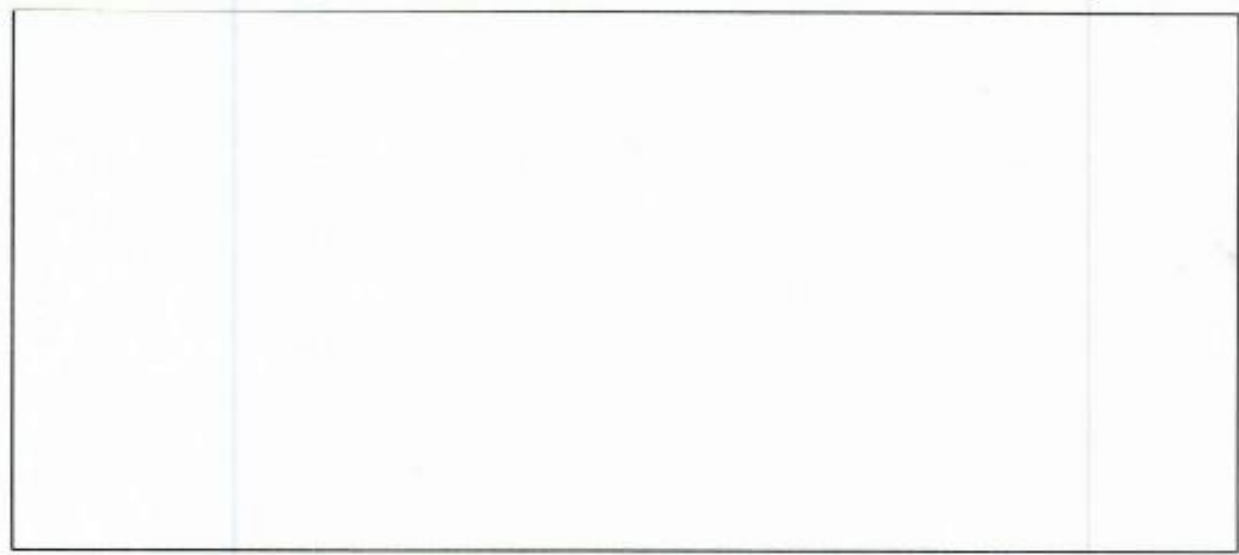

Fig. 1. Machined couple sections

Surfaces were EDM wire cut and them 0.01 " was mechanically removed from top surfaces.

Grooves have been milled (no thermal cutting involved).

Mandatory Standards

\begin{tabular}{|l|l|l|}
\hline [1] & AWS G2.3M/G2.3:2019 & $\begin{array}{l}\text { Guide for the Joining of Solid Solution for Austenitic Stainless } \\
\text { Steels }\end{array}$ \\
\hline [2] & AW3 A5.22/A5.22M:2012 & $\begin{array}{l}\text { Specification for Stainless Steel Flux Cured and Metal Cored } \\
\text { Welding Electrodes and Rods }\end{array}$ \\
\hline
\end{tabular}

Start date: $\quad 2-19.20 \quad$ Start time: $\quad 8: 00$ Am

Lead weld technician: Bgyan Knichi

Inspector:

Coupon number:

Before photo

Photo of each weld pass

After photo

Starting notes:

Signature weld lead:

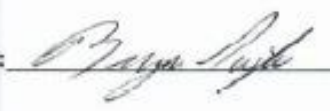

Signature inspector:

1 of 4 
ORNL/SPR-2020/1879

\section{Coupon Joint Preparation}

1. All coupon surfaces must be chemically cleaned in preparation of the weld

2. Handle with clean cotton gloves after cleaning. Do not handle with hands

3. Allow coupons to dry in a dry and clean environment free from humidity and dirt.

\begin{tabular}{|l|c|}
\hline Grove angle & 33 \\
\hline Root face & Knife Edge \\
\hline Root opening & $1 / 16$ \\
\hline
\end{tabular}

Enviroument:

1. Work area must be clean and protected from dirt, smoke and airborne contaminants from welding, cutting and grinding operations.

2. Work area must be protected from wind drafts that can interfere with inert gas shielding.

3. All equipment and fixtures must be free from moisture.

4. Take notice of material identification and storage as well as the special notes on inert gas protection and welding procedures stipulated in the guide [1].

Equipment and Welding Techuique

Technique: FCAW

Electrode filler material specification: Electrode diameter: (inches)

Amperage settings: Voltage: Travel speed:

Inter pass temperature:

Weld rod manufacturer: Washingjen Hlloy AwS class: $134771-1 / 4$ Diameter: . ${ }^{035}$

Shielding gas used: Argon / Helium

Gas purity: Moisture content: Ppm

Torch gas flow rate setting: 15.25 (CFH)

Trail gas flow rate setting: $\quad N_{\mathrm{A}}$

Backing gas flow rate sctting: 5.25

Trail cup dimensions:

Backing fixture description:

$$
\text { I"X18"X7" wide Aturn plaie }
$$

Trailing shield material:

Signature weld lead: Signature inspector: 
ORNL/SPR-2020/1879

Instructions:

1. Inspect weld rods and make sure that it is in a clean condition and free from contaminants like lubrication. Handle filler only with clean cotton gloves after cleaning.

2. Before starting the arc, pre-purged the torch, trailing shield as well as the backup shielding gas hoses and devices.

3. Allow a timed pre-flow of argon gas to remove moisture inside of the torch.

4. The torch shield should be positioned over the part and held for 5 to 10 seconds before the arc is initiated to allow an inert gas blanket to form.

5. Allow 30 seconds of torch shielding gas post flow to protect the weld after the are has extinguished.

6. Several passes may be required. Each weld pass should be visually inspected. Unacceptable area should be repaired.

Preheat temperature:

$\left|{ }^{\circ} \mathrm{F}\right| /{ }^{\circ} \mathrm{C} \mid$

Weld passes - more blanks are listed on this worksheet than are required. Do as many weld passes as needed, and record information for each one. Do the same number of weld passes for all bars with the same thickness.

\section{First weld pass:}

Repair required: Yes / No

Weld temperature: $\left[{ }^{\circ} \mathrm{F}\right]\left[{ }^{\circ} \mathrm{C}\right]$

After 5 minutes: $\quad 84$

$4^{\circ}$ After 20 minutes: $\quad 74^{\circ}$ After 40 minutes:

Second weld pass:

Repair required: Yes/No

Weld temperature: $\left.\left[{ }^{\circ} \mathrm{F}\right] /{ }^{\circ} \mathrm{C}\right]$

After 5 minutes: $102^{\circ}$ After 20 minutes:

$90^{\circ}$ After 40 minutes:

Third weld pass:

Repair required: Yes/No

Weld temperature: $\left[{ }^{\circ} \mathrm{F} V{ }^{\circ} \mathrm{C}\right]$

After 5 minutes: $\quad 96^{\circ}$ After 20 minutes: After 40 minutes:

Fourth weld pass:

Repair required: Yes/No

Weld temperature: $\left.\left[{ }^{\circ} \mathrm{F}\right] /{ }^{\circ} \mathrm{C}\right]$

After 5 minutes: $\quad 118^{\circ}$ After 20 minutes:

$98^{\circ}$ After 40 minutes; 
ORNL/SPR-2020/1879

\section{PI}

Signature weld lead:

Signature inspector:

Fifth weld pass:

Repair required: Yes / No

Weld temperature: $\left[{ }^{\circ} \mathrm{F}\right] /\left[{ }^{\circ} \mathrm{C}\right]$

After 5 minutes: $122^{\circ}$ After 20 minutes: $\quad 10 /^{\circ}$ After 40 minutes:

Sixth weld pass:

Repair required: Yes / No

Weld temperature: $\left.\left[{ }^{\circ} \mathrm{F}\right] /{ }^{\circ} \mathrm{C}\right]$

After 5 minutes: $\quad 120^{\circ}$ After 20 minutes: $\quad 97^{\circ}$ After 40 minutes:

Seventh weld pass:

Repair required: Yes / No

Weld temperature: $\left[{ }^{\circ} \mathrm{F}\right] /\left[{ }^{\circ} \mathrm{C}\right]$

After 5 minutes: After 20 minutes: After 40 minutes: 
ORNL/SPR-2020/1879

Example Weld Tracker sheet for GTAW on stainless steel 347

GTAW Wclding of 0.25" Thick Stainless Steel 347 HFIR Irradiation Coupons

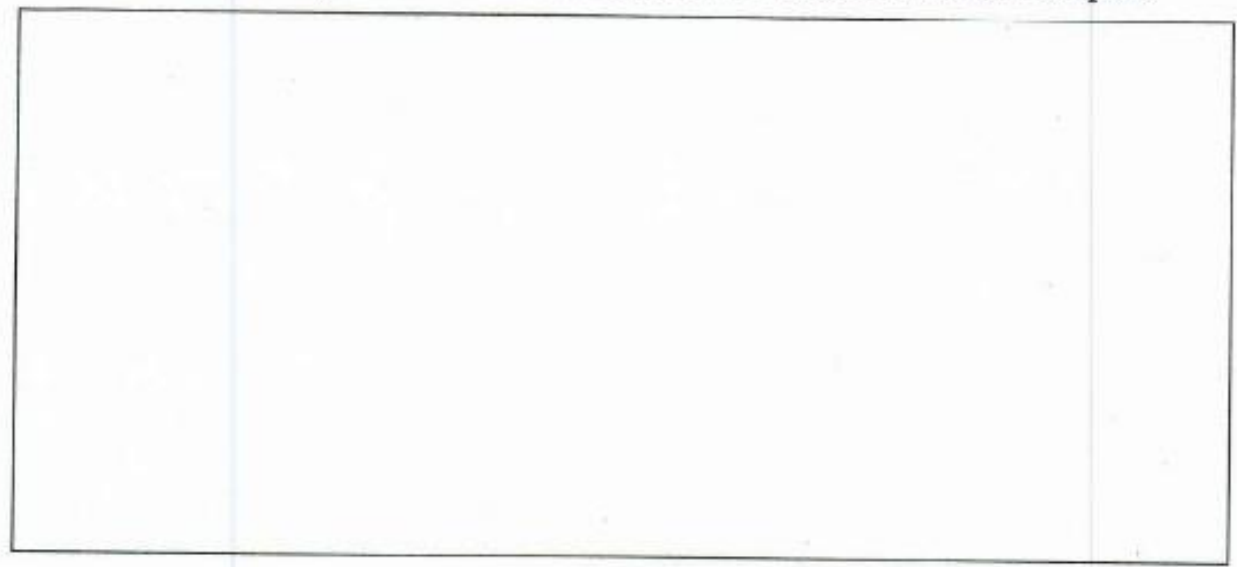

Fig. 1. Machined couple sections

Surfaces were EDM wire cut and them 0.01 " was mechanically removed from top surfaces.

Grooves have been milled (no thermal cutting involved).

Mandatory Standards

\begin{tabular}{|l|l|l|} 
[1] & AWS G2.3M/G2.3:2019 & $\begin{array}{l}\text { Guide for the Joining of Solid Solution for Austenitic Stainless } \\
\text { Steels }\end{array}$ \\
\hline [2] & $\begin{array}{l}\text { AWS A5.9/A5.9M:2017 } \\
\text { (ISO 14343:2009 MOD) }\end{array}$ & $\begin{array}{l}\text { Welding Consumables-Wire Elcctrodes, Strip Electrodes, Wires, } \\
\text { and Rods for Are Welding of Stainless and Heat Resisting }\end{array}$ \\
\hline
\end{tabular}

Start date: $\quad 2.12 \cdot 20 \quad$ Start time: 9:10

Lead weld technician: Bryan knight

Inspector:

Cuupon number: $\beta /$

Before photo

Photo of each weld pass

After photo

Ces $/$ No

(QS)/No

Qes/ No

Starting uvies:

had To grind on Plates. EDM left Brass in wedd area. Brass Causes Crecking in wdids

Signature weld lead:

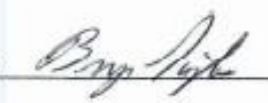
Signature inspector: 
ORNL/SPR-2020/1879

\section{Same for $R 2: R 3$}

\section{Coupon Joint Preparation}

1. All compon surfaces must be chemically cleaned in preparation of the weld

2. Handle with clean cotton gloves after cleaning. Do not handle with hands.

3. Allow coupons to dry in a dry and clean environment free from humidity and dirt.

\begin{tabular}{|l|l|}
\hline Grove angle & Looks To $3 c 33^{\circ}$ \\
\hline Root face & $\frac{1}{1}$ ini he edge \\
\hline Root opening & $3 / 32$ \\
\hline
\end{tabular}

\section{Environment:}

1. Work area must be clean and protected from dirh smoke and airborne contaminants from welding, cutting and grinding operations.

2. Work area must be protected from wind drafts that can interfere with inert gas shielding.

3. All equipment and fixtures must be free from moisture.

4. Take notice of material identification and storage as well as the special notes on inert gas protection and welding procedures stipulated in the guide [1].

\section{Equipment and Welding Technique}

\section{Tedmiq̨ue: GTAW}

Electrode filler material specification: ER 347 Electrode diamèter: $3 / 32$ (inchès)

Amperage settings: Voltage: Travel speed:

Inter pass temperature:

Weld filler manufacturer: Washing Toa Aflloy AWS class: A S.9 Diameter: $1 / 16-3 / 32$.

Shielding gas used: Argon / Helium

Gas purity

Moisture content: ppm

Dew point moisture content:

Torch gas flow rate setting: $15.25 \quad$ (CFH)

Trail gas flow rate setting:

Backing gas flow rate setting:

$5-15$ (CFH)

Truil cup dimensions:

Backing fixture description:

$$
\begin{aligned}
& \text { Alum Plate KLT with weld groone In ceviler for Bock } \\
& \text { Puge gas }
\end{aligned}
$$

Trailing shield material:

Signature weld lead: Signature inspector: 


\section{Instructions:}

1. Inspect tiller rods and make sure that it is in a clean condition and free from contaminants like lubrication. Handle filler only with clean cotton gloves after cleaning,

2. Before starting the arc, pre-purged the torch, trailing shield as well as the backup shielding gas hoses and devices.

3. Allow a timed pre-flow of argon gas to remove mnisture inside of the torch.

4. The torch shield should be positioned over the part and held for 5 to 10 seconds before the are is initiated to allow an inert gas blanket to funm.

5. Allow 30 seconds of torch shielding gas post flow to protect the weld after the arc has extinguished.

6. Several passes may be required. Each weld pass should be visually inspected. Unacceptable area should be repaired.

Preheat temperature:

$\left.\left[{ }^{*} \mathbf{F}\right] /{ }^{*} \mathbf{C}\right]$

Weld passes - more blanks are listed on this worksheet than are required. Do as many weld passes as needed, and record information for each one. Do the same number of weld passes for all bars with the same thickness.

First weld pass:

Repair required: Yes / 10 )

Weld temperature: $\left[{ }^{\circ} \mathrm{F}\right]\left[{ }^{\circ} \mathrm{C}\right]$

After 5 minutes: $98^{\circ}$ After 20 minutes:

$23^{\circ}$ After 40 minutes:

Second weld pass:

Repair required: Yes / (10)

Weld temperature: [" $\left.\mathrm{H}]]^{\circ} \mathrm{C}\right]$

After 3 minutes: $\quad 85^{\circ}$ After 20 minutes: $\quad 75^{\circ}$ After 40 minutes:

\section{Third weld pass:}

Repair required: Yes / (이

Weld temperature: $\left[{ }^{\circ} \mathrm{F}\right] /\left[{ }^{\circ} \mathrm{C}\right]$

After 5 minutes: $\quad 89^{\circ}$ After 20 minutes: $\quad 72$ After 40 minutes:

\section{Fourth weld pass:}

Repair required: Yes / No

Weld temperature: $\left.\left[{ }^{\circ} \mathrm{F}\right]{ }^{\circ} \mathrm{C}\right]$

After 3 minutes: 107 After 20 minutes. $75^{\circ}$ Afer 40 minutes: 
ORNL/SPR-2020/1879

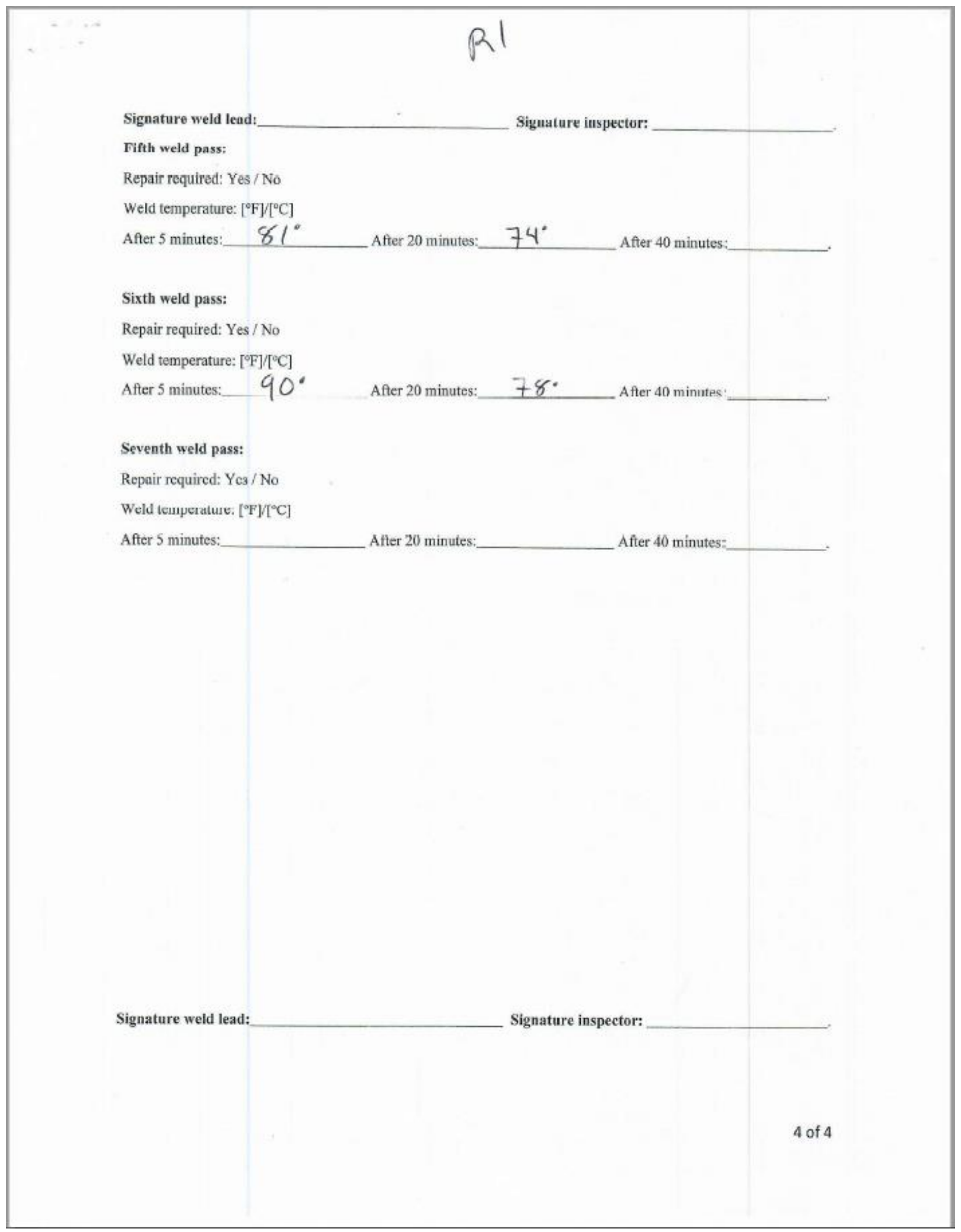

